\title{
QUANTIFYING THE ENVIRONMENTAL IMPACT OF PARTICULATE DEPOSITION FROM DRY UNPAVED ROADWAYS
}

\author{
Dennis Lee Becker
}

Based on a M.S. thesis submitted to Iowa State University

Ames Laboratory, USDOE

Iowa State University

Ames, Iowa 50011

\begin{abstract}
Date Transmitted: January 1979
PREPARED FOR THE U.S. DEPARTMENT OF ENERGY

UNDER CONTRACT NO. W-7405-eng-82
\end{abstract}

UNDER CONTRACT NO. W-7405-eng-82 


\section{DISCLAIMER}

This report was prepared as an account of work sponsored by an agency of the United States Government. Neither the United States Government nor any agency Thereof, nor any of their employees, makes any warranty, express or implied, or assumes any legal liability or responsibility for the accuracy, completeness, or usefulness of any information, apparatus, product, or process disclosed, or represents that its use would not infringe privately owned rights. Reference herein to any specific commercial product, process, or service by trade name, trademark, manufacturer, or otherwise does not necessarily constitute or imply its endorsement, recommendation, or favoring by the United States Government or any agency thereof. The views and opinions of authors expressed herein do not necessarily state or reflect those of the United States Government or any agency thereof. 


\section{DISCLAIMER}

Portions of this document may be illegible in electronic image products. Images are produced from the best available original document. 


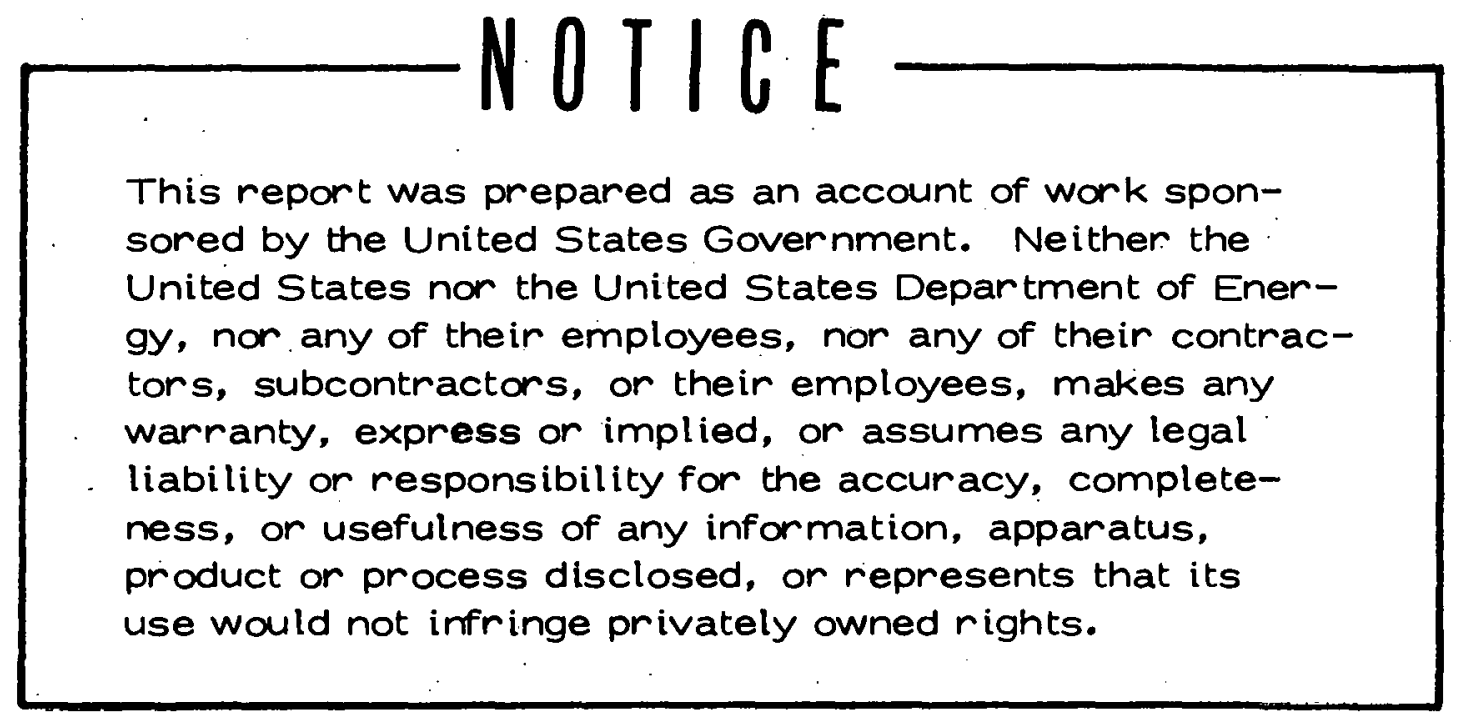

Available from: National Technical Information Service

1.. S. Department of Eommerce

P.O. Box 1553

Springfield, VA 22161

Price: Microfiche $\$ 3.00$ 
Quantifying the environmental impact of particulate deposition from dry unpaved roadways

by

Dennis Lee Becker

A Thesis Submitted to the

Graduate Faculty in Partial Fulfillment of

The Requirements for the Degree of

MASTER OF SCIENCE

Department: Earth Sciences

Major: Meteorology

Approved:

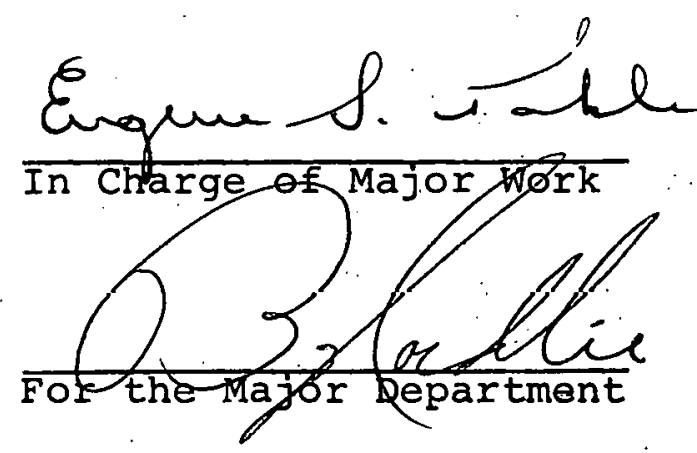

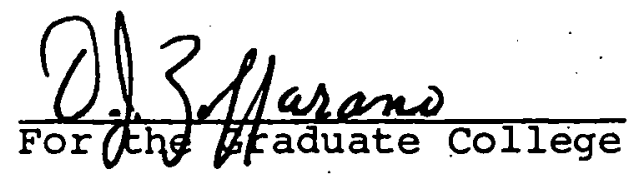

Iowa State University

Ames, Iowa 
TABLE OF CONTENTS

Abstract

Page

PREFACE

vi

vi i

I. INTRODUCTION

II. HISTORICAL BACKGROUND

A. Definitions and Concepts 4

1. Coordinate system 4

2. Settling velocity 4

3. Surface and atmospheric characterizations 6

4. Deposition velocity. 12

B. Diffusion Models 18

1. Sutton's model 20

2. Csanady's model 22

3. Overcamp's model 24

4. Tang's model . 26

5. Ermak's model 28

III. QUANTIFICATION METHODOLOGY . 32

A. The Mathematical Model $\quad 35$

B. Source Strength Estimation 38

C. Particulate Deposition Calculations : 41

D. Particle Effective Area Coverage $\quad 42$

E. Effective Area Coverage Standards 45

IV. DATA ACQUISITION $\quad: \quad 47$

A. Equipment, Measurement Procedures, and Data Handling

1. Meteorological data . 47

2. Particulate sizing data 47

B. Experimental Data 49

1. Ambient conditions. 49

2. Unpaved roadway contribution 52 
V. DEPOSITION SENSITIVITY TESTS

A. Testing Criteria and Limitations 60

B. Response to Atmospheric Stability 69

C. Response to Roughness Height 72

D. Response to Deposition Height 83

E. Response to Source Height 94

F. Response to Wind Speed 105

G. Sensitivity Synopsis $\quad 117$

VI. APPLICATIONS OF THE QUANTIFICATION METHODOLOGY 120
A. Particulate Deposition from Dry Unpaved Roadways

B. Particulate Deposition due to Ambient Conditions

C. Additional Applications $\quad 126$

VII. RECOMMENDATORY DEPOSITION MODEL IMPROVEMENTS 128

VIII. SUMMARY . . $\quad 132$

IX. BIBLIOGRAPHY $\quad 134$

$\mathrm{X}$. ACKNOWLEDGEMENTS $\quad 137$

XI. APPENDIX A: PASQUILL-GIFFORD STABILITY :
CLASSIFICATION

XII. APPENDIX B : PROPERTIES OF THE LOG-NORMAL DISTRIBUTION 


\begin{abstract}
Airborne dust is the air pollutant most frequently observed to exceed National Ambient Air Quality Standards in rural areas. This pollutant (also referred to as suspended particulates) may originate from point sources (e.g., large areas of bare soil or pollen-producing vegetation.) Most sources of atmospheric particulates, whether natural or anthropogenic, are difficult to quantify by means of a source strength (i.e., mass of particulates emitted per unit time). A numerical model has been developed for calculating the source strength and quantifying the atmospheric transport and deposition of dust generated on unpaved roadways. This model satisfies the second-order differential equation for the diffusion process and also the equation of mass conservation. Input to the model includes meterological variables, surface roughness characteristics, and the size distribution and suspended particulate concentration of dust as sampled downwind of an unpaved roadway. By using predetermined tolerance levels of airborne concentrations or tolerance levels of deposition, maximum allowable vehicular traffic volume can be established. The model also may be used to estimate reduction in photosynthesis resulting from fugitive dust from point or line sources. The contribution to sedimentation in aquatic bodies, resulting from airborne particulates also may be assessed with this model.
\end{abstract}




\section{PREFACE}

The material in this thesis was prepared under USDOE Report IS-T-808. This work was performed under Contract W-7405-eng-82 with the Department of Energy. Researchers undertaking similar projects under Government sponsorship are encoliraged to express freely theix professional judgment. 


\section{INTRODUCTION}

State and federal environmental agencies occasionally receive complaints from persons living in the vicinity of unpaved roads concerning the amount of dust generated by vehicular traffic, especially during dry conditions. Heretofore, there has been little concerted effort to establish a method to quantify the level of dustiness that is judged to be a nuisance by the population at large. According to Hancock, Esmen, and Furber (1976), dustiness is a visually perceived phenomena. However, the judgment of whether or not a surface is dusty is based on an individual's past experience or some other personal guideline. At present, there are no known standards or methods related to the quantification of these subjective evaluations; thus, if a dust problem really does exist, it is essentially impossible to assess its magnitude. The goal of this study is to develop a procedure for quantifying the short-range transport and deposition of dust for a continuous particle-size distribution at various locations downwind of frequently traveled roadways.

To begin, we consider the historical development of several concepts that are necessary for understanding the diffusion-deposition process. We also review some of the milestones of diffusion modeling and the ability of certain diffusion models to conserve mass. Since rnar emissions 
usually take place in what is frequently known as the atmospheric surface layer (sometimes referred to as the surface layer or the microscale), surface-layer concepts alone are used to describe most of the atmospheric transport and diffusion processes and the accompanying deposition. This study specifically considers the close-in deposition for a rural environment over flat terrain. After combining the above concepts with an extension of Ermak's (1977) model, we develop a possible quantification procedure for determining the environmental impact of particulate deposition from dry unpaved roadways.

The procedure consists of establishing a mathematical model which predicts the downwind concentration and deposition, while also conserving mass. It incorporates an experimentally determined particle-size distribution measured at some close-in downwind distance. This, in turn, is extrapolated to obtain an estimate of the initial source strength and its particle-size distribution. The estimated source strength is substituted into the mathematical model, whereby the deposition is calculated for various downwind distances. These deposition calculations are converted to an effective area coverage and are compared with a preliminary dust-deposition level that is taken as a tentative standard. At this point, it is possible to estimate (as a function of the downwind distance) the number of vehicle passes permitted before exceeding the tentative 
standard. Unfortunately, the procedure does not possess a simple analytical solution of the diffusion-deposition equations; consequently, numerical methods are used to evaluate definite integrals.

We also examine the model sensitivity to atmospheric stability, surface roughness, deposition height, source height and wind speed, and include a synopsis of the relative influence of each of the modeling parameters. In addition, the particulate deposition due to roadways is compared with that which occurs under typical road conditions and normal ambient suspended-particulate concentrations. Other possible extensions of the proposed methodology are briefly considered. Finally, inherent assumptions of the modeling procedure and recommended improvements are discussed. 
II. HISTORICAL BACKGROUND

\section{A. Definitions and Concepts}

The purpose of this section is to establish definitions and outline the concepts describing the diffusion-deposition process.

\section{Coordinate system}

The coordinate system used is similar to that described by Turner (1969). This system considers the origin at ground level at or beneath the point of emission. The $x$-axis extends horizontally in the direction of the mean wind, $U$, which is assumed uniform and steady. The y-axis is in the horizontal plane, and the z-axis extends vertically. A plume with an initial height, $h$, is transported along or parallel to the $\mathrm{x}$-axis as shown in Figure 2.1.

\section{Settling velocity}

If the particulate plume considered is assumed passive and nonreactive, then in the absence of chemical reactions; coagulation, resuspension, and static electrical forces, the particulate size spectrum will change only by sedimentation at the earth's'surface. A particle's fall velocity is dependent upon gravitational and aerodynamic drag forces. For spherical particles, the relationship between the terminal settling velocity $\left(V_{t}\right)$, the particle diameter $(D)$, and particle density 


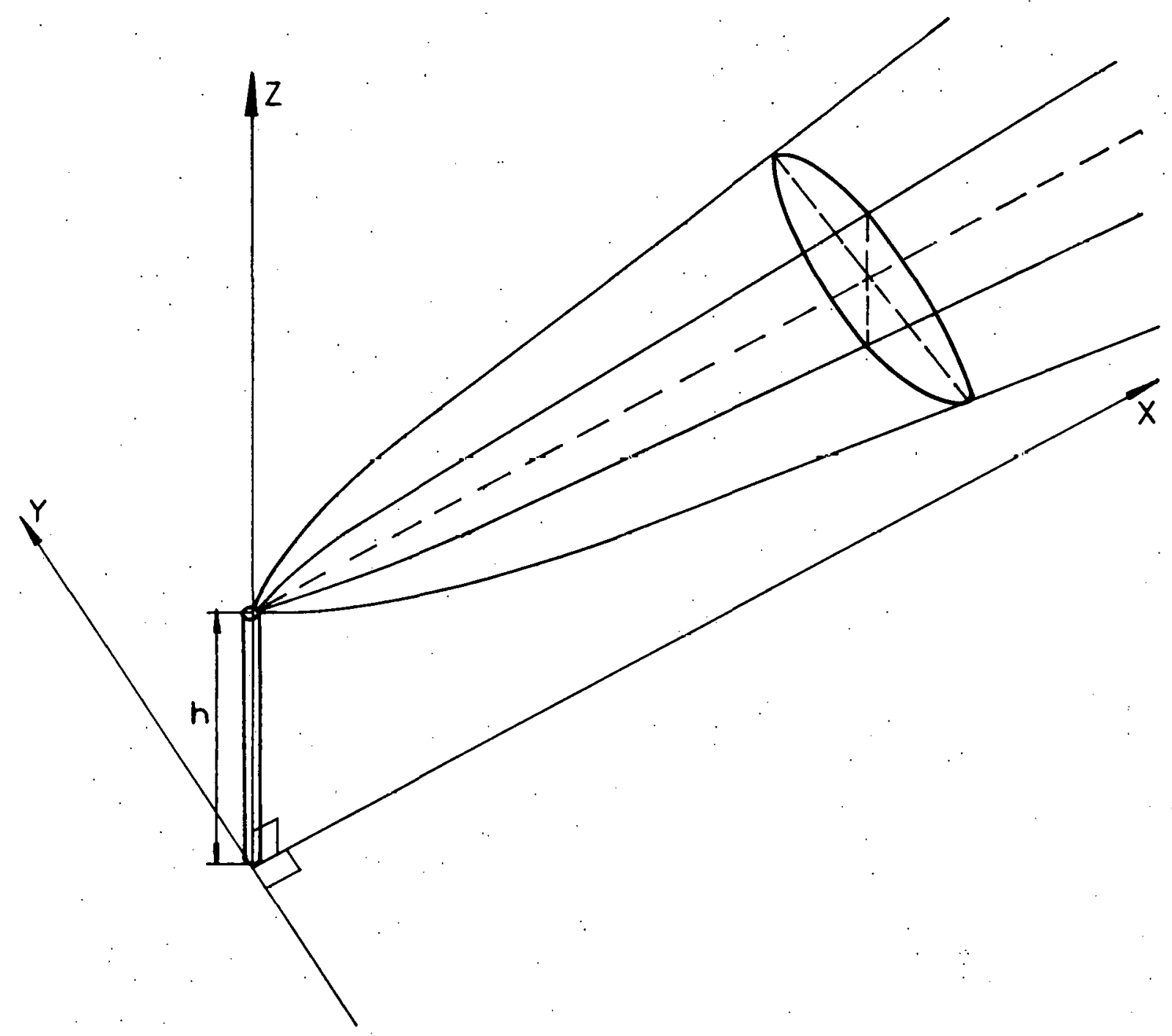

Figure 2.1. Coordinate system for a continuous point-source plume 
( $\rho)$ is given by Stokes equation (Slade, 1968):

$$
v_{t}=\frac{g \rho D^{2}}{18 \mu} c
$$

The constant $g$ is the gravitational acceleration assumed to be $9.81 \mathrm{~m} / \mathrm{s}$, and $\mu$ is the dynamic viscosity of air which is approximately $1.85 \times 10^{-4} \mathrm{~g} / \mathrm{cm}-\mathrm{sec}$ at $299 \mathrm{~K}$. For particles less than $10 \mu \mathrm{m}$, the Cunningham slip factor (C) is appreciable and accounts for the effect of slip flow upon the fall velocity. The degree of slip is a function of the ratio of the mean free. path of the air molecules, $\lambda$, to the particle size. (slade, 1968). The Cunningham slip factor is given by

$$
C=1+\frac{2 \lambda}{D} \cdot\left[1.257+0.400 \operatorname{ExP}\left(\frac{-0.55 D}{\lambda}\right)\right]
$$

where for the atmosphere at standard conditions (298. K, $1.0 \mathrm{~atm}), \lambda=0.0667$ microns (Crawford, 1976). Crawford (1976) states most particulate settling can be described by the stokes relation since most particles are small enough that the terminal velocity is reached at very small. Reynolds numbers. Slade (1968) considers the applicable range of Reynolds numbers for atmospheric particulates to be $10^{-4}$ to 10 .

\section{Surface and atmospheric characterizations}

$$
\text { a. Friction velocity Iumley and Panofsky (1964) }
$$

state that stress in the atmospheric surface layer is constant 
in direction and magnitude. Within the constant stress layer it is possible to define a 'friction velocity', constant with height, by $u_{*}=(\tau / \rho)^{\frac{1}{2}}$, where $\tau$ is the magnitude of the surface stress, and $\rho$ is the density of air (Lumley and Panofsky, 1964). Under these conditions the vertical wind shear $(\partial U / \partial z)$ is related to the stress by

$$
\tau / \rho=K_{m} \frac{\partial U}{\partial z}
$$

where $K_{m}$ is the scalar eddy diffusivity. Johnson and Ruff (1975) suggest the thermal component of diffusivity is small compared to the momentum component; so too is the contribution due to molecular diffusion.

$$
\text { b. Roughness length For the case of neutral }
$$

stability, the vertical wind shear can be obtained from similarity theory, and is given by

$$
\frac{\mathrm{d} u(z)}{\mathrm{dz}}=\frac{\mathrm{u}_{*}}{\mathrm{kz}}
$$

where $\mathrm{k}$ is Von Karman's dimensionless constant, assumed to be 0.40. This applies to fully turbulent flow over a rough surface (Slade, 1968). Integrating Equation 2.4 yields the wind profile near the surface in the constant-stress layer:

$$
U(z)=\frac{u_{*}}{k} \ln (z)+\text { constant }
$$


The constant of integration typically is defined to introduce the effect of surface roughness by requiring the mean wind speed to become zero at $z=z_{0}$, where $z_{0}$ is the roughness height. According to slade (1968), $z_{0}$ is called the roughness length because it delineates the effect of varying surface roughness on the wind profile. Thus,

$$
U(z)=\frac{u_{*}}{k} \ln \left(\frac{z}{z_{0}}\right)
$$

Typical rnughness heighto have been publlshed by several authors (Slade, 1968, p. 73; Stern, 1976, p. 409; Seinfeld, 1975, p. 239; Pasquill, 1962, p. 72; Sutton, 1953, p. 233) for various surface configurations. Lettau (1969) developed the following equation for estimating $z_{0}$ in terms of dimensions and distribution elements (Stern, 1976):

$$
z_{0}=\frac{H_{a}}{2 A} \text {, }
$$

where $\mathrm{H}$ is the average height of the roughness elements, $a^{*}$ is the cross-sectional (silhouette) area normal to the wind, $A$ is the total ground area per element (total horizontal area/number of elements) and $1 / 2$ is the average drag coefficient (U.S. E.P.A., 1974).

$$
\text { c. Monin-Obukhov length For nonneutral conditions, }
$$
the vertical velocity profile is described by the log-linear form: 


$$
U(z)=\frac{u_{*}}{k}\left[\ln \left(\frac{z}{z_{0}}\right)+\frac{\beta z}{L}\right]
$$

where $L$ is the stability-dependent Monin-Obukhov length; and $B$ is an experimentally determined constant. Busch (1972) lists $\beta$ values from 4.7 to 7 . Slade (1968) states that $\beta=$ 6.0 results in good agreement with experimental evidence for moderately stable and unstable conditions. Under extremely stable conditions, the log-linear profile seems to fail. According to Seinfeld (1975) the Monin-obukhov length is simply the height above the ground at which the production of turbulence by both mechanical and buoyancy forces is equal. Hence, L provides a measure of the stability of the atmospheric surface layer. Shir and Shieh (1974) presented an empirical expression for calculating the Monin-obukhov length as a function of the Pasquill-Gifford stability class (described in Appendix A) and surface roughness height, based on experimental surface-layer data published by Golder (1972). The empirical relation. is

$$
\begin{aligned}
& 1 / L=\frac{S}{T S}\left[0.216586 \ln \left(1.2+\frac{10}{z_{O}}\right)\right]^{2} 10^{f(S)} \\
& f(S)=-4 /\left(1+1.3|S|^{0.85}\right)
\end{aligned}
$$

where $\mathrm{S}$ is the stability class $(-3,-2,-1,0,1$, and 2$)$ which corresponds to Pasquill's discrete stability categories 
(represented by $A, B, C, D, E$, and F). The sign of $L$ must be the same as $S$, and $S=0$ denotes neutral conditions. Shir and Shieh (1974) state, "Since this method is much easier to use than measuring vertical temperature distributions, its merits should not be overlooked. Certainly it may require further improvements such as continuous insolation classification, nonuniform spatial stability distributions, and effects of precipitations."

d. Eddy diffusivity If both the wind speed and roughness height are known, then Equation 2.8 can be solved to obtain the friction speed:

$$
u_{*}=\frac{k U(z)}{\ln \left(\frac{\mathbf{z}}{\mathbf{z}_{0}}\right)+\frac{\beta z}{L}}
$$

Yordanov (1972) used a two-layer formulation of the vertical exchange coefficient, $\mathrm{K}_{\mathrm{z}}$, for neutral conditions. This relation is given by

$$
\begin{aligned}
\mathrm{k}_{z}=k u_{\star} z & \text { for } z \leq a_{1} k u_{\star} / f \\
a_{1} k^{2} u_{\star}^{2} / f & \text { for } z \geq a_{1} k u_{\star} / f,
\end{aligned}
$$

where $f$ is the Coriolis parameter, and $a_{1}$ is a dimensionless constant approximately equal to 0.1. Yordanov (1972) used the following relations for $\mathrm{K}_{\mathrm{z}}$ for unstable stratification: 


$$
\begin{array}{ll}
k_{z}=k u_{*} z & \text { for } z \leq a_{2} L \\
k \quad k u_{*}\left(a_{2} L\right)^{-1 / 3} z^{4 / 3} & \text { for } z \geq z_{2} L
\end{array}
$$

where $a_{2}$ is an experimentally determined dimensionless constant ranging from -0.16 to -0.04 . For stable conditions, Yordanov (1972) used the interpolation formula

$$
\begin{array}{rll}
k_{z}=k u_{\star} z & \text { for } & z \leq a_{3} L \\
a_{3} k u_{*} L & \text { for } & z \geq a_{3} L
\end{array}
$$

in which the value of the dimensionless constant $a_{3}$ is close to unity. $\mathrm{K}_{\mathrm{z}}$ reduces to the following common expression for all stabilities near the surface:

$$
\mathrm{K}_{\mathrm{z}}=\mathrm{ku}_{\star} \mathrm{z}
$$

Close to the source, the effects of stability are frequently overshadowed by mechanical turbulence generated by flow over rough surfaces or large etructures. According to Johnson and Ruff (1975), these effects are particularly pronounced in the case of near-surface sources. Thus, only the kinematic eddy-viscosity coefficient is considered, and not the eddy heat conductivity coefficient.

As a further simplification, the turbulence field near the surface is assumed to be anproximatcly isutrop1c; hence, 
the horizontal eddy diffusivities have been assumed to be equal to $\mathrm{K}_{z}$. Sutton (1953) states that this condition is applicable to the atmosphere above the surface layers. This approximation is used exclusively in the diffusion-deposition equations and calculations which appear in subsequent chapters.

\section{Deposition velocity}

As gases or particulates approach the ground, a fraction will be deposited on the surface or on vegetation by direct sedimentation, inertial impaction, adsorption, chemical reaction, and other mechanisms (Overcamp, 1976). This removal causes the downward flux of airborne gases or particulates to decrease in the downwind direction. Without considering the details of the deposition mechanism, Chamberlain (1953) proposed the deposition rate $\omega(x, y)$ was proportional to the ground level concentration $X(x ; y, 0)$. Calder (1961) proposed both the gravitational settling flux and the ground deposition should be proportional to the local air concentration $X(x, y, z)$. The constant of proportionality has the dimensions of length/ time, and hence the term velocity. Here the deposition velocity, $v_{d^{\prime}}$ is determined either experimentally or from theory. Thus the surface deposition flux is

$$
\omega(x, y)=v_{d} x(x, y, 0)
$$


According to Overcamp (1976), the deposition velocity for particulates need not equal the terminal settling velocity, $V_{t}$; however, this is no doubt true for larger particles with greater settling velocities. Experimental field data of the deposition velocity over a variety of different surfaces have been published by slade (1968, p. 207).

Recent wind tunnel experiments (Sehmel and Hodgson, 1976) suggest the deposition velocity is a function of the measurement height above the surface, roughness height, friction speed, particle size and atmospheric stability. They considered a one-dimensional mass transfer model where particles diffuse at a constant rate from a uniform concentration. Additional assumptions were that a relationship for particle eddy diffusivity could be determined, that the effect of gravity could be described by the terminal settling velocity, and finally that particle agglomeration and resuspension would not occur. The resulting deposition flux, $\omega$, to a surface is then given by

$$
\omega=-\left(B+k_{\varepsilon}\right) \frac{d x}{d z}-v_{t} x
$$

where $B$ is the Brownian diffusivity, and $K_{\varepsilon}$ is the particle eddy diffusivity. In most cases, $B$ is small compared to $K_{\varepsilon}$ and is neglected, while $K_{\varepsilon}$ is assumed equal to the eddy diffusivily ir air momentum (3ehmel and Ilodgson, 1976). Thic 
formulation can be extended to an infinite instantaneous line source by considering the deposition flux as a finite number of approximately steady-state fluxes (G. A. Sehmel, Battelle, Pacific Northwest Laboratories, Richland, Washington, private communication, 1977). Thus the approximate deposition flux for the $j$ th time interval resulting from an infinite instantaneous line source is given by

$$
\omega_{j} \approx-\left(B+k_{\varepsilon}\right) \frac{d x_{j}(t)}{d z}-v_{t} x_{j}(t)
$$

Integrating Equation 2.16 and solving for $\omega$ yields

$$
\omega=\frac{v_{t} x_{z}{ }^{\alpha}}{1-\alpha}
$$

where

$$
\alpha=\operatorname{EXP}\left[-V_{t}(I N T) / u_{*}\right]
$$

and INT is found by

$$
\mathrm{INT}=\mathrm{INT}_{1}+\mathrm{INT}_{2}
$$

where $\mathrm{INT}_{1}$ and $\mathrm{INT}_{2}$ are defined below. The deposition velocity is defined in terms of a reference concentration $x_{z}$ at $z \mathrm{~cm}$. Thus,

$$
\mathrm{v}_{\mathrm{d}}=\frac{-\omega}{\mathrm{x}_{\mathrm{z}}}
$$


and substituting Equation 2.18 into Equation 2.21 yields

$$
v_{d}=\frac{v_{t}}{1-1 / \alpha}
$$

In the overall deposition process, the plume approaches and interacts with the air layer immediately above the surface elements. INT 1 is a measure of the diffusional resistance of the plume mass transfer described by the micrometeorological eddy diffusivities. Sehmel and Hodgson (1976) standardize the resislances tu a helght of $\mathrm{I} \mathrm{cm}$, since above this height the Brownian diffusivity is small compared to the particle eddy diffusivity. Similar techniques have been used in researching pollutant transport over the Great Lakes (Hicks, 1977). Values of INT $_{1}$ are stability dependent and are determined for a specific deposition height, $z_{d}$, as follows:

Stable Atmosphere ( $(\mathrm{P}>0)$ :

$$
\operatorname{INT}_{1}=\frac{-1}{k}\left[\ln \left(\frac{z_{d}}{1 \mathrm{~cm}}\right)+4.7\left(\frac{z_{d}-1 \mathrm{~cm}}{L}\right)\right]
$$

Neutral Atmosphere $(L= \pm \infty)$ :

$$
\mathrm{INT}_{1}=\frac{-1}{\mathrm{k}} \ln \left(\frac{\mathrm{z}_{\mathrm{d}}}{1 \mathrm{~cm}}\right)
$$

Unstable Atmosphere $(I<0)$ :

$$
\mathrm{INT}_{1}=\frac{-1}{\mathrm{k}}\left[\ln \left(\frac{\mathrm{z}_{\mathrm{d}}}{1 \mathrm{~cm}}\right)-\psi\right]
$$


where

$$
\psi=2\left[\ln \left(\frac{1+\phi_{d}}{1+\phi_{0}}\right)+\frac{1}{2} \ln \left(\frac{1+\phi_{d}^{2}}{1+\phi_{0}^{2}}\right)-\tan ^{-1}\left(\phi_{d}\right)+\tan ^{-1}\left(\phi_{0}\right)\right]
$$

Values of $\phi_{\mathrm{d}}$ and $\phi_{\mathrm{o}}$ are given by

$$
\begin{aligned}
& \phi_{\mathrm{d}}=\left(1-\frac{15 \mathrm{z}_{\mathrm{d}}}{\mathrm{L}}\right)^{0.25} \\
& \phi_{0}=\left(1-\frac{15}{\mathrm{~L}}\right)^{0.25}
\end{aligned}
$$

If $z_{d}$ is less than $1 \mathrm{~cm}$, then INT 1 is set equal to zero (G. A. Sehmel, Battelle, Pacific Northwest Laboratories, Richland, Washington, private communication, 1977). This allows prediction of deposition velocities below $1 \mathrm{~cm}$. As a word of caution, this method has the disadvantages in that $v_{d}$ is not differentiable at $1 \mathrm{~cm}$, and that this arbitrary height has no substantial physical basis.

Using a least-squares technique on some wind tunnel data, Sehmel and Hodgson (1976) obtained a dimensionless correlation for $\mathrm{INT}_{2}$. The dimensionless correlation of. $\mathrm{INT}_{2}$ is given by 


$$
\begin{aligned}
I N T_{2}=-\operatorname{EXP}[ & -23.667+5.555 \ln \left(\frac{D}{z_{0}}\right)-0.07681 \ln ^{2}\left(\frac{D}{z_{o}}\right) \\
& +0.9722 \ln \left(\frac{u_{\star}}{V_{t}}\right)+0.03799 \ln ^{2}\left(\frac{u_{\star}}{v_{t}}\right) \\
& \left.-2.254 \ln \left(\frac{\nabla}{u_{\star} z_{o}}\right)-3.724 \ln \left(\frac{\rho u_{\star} D^{2}}{18 \mu z_{0}}\right)\right]
\end{aligned}
$$

where $D$ is the particle diameter, $\mu$ is the viscosity of air, and $\rho$ is the particle density of $1.5 \mathrm{~g} / \mathrm{cm}^{3}$. According to Davies (1973), the coefficient of diffusion, $\nabla$, is related to the particle diameter by Einstein's theory of Brownian motion. Values of $\nabla$ can be calculated from

$$
\nabla=\frac{K^{*} T C}{3 \pi D \mu}
$$

where $K *$ is Boltzmann's constant, and $T$ is the absolute temperature. Sehmel and Hodgson suggest that if a particle density different from $1.5 \mathrm{~g} / \mathrm{cm}^{3}$ is used, then $I^{3} T_{2}$ should be assumed independent of particle density.

Despite shortcomings, the method of resistance integrals is the best-available procedure for predicting dry-deposition velocities. Based on wind-tunnel studies and theoretical consideration, Hicks (1977) states, "it seems best to adopt some particle-size dependence, even though the magnitude of the effect remains unknown." He warns against blind usage of the method because, as of yet, there are no field experiments 
that unquestionably support this. Therefore despite deficiencies, the technique suggested by sehmel and Hodgson (1976) will be used in determining dry-deposition velocities. Additional research is obviously needed.

\section{B. Diffusion Models}

Most atmospheric dispersion models are based on the molecular-scale Fickian diffusion equation:

$$
\frac{\partial x}{\partial t}=\frac{\partial}{\partial x} \text { B } \frac{\partial x}{\partial x}+\frac{\partial}{\partial y} \text { B } \frac{\partial x}{\partial y}+\frac{\partial}{\partial z} \text { B } \frac{\partial x}{\partial z}
$$

where $x$ is the concentration at some point $(x, y, z)$ and $B$ is the Brownian diffusivity. In a turbulent atmosphere, the Brownian diffusivity is orders of magnitude less than the turbulent counterpart known as the eddy diffusivity, $K$. Extending Equation 2.30 to a turbulent atmosphere where advection is permitted in the $\mathrm{x}$-direction, the gravitational settling is significant, and Brownian diffusion is negligible, the material transport may be described by the semi-empirical second-order advection-diffusion equation:

$$
\frac{\partial x}{\partial t}+U \frac{\partial x}{\partial x}=\frac{\partial}{\partial x} \dot{K}_{x} \frac{\partial x}{\partial x}+\frac{\partial}{\partial y} K_{y} \frac{\partial x}{\partial y}+\frac{\partial}{\partial z} K_{z} \frac{\partial x}{\partial z}+v_{t} \cdot \frac{\partial x}{\partial z}
$$

Here $U$ is the mean wind which is assumed steady and uniform; $K_{x}, K_{y}$, and $K_{z}$ are the eddy diffusivities in the $x-, y-$, and z-directions, respectively; and $v_{t}$ is the gravitational setting 
velocity and is positive in the downward (negative $z$ ) direction (Ermak, 1977).

Historically, various model designs and assumptions have been used to simplify Equation 2.31, thus allowing approximate solutions of the general diffusion-deposition process. Furthermore, the eddy diffusivities can be related to the statistical concept of variance (say, $\sigma^{2}=2 \mathrm{Kt}$ ); thus, solutions may be expressed in a form which contains the power and elegance of statistical theory. This approach has been used by Sutton (1953), Pasquill (1962), and others.

Sutton (1947, 1953) was one of the first to develop a statistical theory for describing the concentration field downwind of a continuously-emitting point source in a uniform and steady wind. His approach was simplified in that gravitational settling and ground absorption were assumed to be zero, and is applicable to an inert gas. The model has the desirable property that mass is conserved. Csanady (1955) extended Sutton's equation for a continuous point source to the case of particles with a nonzero settling velocity with the boundary condition that the dust-fall rate equals the settling velocity times the ground-level concentration. He incorporated a sloping plume to allow for the appreciable settling velocity and applied a reflection multiplier to the image source term which aided in approximately conserving mass. Overcamp (1976), using a modified version of Csanady's model for a continuous 
point source, attempted to incorporate the definition of deposition velocity into a conservation-of-mass relation where the decrease in the downwind flux equals the crosswindintegrated deposition. Overcamp claims his modified model conserves mass; however a few simple cases seem to suggest otherwise. Tang (1969) formulated a second-order differential equation with constant coefficients for an unsteady infinite crosswind line source. The equation is solved by applying Laplace transformations and finding a Green's function. Ermak (1977) used a similal technique for the case of a continuously emitting point source in a uniform and steady wind. Both the Tang and Ermak models satisfy their appropriate conservation of mass equation for specific cases.

\section{Sutton's model}

Sutton (1953) considers a continuously emitting point source in a steady and uniform wind, where the plume is not subjected to buoyancy forces and the particles are not permitted to fall out. Allowing for reflection at the surface, the resulting spatial concentration, $x(x, y, z)$, is given by

$$
\begin{array}{r}
x_{(x, y, z)=} \frac{Q}{\pi c_{y} c_{z} U x^{2-n}} \operatorname{EXP}\left[\frac{-y^{2}}{c_{y}^{2} x^{2-n}}\right]\left(\operatorname{ExP}\left[\frac{-(z-h)^{2}}{c_{z^{2} x^{2-n}}}\right]\right. \\
\left.+\operatorname{ExP}\left[\frac{-(z+h)^{2}}{c^{2} x^{2-n}}\right]\right),
\end{array}
$$


where $Q$ is the time rate of material emission (i.e., source strength), and $U$ is the mean wind speed that is assumed constant with height. The generalized diffusion coefficients $c_{y}$ and $c_{z}$ are given by

$$
\begin{aligned}
& c_{y}^{2}=\frac{4 v^{n}}{(1-n)(2-n) u^{n}}\left(\frac{\bar{v} \cdot 2}{U^{2}}\right)^{1-n} \\
& c_{z}^{2}=\frac{4 v^{n}}{(1-n)(2-n) u^{n}}\left(\frac{\bar{w}^{1}}{U^{2}}\right)^{1-n}
\end{aligned}
$$

where $v$ is the kinematic viscosity of air; $v^{\prime}$ and $w^{\prime}$ are the eddy velocities in the crosswind and vertical direction, respectively. The dimensionless number $\mathrm{n}$ is between 0 and 1 , and is a parameter related to the diffusing capability of atmospheric turbulence.

If Equation 2.32 is integrated over $y$ from $-\infty$ to $+\infty$, the result is the concentration field for a continuously emitting crosswind line source of infinite extent. Thus,

$$
X(x, z)=\frac{Q_{\ell}}{\sqrt{\pi} c_{z} U x^{1-n / 2}}\left(\operatorname{EXP}\left[\frac{-(z-h)^{2}}{C_{z}^{2} x^{2-n}}\right]+\operatorname{ExP}\left[\frac{-(z+h)^{2}}{C^{2} x^{2-n}}\right]\right)
$$

where $Q_{\ell}$ is the total amount of material emitted per unit length from the line source. 
If mass is to be conserved, then the flux of material across an infinite plane must be equal to the source strength at all distances downwind. Mathematically, the conservation of mass is given by

$$
\int_{-\infty}^{\infty} \int_{0}^{\infty} U X(x, y, z) d y d z=Q
$$

for a continuous point source, and

$$
\int_{0}^{\infty} U X(x, z) d z=Q_{\ell}
$$

for a continuous infinite crosswind line source, where $x(x, y, z)$ is given by Equation 2.32 , and $x(x, z)$ is given by Equation 2.34.

2. Csanady's model

Csanady's (1955) extension of the sutton equation for a continuous point source includes a nonzero settling velocity with the boundary condition that the dust-fall rate equals the settling velocity times the ground-level concentration. The equation of the concentration is

$$
\begin{aligned}
X(x, y, z)=\frac{Q}{\pi c_{y} c_{z} U x^{2-n}} & \operatorname{Exp}\left[\frac{-y^{2}}{c_{y}^{2} x^{2-n}}\right] \cdot \operatorname{ExP}\left[\frac{-\left(z-h+V t^{x / U}\right)^{2}}{c_{z x^{2}-n}^{2-n}}\right] \\
& \left.+\alpha(x, z) \operatorname{ExP}\left[\frac{-\left(z+h-v_{t} x / U\right)^{2}}{c_{z}^{2} x^{2-n}}\right]\right)
\end{aligned}
$$


where

$$
\alpha(x, z)=1-\frac{2}{\left(1-\frac{n}{2}\right)\left(\frac{U h}{V_{t} x_{g}}-1\right)+2}
$$

and $x_{g}=x_{g}(x, z)$ is found from

$$
\left(h-\frac{v_{t} x_{g}}{U}\right)\left(\frac{x}{x_{g}}\right)^{1-n / 2}+\frac{v_{t} x}{U}+z-h=0
$$

Here $\alpha(x, z)$ is the dimensionless degree of reflection on the ground which varies with the distance from the source, and $\mathrm{x}_{\mathrm{g}}$ is the point of reflection which determines the strength of the reflected beam.

Integrating Equation 2.37 over $y$ from $-\infty$ to $+\infty$ gives the concentration field for a continuous infinite crosswind line source, which is

$$
\begin{aligned}
x(x, z)= & \frac{Q_{l}}{\sqrt{\pi} c_{z} U x^{I-n T 2}}\left[\operatorname{ExP}\left[\frac{-\left(z-h+v_{t} x / U\right)^{2}}{c_{z}^{2} x^{2-n}}\right] \ldots\right. \\
& \left.+\alpha(x, z) \operatorname{ExP}\left[\frac{-\left(z+h-v_{t} x / U\right)^{2}}{c_{z^{2} x^{2-n}}}\right]\right)
\end{aligned}
$$

Csanady (1955) cautions that the introduction of the $\alpha(x, z)$ multiplier on the image term allows for only approximate mass conservation. 


\section{Overcamp's model}

Overcamp (1976) improved upon the Csanady (1955) model for a continuously emitting point source in a uniform and steady wind: He contends that, in contrast to Csanady's definition, $x_{g}$ is the downwind distance where the streamline, passing through the point of interest and the image source, crosses the $x$-axis at the surface. The Csanady and overcamp definitions of $x_{g}$ are equal only at the ground surface. With this modification, Overcamp's form of the equation for the concentration is

$$
\begin{aligned}
x(x, y, z)=\frac{Q}{2 \pi \sigma_{y} \sigma^{U}} \operatorname{ExP} & {\left[-\frac{1}{2}\left(\frac{y^{2}}{\sigma_{y}}\right)^{2}\right]\left[\operatorname{ExP}\left[-\frac{1}{2}\left(\frac{z-h+v_{t} x / u^{2}}{\sigma_{z}}\right)\right]\right.} \\
& +\alpha_{o}\left(x_{g}\right) \operatorname{ExP}\left[-\frac{1}{2}\left(\frac{z+h-v_{t} x / U}{\sigma_{z}}\right)^{2}\right],
\end{aligned}
$$

where

$$
\alpha_{0}\left(x_{g}\right)=\left[1-\frac{2}{v_{t}+v_{d}+\left(\frac{U h-v_{t} x}{\sigma_{z}(x)}\right) \frac{d \sigma_{z}(x)}{d x}}\right]_{x=x_{g}}
$$

and where $x_{g}=x_{g}(x, z)$ is determined from

$$
z+h-\frac{v_{t} x}{U}=\left(h-\frac{v_{t} x_{g}}{U}\right) \frac{\sigma_{z}(x)}{\sigma_{z}\left(x_{g}\right)}
$$


Here $\sigma_{y}$ and $\sigma_{z}$ are the standard deviations of the width and thickness of the plume. The remaining variables are as previously defined.

overcamp incorporates the definition of deposition velocity into the following form of the conservation-of-mass equation:

$$
-\frac{\partial}{\partial x} \int_{-\infty}^{\infty} \int_{0}^{\infty} U_{X}(x, y, z) d z d y=\int_{-\infty}^{\infty} V_{d} X(x, y, 0) d y
$$

where $V_{d}$ is the deposition velocity. This expression states that the decrease in the downwind flux equals the crosswindintegrated deposition for all distances downwind of the continuous point. source.

For an arbitrary $\sigma_{z}$, Equation 2.44 cannot be put into an explicit, analytical form (overcamp; 1976). Unfortunately, a simple test case where $\sigma_{z}=$ ax (i.e. linear plume growth) seems to suggest that Equation 2.41 approximately conserves mass according to Equation 2.44 only when $h>>v_{t} x / U$, where $h$ is the effective stack height resulting from a buoyant plume. Thus, it is essential that the plume initially be "sufficiently". high above the surface, relative to the downwind distance, if mass is to be approximately conserved. 
4. Tang's mode1

Tang (1969) solved the advection-diffusion equation in the two-dimensional vertical plane for an unsteady infinite crosswind line source. The resulting second-order differential equation is

$$
\frac{\partial x}{\partial t}+u \frac{\partial x}{\partial x}=k_{z} \frac{\partial^{2} x}{\partial z^{2}}+v_{t} \frac{\partial x}{\partial z}
$$

where $t$ is the time, and $\mathrm{K}_{z}$ is the vertical eddy diffusivity. Values of $U, V_{t^{\prime}}$, and $K_{z}$ are all constants. Here Tang ignorea the diffusive transport in the $\mathrm{x}$-direction, and considers only the advection. The initial and boundary conditions accompanying Equation 2.45 are

$$
\begin{aligned}
& \lim _{t \rightarrow 0} x=0, \quad \lim _{z \rightarrow \infty} x=0 \\
& \lim _{x \rightarrow 0} U x=Q_{\ell}(t) \delta(z-h) \\
& \lim _{z \rightarrow 0}\left\{k_{z} \frac{\partial x}{\partial z}+\left(v_{t}-v_{d}\right) x\right\}=0
\end{aligned}
$$

where $Q_{\ell}$ is the source strength of a crosswind line source at height $h$, and $\delta$ is the Dirac delta function, which is defined to have the properties 


$$
\begin{aligned}
& \delta(t)=0, \quad t \neq 0 ; \\
& \int_{-\infty}^{\infty} \delta(t) d t=1
\end{aligned}
$$

Using Laplace transforms, Tang arrives with an equation for the downwind concentration for an unsteady infinite crosswind in a uniform and steady wind, which is

$$
\begin{aligned}
& x(x, z)=0, \text { for } t<\frac{x}{\bar{U}} ; \\
& X(x, z)=Q_{\ell}\left(t-\frac{x}{u}\right) \cdot\left(\frac { 1 } { 2 \sqrt { K _ { z } \pi U x } } \operatorname { E x p } [ \frac { v _ { t } ( h - z ) } { 2 K _ { z } } - \frac { v _ { t } ^ { 2 } x } { 4 K _ { z } U } ] \left[\operatorname{Exp}\left(\frac{-U(z-h)^{2}}{4 K_{z} x}\right)\right.\right. \\
& \left.+\operatorname{ExP}\left(\frac{-U(z+h)^{2}}{4 K_{z} x}\right)\right]+\frac{v_{t}-2 v_{d}}{2 K_{z} U} \operatorname{ExP}\left[\frac{v_{d}\left(v_{d}-v_{t}\right) x}{K_{z} U}+\frac{v_{d}(z+h)-v_{t} z}{K_{z}}\right] \\
& \left.\operatorname{ERFC}\left[\frac{z+h}{2}\left[\frac{U}{K_{z} x}\right)^{\frac{1}{2}}+\frac{2 V_{d}-V_{t}}{2} \cdot\left(\frac{x}{K_{z} U}\right)^{\frac{1}{2}}\right]\right) \text {, for } t>\frac{x}{U}
\end{aligned}
$$

If $Q_{\ell}$ is steady, then Equation 2.48 conserves mass according to

$$
\frac{-\partial}{\partial x} \int_{0}^{\infty} U x(x, z) d z=v_{d} x(x, 0)
$$

which relates the decrease in the downwind flux to the rate of deposition at all downwind distances. 
5. Ermak's model

Ermak (1977) presents a modified Gaussian plume model for the case of a continuously emitting point source in a uniform and steady wind. By assuming a steady source and neglecting diffusion in the $\mathrm{x}$-direction and considering only its advection, Ermak reduces the problem from Equation 2.31 to

$$
U \frac{\partial x}{\partial x}=K_{y} \frac{\partial^{2} x}{\partial y^{2}}+K_{z} \frac{\partial^{2} x}{\partial z^{2}}+v_{t} \frac{\partial x}{\partial z}
$$

where $K_{Y^{\prime}}$, and $K_{z}$ are the eddy diffusivities in the $y_{-}^{-}$, and $z-$ directions, respectively, and are at most functions of $x$. Here $v_{t}$ is the pollutant particle gravitational settling velocity and is positive in the downward direction. Ermak points out that both the vertical diffusivity $K_{z}(x)$ and the settling velocity $V_{t}(x)$ are assumed to approach the limiting values of $\mathrm{K}_{z}$ and $\mathrm{v}_{t}$, respectively, for large downwind distances. The accompanying boundary conditions are

$$
\begin{aligned}
& \lim _{x \rightarrow 0} x=\frac{Q}{U} \delta(y) \delta(z-h), \\
& \lim _{y \rightarrow-\infty} x=0, \quad \lim _{y \rightarrow \infty} x=0, \\
& \lim _{z \rightarrow \infty} x=0, \\
& \lim _{z \rightarrow 0}\left[k \frac{\partial x}{\partial z}+\left(v_{t}-v_{d}\right) x\right]=0 .
\end{aligned}
$$


The solution to Equation 2.50 is expressed in terms of the Gaussian plume parameters for the standard deviation of the plume width and height, $\sigma_{y}$ and $\sigma_{z}$. These parameters, defined in terms of their respective diffusion coefficients, are

$$
\sigma^{2}(x)=\frac{2}{U} \cdot \int_{0}^{x} K\left(x^{\prime}\right) d x^{\prime}
$$

Here they can be used to describe the non-Gaussian plume which occurs in the general situation when settling and deposition are included.

Ermak's solution uses separation of variables and Laplace transforms to obtain a general equation for the concentration downwind of a continuous point source. Thus, the general equation for the concentration is

$$
\begin{aligned}
& X(x, y, z)=\frac{Q}{2 \pi \sigma_{y} \sigma_{z}^{U}} \operatorname{ExP}\left[\frac{-1}{2}\left(\frac{y}{\sigma_{y}}\right)^{2}\right] \operatorname{EXP}\left[\frac{v_{t}(h-z)}{K}-\frac{v_{t}^{2} \sigma^{2}}{8 K^{2}}\right] \\
& \left(\operatorname{ExP}\left[-\frac{1}{2}\left(\frac{z-h}{\sigma_{z}}\right)^{2}\right]+\operatorname{ExP}\left[-\frac{1}{2}\left(\frac{z+h}{\sigma_{z}}\right)^{2}\right]-\sqrt{2 \pi} \frac{\mathrm{v}_{1} \sigma_{z}}{\mathrm{~K}}\right. \\
& \left.\operatorname{ExP}\left[\frac{v_{1}(z+h)}{K}+\frac{v_{1}^{2} \sigma^{2}}{k^{2}}\right] \operatorname{ERFC}\left[\frac{v_{1} \sigma_{z}}{\sqrt{2} k}+\frac{z+h}{\sqrt{2} \sigma_{z}}\right]\right),
\end{aligned}
$$


where $v_{1}=v_{d}-\frac{1}{2} v_{t^{\prime}}$ and $\sigma_{y}=\sigma_{y}(x)$ and $\sigma_{z}=\sigma_{z}(x)$ as defined in Equation 2.52. All other variables are as previously described.

For the special case of $\sigma_{z}^{2}=2 \mathrm{Kx} / \mathrm{U}$, (i.e. $\mathrm{K}_{\mathrm{z}}=\mathrm{K}=$ constant) the conservation of mass equation

$$
\frac{-\partial}{\partial x} \int_{-\infty}^{\infty} \int_{0}^{\infty} U x(x, y, z) d z d y=\int_{-\infty}^{\infty} v_{d} x(x, y, 0) d y
$$

is also satisfied. If the genoral form $\sigma_{z}$ is used (1.e. Equation 2.52), then mass is conserved only in the limit as $\mathrm{K}_{\mathrm{z}}(\mathrm{x})$ approaches $\mathrm{K}$.

Integrating Equation 2.53 over $y$ from $-\infty$ to $+\infty$ yields the solution for a continuous infinite crosswind line source which satisfies the following second-order differential equation:

$$
\text { U. } \frac{\partial x}{\partial x}=K_{z} \frac{\partial^{2} x}{\partial z^{2}}+v_{t} \frac{\partial \dot{x}}{\partial z}
$$

The solution to Equation 2.55 is

$$
x(x, z)=x(x, y, z) \frac{\sqrt{2 \pi} \sigma y_{\ell} \ell}{Q} \quad \operatorname{EXP}\left[\frac{y^{2}}{2 \sigma_{y}^{2}}\right]
$$

where $x(x, y, z)$ is the solution for the continuous point source given by Equation 2.53. Due to the similarity between EquaLiuns 2.53 and 2.56 , the continuous infinite crosswind line 
source conserves mass in a manner not unlike the continuous point source, with the same restrictions on $\sigma_{z}$ still applying. 
III. QUANTIFICATION METHODOLOGY

This chapter describes the methodology used in quantifying the particulate deposition which results from vehicular traffic on dry unpaved roadways.

The dispersion and transport of a particulate plume is described by a mathematical model in which the effects of $\mathrm{K}-$ theory diffusion are superimposed on the horizontal advection of the plume by the mean wind field. For simplicity, the vertical and horizontal eddy diffusivities are assumed to be constant both with respect to height and the downwind distance from the source (see section II.A.3). This pretense, though very crude, is used by several authors as a first approximation. This approach greatly simplifies the mathematics, while still retaining the qualitative features of the physical processes involved. Furthermore, these assumptions, together with the surface and atmospheric characterizations discussed in section II.A.3, give the necessary machinery with which to use general diffuston-deposition concepts.

A particulate plume resulting from a vehicle traversing a dry unpaved roadway, may be considered as originating from a moving point source, or it may be treated, approximately, as an infinite instantaneous line source. For short sampling periods the latter is less desirable in estimating the downwind deposiliun because of spatial and temporal variations in 
the concentration field and their influences on the associated deposition flux. However, if the sampling period is sufficiently large, relative to the trend time of the plume to the receptor, then the downwind deposition may be calculated using an infinite instantaneous line source. The assumption here is that, for large sampling periods, the difference in deposition between a moving point source and an infinite instantaneous line source is negligible. The result is a much simplified model with which to predict deposition and its associated visual impact (without the additional complexities of temporal and spatial dependencies from crosswind turbulent diffusion fluxes).

Information on the particle-size distribution is obtained using a cascade impactor placed downwind of a roadway. The sampler measures the time-averaged concentration which results from both the source and ambient conditions. From theoretical considerations (and the sensitivity tests described in Chapter $V)$, the ambient contribution at closein distances is usually less than 108 of the total timeaveraged concentration when the vehicle frequency is in excess of approximately one pass per minute; consequently, the ambient contribution may be neglected as a first approximation at close-in distances.

The particle-size information, together with the surface roughness and atmospheric dispersion potential, permits the 
estimation of downwind concentration and deposition as a function of particle size. The deposition surface, which acts as a sink term for the particulate plume, is assumed to be a flat horizontally homogeneous surface. Here, only a single layer of particles is assumed to exist (i.e. no overlapping is permitted). Thus, the actual area coverage by the particles is based on the number and size of the particles. Furthermore, maximum visual contrast is assumed to exist between the deposition surface and the single layer of dust particles. Tuyether, these assumptions allow for a conversion from the mass deposition to the actual area coverage by the particles, without the additional complexities associated with conditional probabilities and multiple receptor heights. When less than maximum contrast occurs between the particulates and the deposition surface, it is conventional to speak of an effective area coverage; this is described in section III.D. Finally, if the effective area coverage estimates are compared with some predetermined standard of dustiness, then it is possible to predict and quantify the environmental impact of particulate deposition resulting from vehicles traveling dry unpaved roadway. This is described in sections VI.A and VI.B.

In summary, the quantification methodology consists of the following: (1) establishing a mathematical model which predicts the downwind concentration and deposition, while also 
conserving mass, (2) experimentally determining the particlesize distribution at some close-in downwind distance and then extrapolating this information to obtain a source strength estimate, (3) incorporating the extrapolated source strength into the model to estimate the deposition at various downwind distances, and (4) converting the mass deposition to an effective area coverage and comparing this result with some predetermined standard.

\section{A. The Mathematical Model}

In this section a mathematical model is developed to predict the concentration downwind of an infinite instantaneous line source by integrating Equation 2.53 over $y$ from $-\infty$ to $+\infty$, and then multiplying by $\left(2 \pi \sigma_{x}^{2}\right)^{-\frac{1}{2}} \operatorname{ExP}\left[-\frac{1}{2}(x-U t)^{2} \sigma_{x}^{-2}\right]$ : The resulting equation for the downwind concentration, $x(x, z, t)$, is given by

$$
\begin{aligned}
& x(x, z, t)=\frac{Q_{\ell}}{2 \pi \sigma_{x} \sigma_{z}} \operatorname{Exp}\left[-\frac{1}{2}\left(\frac{x-U t}{\sigma_{x}}\right)^{2}+\frac{v_{t}(h-z)}{2 K}-\frac{1}{2}\left(\frac{v_{t}{ }^{\sigma} z}{2 K}\right)^{2}\right] \\
& \left(\operatorname{ExP}\left[-\frac{1}{2}\left(\frac{z-h}{\sigma_{z}}\right)^{2}\right]+\operatorname{ExP}\left[-\frac{1}{2}\left(\frac{z+h}{\sigma_{z}}\right)^{2}\right]-\frac{\sqrt{2 \pi} v_{1} \sigma_{z}}{k}\right. \\
& \left.\operatorname{Exp}\left[\frac{v_{1}(z+h)}{K}+\frac{1}{2}\left(\frac{v_{1} \sigma_{z}}{k}\right)^{2}\right] \operatorname{ERFC}\left[\frac{v_{1} \sigma_{z}}{\sqrt{2} k}+\frac{z+h}{\sqrt{2} \sigma_{z}}\right]\right)
\end{aligned}
$$


where $\sigma_{x}^{2}=2 K_{x} t$ and $\sigma_{z}^{2}=2 k_{z} t$ for constant $k_{x}$ and $k_{z}$. As before, $Q_{\ell}$ is the total amount of material emitted per unit length, $\sigma_{x}$ and $\sigma_{z}$ are the standard deviations in the $x$ and $z$ directions, $U$ is the mean vertical wind speed, $t$ is the time since emission, $\mathrm{K}$. is the vertical eddy diffusivity approached at some large downwind distance, and $\mathrm{h}$ is the height of the infinite instantaneous line source. $v_{1}=v_{d}-\frac{v_{t}}{2}$ where $v_{d}$ is the deposition velocity, and $v_{t}$ is the terminal settling velocity.

It is noteworthy that the above model for an infinite instantaneous line source satisfies two important criteria. First, Equation 3.1 satisfies the second-order differential equation with constant coefficients,

$$
\frac{\partial x}{\partial t}+U \frac{\partial x}{\partial x}=K_{x} \frac{\partial^{2} x}{\partial x^{2}}+K_{z} \frac{\partial^{2} x}{\partial z^{2}}+v_{t} \frac{\partial x}{\partial z}
$$

for $\mathrm{K}_{\mathrm{z}}=\mathrm{K}$, where $\mathrm{K}_{\mathrm{x}}$ and $\mathrm{K}_{\mathrm{z}}$ are the eddy diffusivities in the $x$ - and z-direction, respectively. The first term on the lefthand-side represents the rate of change of local concentration, while the second term is the concentration advected in the downwind direction. " on the right-hand-side, the terms from left to right are the turbulent diffusion in the $\mathbf{x}$ and $\mathbf{z}$ directions, and the gravitational settling. The mathematical description of the problem is completed by the following initial and boundary conditions: 


$$
\begin{aligned}
& \lim _{t \rightarrow 0} x=0, \quad \lim _{z \rightarrow \infty} x=0 \\
& \lim _{x \rightarrow 0} U x=Q_{\ell}(t) \quad \delta(z-h), \\
& \lim _{z \rightarrow 0}\left[K_{z} \frac{\partial x}{\partial z}+\left(V_{t}-v_{d}\right) x\right]=0
\end{aligned}
$$

where $\delta$ is the Dirac delta function.

Equation 3.1 also meets the criteria that, in the case of long-term deposition (i.e., as $t$ becomes large), the model satisfies conservation of mass as follows:

$$
\lim _{t \rightarrow \infty}\left[\int_{-\infty}^{\infty} \int_{0}^{\infty} x(x, z, t) d z d x+\int_{-\infty}^{\infty} \int_{0}^{t} v_{d} x\left(x, 0, t^{\prime}\right) d t^{\prime} d x\right]=Q_{\ell}
$$

where $Q_{\ell}$ is the total amount of material emitted per unit length from an infinite instantaneous line source. On the left-hand-side, the first term represents the amount of material remaining in the air, while the second term accounts for deposition. Table 3.1 shows the various relationships between the two terms for different values of $v_{d}$ and $v_{t}$. It was not possible to obtain an analytical result of the deposition term for the case $v_{d} \neq v_{t}=0$. However, this result has no application to a particulate plume and is presented for completeness only. 
Table 3.1. Percentage of material remaining in the air and deposited at the surface in the limit as $t$ approaches infinity

\begin{tabular}{ccc} 
Amount of material & $\begin{array}{c}\text { Amount of material } \\
\text { remaining in the } \\
\text { atmosphere }\end{array}$ & $\begin{array}{c}\text { deposited at the } \\
\text { surface }\end{array}$ \\
\hline
\end{tabular}

$\mathrm{v}_{\mathrm{d}}=\mathrm{v}_{\mathrm{t}}:$

$\begin{array}{ll}\mathrm{v}_{\mathrm{d}}=\mathrm{v}_{\mathrm{t}}=0 & 1008\end{array}$

08

$v_{d}=v_{t} \neq 0$

$0 \%$

1008

$\mathrm{v}_{\mathrm{d}} \neq \mathrm{v}_{\mathrm{t}}:$

$v_{d}=0, v_{t} \neq 0$

1008

$0 \%$

$v_{d} \neq 0, v_{t}=0 \quad, 0 \%$

$v_{d} \neq 0, v_{t} \neq 0 \quad 08 \quad 1008$

\section{B. Source Strength Estimation}

In this section a method for determining the upwind sourie strength is developed by incorporating an experimentally determined particle-size distribution at some close-in downwind distance.

From conservation of mass considerations, the instantaneous concentration at a receptor must equal that resulting from the source plus the ambient concentration. If there are iv vehilile passes and they àrè treated as a single pass, then 
the time-averaged concentration measured at a receptor $\left(x_{I}, z_{I}\right)$ is given by

$$
\bar{x}_{r}=\sum_{n=1}^{N} \frac{1}{T} \int_{0}^{T} x_{n}\left(x_{r}, z_{r} ; t\right) d t+\bar{x}_{a}
$$

where $x_{n}\left(x_{r}, z_{r}, t\right)$ for the nth vehicle pass is given by Equation 3.1 evaluated at $\mathbf{x}=\mathbf{x}_{r}$ and $z=z_{r}$, and where $Q_{\ell}$ is replaced with $Q_{\ell p}$. Here $\bar{\chi}_{a}$ is the ambient concentration which is assumed constant over the sampling period, T. Rewriting Equation 3.5 yields

$$
\bar{x}_{r}=\frac{N Q_{l p}}{T} I_{1}+\bar{x}_{a}
$$

where

$$
I_{1}=\int_{0}^{T} \frac{x_{n}\left(x_{r}, z_{r}, t\right) d t}{Q_{\ell p}}
$$

and is evaluated by simpson's method of numerical integration. Here $Q_{\ell}=N Q_{\ell p}$, where $Q_{\ell p}$ is the source strength per. vehicle pass.

The source strength per vehicle pass for an infinite instantaneous line source is obtained by solving Equation 3.6 for $Q_{\ell p}$ ' which is given by

$$
Q_{l p}=\frac{T\left(\bar{x}_{I}-\bar{x}_{a}\right)}{\text { NI }_{1}}
$$


If the data are collected on a finite particle-size interval, $i$, then values for $\bar{\chi}_{r}, \bar{\chi}_{a}, Q_{\ell p}, V_{d}, v_{t}, v_{1}$, and $I_{l}$ are replaced by the interval estimates of $\bar{\chi}_{r i}$, $\bar{x}_{a i}$ ' $Q_{\ell p i}$ ' $V_{d i}$, $V_{t i}, V_{I i}$, and $I_{I i}$, respectively. Thus, the fractional source strength per vehicle pass corresponding to the ith finite particle-size interval is given by

$$
Q_{\ell p i}=\frac{T\left(\bar{x}_{r i}-\bar{x}_{a i}\right)}{N I_{1 i}},
$$

and the total source strength per vehicle pass is givon by

$$
Q_{\ell p s}=\sum_{i} Q_{\ell p i}
$$

In order to determine representative values of $\mathrm{V}_{\mathrm{di}}$ and $V_{t i}$, it is necessary to have a single particle-size estimator which approximates the entire particle-size interval. Since the particulate distribution is approximately log-normally distributed, the geometric mean diameter on a mass basis, $\mathrm{D}_{\mathrm{g}} 3 \mathrm{I}^{\prime}$ is chosen as a point estimator for a finite particle-size interval, $i$. Values of $D_{g 3 i}$ are calculated by integrating the weighted log-normal probability-density function over the finite interval, and then dividing by the probability of occurrence. The method is outlined in Appendix B. Finally, $\mathrm{D}_{\mathrm{g} 3 \mathrm{i}}$ is incorporated into Equations 2.1 and 2.2 to compute $\mathrm{V}_{\mathrm{ti}}$, and into Equations 2.22 and 2.28 to compute $\mathrm{v}_{\mathrm{di}}$. 


\section{Particulate Deposition Calculations}

The source strength estimates described in section III.B can be incorporated into Equation 3.1 to predict the timedependent concentration and deposition flux at various downwind distances, which, in turn, may be used to calculate the downwind deposition.

The definition of deposition flux given by Equation 2.15 can readily be extended to allow calculation of the deposition per vehicle. pass at any deposiliun helght, $\mathbf{z}_{\alpha}$, by integrating over time. The resulting general equation for the deposition per vehicle pass is given by

$$
\Omega_{p}=v_{d} \int_{0}^{\infty} x_{p}\left(x, z_{d}, t\right) d t
$$

where $x_{\mathrm{p}}\left(x, z_{\mathrm{d}}, t\right)$ is given by Equation 3.1 evaluated at $\mathbf{z}=\mathbf{z}_{\mathrm{d}}$ and where $Q_{\ell}$ is replaced with $Q_{\ell p}$. If we define

$$
I_{2}=\int_{0}^{\infty} x_{p}\left(x, z_{d}, t\right) d t,
$$

then Equation 3.11 becomes

$$
\Omega_{p}=v_{d} I_{2}
$$

where $I_{2}$ is evaluated by Simpson's method of numerical integration. 
For a finite particle-size interval, $i$, values of $\Omega_{p}$ ' $\mathrm{V}_{\mathrm{d}}$ and $\mathrm{I}_{2}$ are replaced with $\Omega_{\mathrm{pi}}, \mathrm{V}_{\mathrm{di}}$ and $I_{2 i}$, respectively. Thus the fractional deposition per vehicle pass corresponding to the ith particle size interval is given by

$$
\Omega_{\mathrm{pi}}=\mathrm{V}_{\mathrm{di}} \mathrm{I}_{2 i}
$$

and the total deposition per vehicle pass is

$$
\Omega_{\mathrm{ps}}=\Gamma_{i} \Omega_{\mathrm{pi}}
$$

The same particle-size estimators for a finite interval found in section III.B are also applied here.

\section{Particle Effective Area Coverage}

In this section the deposition calculations described in section III.C are converted to an effective area coverage. These effective area coverages are then used to estimate the total and daily number of vehicle passes allowed (as a function of the downwind distance) before exceeding an arbitrary standard.

To obtain the area coverage of the particles, we must be able to convert the deposition, which is on a mass basis, to the percentage of area covered by the particles, which is on an area basis. Fortunately, such a transformation exists between a mass basis (i.e., $n=3$ ) and an area basis (i.e., 
$\mathrm{n}=2$ ) for a distribution which is log-normally distributed, and this is described in Appendix B. A log-probability plot of the cumulative deposition less than a stated particle size reveals the particulate deposition downwind of an infinite instantaneous line source is approximately log-normally distributed. The population parameters, $\mathrm{D}_{\mathrm{g} 3}$ and $\sigma_{\mathrm{g}}$, are read directly off this graph. Values of $\mathrm{D}_{\mathrm{g} 3 i}$ and $\sigma_{\mathrm{gi}}$ are then found by integrating the weighted probability density function (which is a function of $\mathrm{D}_{\mathrm{g} 3}$ and $\sigma_{g}$ ) over the finite particlesize intcrval, $i$, and dividing by the probability of occurrence. Next, the corresponding geometric mean diameter on an area basis, $D_{g 2 i}$, is calculated from $D_{g 3 i}$ and $\sigma_{g i}$ by applying the transformation which exists between any two bases for a log-normal distribution. Finally, $\mathrm{D}_{\mathrm{g} 2 i}$ is used in any equation which requires a representative particle diameter on an area basis.

The particle area coverage per vehicle pass is assumed to be equal to the perpendicular surface area per particle times the number of particles deposited per unit area per vehicle pass, $\mu_{\mathrm{p}}$. For simplicity, we assume a single-layer of particles, thereby eliminating the introduction of conditional probabilities associated with overlapping conditions. When the maximum contrast between the particles and the deposition surface is less than 100\%, it is conventional to speak of an effective area coverage (EAC). The effective area coverage is 
just the product of the actual area coverage times a dimensionless contrast coefficient, R. This coefficient is experimentally determined and is between zero and one, where $R=1$ denotes maximum contrast. Thus, the EAC per vehicle pass, $E_{p}$, for homogeneous particles of radius, $r$, is given by

$$
E_{p}=R\left(\pi r^{2}\right) \mu_{p}
$$

An expression for $\mu_{p}$ is obtained from the definition of deposition. Deposition, which is just the mass per unit area, may be thought of as the number of particles per unit area times the mass per particle. Thus the deposition per vehicle pass, ' $\Omega_{p}$ ' is given by

$$
\Omega_{p}=\mu_{p}\left(\frac{4 \rho \pi r^{3}}{3}\right)
$$

where $\rho$ is the particle density and $r$ is the particle radius. Solving for $\mu_{p}$ and substituting into Equation 3.16 yields the following expression for the EAC per vehicle pass:

$$
E_{p}=R\left(\pi r^{2}\right) \frac{3 \Omega p}{4 \pi \rho r^{3}}
$$

Simplifying Equation 3.18 yields

$$
E_{p}=\frac{3 R \Omega}{2 p D}
$$

where $D$ is the particle diameter. 
For a finite particle-size interval, $i$, values of $E_{p^{\prime}} \Omega_{p}$ and $D$ are replaced with $E_{p i}, \Omega_{p i}$ and $D_{i}$, respectively. Thus the fractional EAC per vehicle pass corresponding to the ith particle-size interval is given by

$$
E_{p i}=\frac{3 R \Omega_{p i}}{2 \rho D_{i}}
$$

and the total EAC per vehicle pass is given by

$$
E_{p s}=\sum_{i} E_{p i}
$$

Here $D_{g 2 i}$ is assumed to be a valid estimator of $D_{i}$ for representing the mean particle diameter on an area basis over a finite particle-size interval.

\section{E. Effective Area Coverage Standards}

Once EAC values have been calculated, it is necessary to relate these results to some specified dust-deposition level that quantifies a nuisance level. Earlier quantification experiments (Hancock, Esmen, and Furber, 1976) tentatively determined detectabie and objectionable levels of dust using a photometric method and a panel survey. These studies found: (1) an effective area coverage (EAC) of 0.28 by dust can be perceived under maximum contrast conditions, (2) the minimum perceivable difference between varying gradations of shading was a change of $0.458 \mathrm{EAC},(3)$ a dust-deposition level of 0.78 
EAC was required before an object so covered was deemed unfit to use, and (4) a dustfall rate less than 0.178 EAC per day would be tolerable for the population at large. The latter two results are just the information that is required to complete the quantification procedure, since they set both an absolute deposition limit and a maximum dustfall rate.

Dividing the 0.78 EAC standard by the total EAC per vehicle pass results in a first approximation of the maximum number of vehicle passes permitted before exceeding the ubjectlonable dust-deposition level. Similarly, dividing the $0.178 \mathrm{EAC} /$ day dustfall rate by the total EAC per vehicle pass gives the maximum number of vehicle passes permitted per day. This completes the quantification methodology for determining the environmental impact of particulate deposition resulting from vehicles traveling dry unpaved roadways. 


\section{DATA ACQUISITION}

A. Equipment, Measurement Procedures, and Data Handling

1. Meteorological data

Meteorological data were collected using instrumentation belonging to the Earth Science Department at Iowa State University. Wind speed measurements were taken with a generator type anemometer, while ambient temperature and atmospheric moisture were measured with a sling psychrometer. The amount of incoming solar radiation was estimated by considering the solar angle and degree of cloudiness. Together, these were used to determine the atmospheric stability by applying the PasquillGifford stability classification method described in Appendix $A$.

2. Particulate sizing data

An ANDERSON 2000 HIGH-VOLUME PARTICLE-SIZING SAMPLER, on loan from the state Hygienic Laboratory in Iowa City, aerodynamically sized suspended particulate matter into four fractionations in the head $(1.1,2.0,3.3$, and 7.0 microns

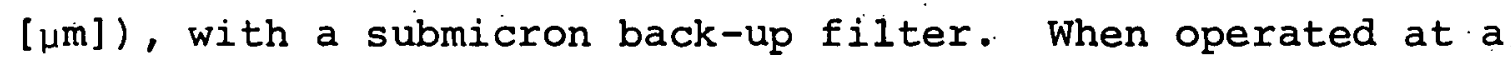
flow rate of 20 cubic feet per minute, the five groups are $7.0 \mu \mathrm{m}$ or larger, $3.3 \mu \mathrm{m}$ to $7.0 \mu \mathrm{m}, 2.0 \mu \mathrm{m}$ to $3.3 \mu \mathrm{m}, 1.1 \mu \mathrm{m}$ to $2.0 \mu \mathrm{m}$, and less than $1.1 \mu \mathrm{m}$. These correspond approximately to particle sizes penetrating to the nasal canal, trachea and primary bronchi, secondary bronchi, terminal 
bronchi, and alveoli, respectively (Anderson 2000 Inc., 1976, Mainwaring and Harsha, 1976). For spherical particles with a density of $2.5 \mathrm{~g} / \mathrm{cm}^{3}$, these approximately correspond to 4.5 $\mu \mathrm{m}$ or larger, $2.1 \mu \mathrm{m}$ to $4.5 \mu \mathrm{m}, 1.25 \mu \mathrm{m}$ to $2.1 \mu \mathrm{m}, 0.7 \mu \mathrm{m}$ to $1.25 \mu \mathrm{m}$, and less than $0.7 \mu \mathrm{m}$. Filters are standardized before initial and final weighing by allowing them to attain an equilibrium condition in a controlled environment of $75^{\circ} \mathrm{F}$ and less than 508 relative humidity. Samples were then weighed on a balance accurate to 0.0001 grams. The results are then graphed on log probability paper, with the effective cutoff diameter as the ordinate and the cumulative probability by weight as the abscissa. If the cumulation distribution becomes a straight line, then the data are log-normally distributed.: Finally, the mass of particulate matter captured by the ith sampling stage (i.e., particle-size range) is converted to a time-averaged concentration expressed in micrograms per cubic meter $\left(\left(\mu \mathrm{g} / \mathrm{m}^{3}\right)\right.$; this is given by $x=\frac{(\text { sample mass }-\mathrm{g})\left(10^{6} \mathrm{\mu g} / \mathrm{g}\right)}{(\text { sampling duration }-\mathrm{h})\left(20 \mathrm{ft}^{3} / \mathrm{min}\right)(60 \mathrm{~min} / \mathrm{h})(0.3048 \mathrm{~m} / \mathrm{ft})^{3}}$

which has an assumed flow rate of $20 \mathrm{ft}^{3} / \mathrm{min}$.

Log-probability plots of the data suggest that suspended particulates are log-normally distributed. The log-normal distribution described in Appendix B is frequently used to approximate the actual particulate-size spectra and annual distributions (Larsen, 1969; Hale, 1972). Thio is espectally marked for ambient conditions that are not biased by numerous 
larger particles typically present near particulate sources. Furthermore, other studies (Mainwaring and Harsha, 1976) suggest the log-normal distribution to be most appropriate for characterizing particulate levels in industrial and urban areas.

\section{B. Experimental Data}

1. Ambient conditions

Before determining the impact of dry unpaved roadways, it is first necessary to have an overall assessment of baokground suspended-particulate levels. Ambient size distributions and associated concentrations were measured on the Iowa state University campus and at the Iowa Coal Project (ICP) mine site office. Background levels at the mine site were measured in absence of any mining activity (i.e., on Saturday afternoon) upwind from the mining pit. Both ambient samples yielded comparable results.

For comparison purposes, ambient aerodynamic size distribution data of suspended particles fur Des Moines, Iowa and Iowa City, Iowa are given in Tables 4.1 and 4.2 respectively. These are the only size-distribution data available for this part of the state, according to Iowa Department of Environmental Quality personnel. Interpolation between Iowa City and Des Moines is not recommended because these two locations are predominanțly urhan and the ICr mine site is rural. 
Table 4.1. 1975 Ambient aerodynamic suspended-particulate sizing data in percent, Des Moines, Iowa - East Location (Arthur at oxford)

\begin{tabular}{rccccc}
\hline & \multicolumn{5}{c}{ Particulate-size distribution in microns } \\
\cline { 2 - 6 } Date & $<1.1$ & $1.1-2.0$ & $2.0-3.3$ & $3.3-7.0$ & $>7.0$ \\
\hline 5 Aug 75 & 23 & 10 & 13 & 19 & 35 \\
7 Aug 75 & 27 & 6 & 11 & 18 & 38 \\
10 Aug 75 & 30 & 9 & 11 & 16 & 34 \\
13 Aug 75 & 23 & 7 & 11 & 18 & 40 \\
18 Aug 75 & 32 & 8 & 13 & 14 & 33 \\
20 Aug 75 & 27 & 6 & 11 & 15 & 42 \\
4 Oct 75 & 27 & 5 & 12 & 15 & 40 \\
10 Oct 75 & 16 & 4 & 10 & 16 & 55 \\
13 Oct 75 & 24 & 5 & 13 & 15 & 43 \\
19 Oct 75 & 18 & 2 & 6 & 18 & 56 \\
23 Oct 75 & 25 & 5 & 13 & 15 & 43 \\
25 Oct 75 & 29 & 3 & 15 & 16 & 37 \\
29 Oct 75 & 20 & 6 & 10 & 16 & 48 \\
3 Nov 75 & 20 & 6 & 9 & 15 & 50 \\
Average & 24.4 & 5.8 & 11.3 & 16.1 & 42.4 \\
\hline
\end{tabular}

These data, together with the fate of inhaled particles (see Section IV.A), indicate that about $33 \%$ to $43 \%$ of all particulates are 7 microns in diameter or larger, and are likely to be collected by nasal hair, the remaining $47 \%$ to $57 \%$ will be deposited deeper within the human respiratory system. These data suggest that the approximate expected proportions of trapped deposits are $16 \%$ to 198 by the trachea and primary 
Table 4.2. 1976 Ambient aerodynamic particulate-sizing data in percent, State Hygienic Lab., Iowa City, Iowa

\begin{tabular}{|c|c|c|c|c|c|c|}
\hline \multirow{2}{*}{ Date } & & \multicolumn{5}{|c|}{ Particle-size distribution in microns } \\
\hline & & $<1.1$ & $1.1-2.0$ & $2.0-3.3 .3$ & $3.3-7.0$ & $>7.0$ \\
\hline $\begin{array}{r}3 \\
9 \\
15 \\
21 \\
27 \\
2 \\
8 \\
14 \\
20 \\
26 \\
2 \\
8 \\
14 \\
20 \\
26\end{array}$ & $\begin{array}{ll}\text { Oct } & 76 \\
\text { Oct } & 76 \\
\text { Oct } & 76 \\
\text { Oct } & 76 \\
\text { Oct } & 76 \\
\text { Nov } & 76 \\
\text { Nov } & 76 \\
\text { Nov } & 76 \\
\text { Nov } & 76 \\
\text { Nov } & 76 \\
\text { Dec } & 76 \\
\text { Der } & 76 \\
\text { Dec } & 76 \\
\text { Dec } & 76 \\
\text { Dec } & 76\end{array}$ & $\begin{array}{l}28.1 \\
25.9 \\
26.0 \\
31.7 \\
24.5 \\
26.3 \\
33.3 \\
15.3 \\
24.3 \\
32.1 \\
30.8 \\
37.6 \\
31.3 \\
23.3 \\
23.1\end{array}$ & $\begin{array}{r}8.3 \\
6.4 \\
8.7 \\
9.8 \\
9.9 \\
8.2 \\
7.5 \\
10.9 \\
6.6 \\
6.5 \\
11.5 \\
10.5 \\
11.1 \\
9.3 \\
9.2\end{array}$ & $\begin{array}{r}14.6 \\
7.8 \\
12.0 \\
11.5 \\
11.7 \\
10.5 \\
10.3 \\
10.9 \\
10.0 \\
8.2 \\
13.5 \\
12.3 \\
10.9 \\
12.0 \\
11.9\end{array}$ & $\begin{array}{l}21.1 \\
16.1 \\
21.4 \\
19.3 \\
20.4 \\
17.9 \\
16.8 \\
21.4 \\
20.3 \\
13.6 \\
17.9 \\
15.4 \\
17.6 \\
18.7 \\
18.6\end{array}$ & $\begin{array}{l}27.9 \\
43.9 \\
31.8 \\
27.7 \\
33.5 \\
37.2 \\
32.1 \\
41.5 \\
38.9 \\
39.6 \\
26.4 \\
24.2 \\
29.1 \\
37.3 \\
37.0\end{array}$ \\
\hline \multicolumn{2}{|c|}{ Average } & 27.6 & 8.9 & 11.2 & 18.4 & 33.9 \\
\hline \multicolumn{7}{|c|}{$\begin{array}{l}1977 \text { Ambient aerodynamic particulate-sizing data } \\
\text { in percent, State Hygienic Lab. , Iowa City, Iowa }\end{array}$} \\
\hline $\begin{array}{r}1 \\
7 \\
13 \\
19 \\
25 \\
31 \\
6 \\
12 \\
18 \\
24 \\
2 \\
8 \\
14 \\
20 \\
26\end{array}$ & $\begin{array}{ll}\text { Jan } & 77 \\
\text { Jan } & 77 \\
\text { Jan } & 77 \\
\text { Jan } & 77 \\
\text { Jan } & 77 \\
\text { Jan } & 77 \\
\text { Feb } & 77 \\
\text { Feb } & 77 \\
\text { Feb } & 77 \\
\text { Feb } & 77 \\
\text { Mar } & 77 \\
\text { Mar } & 77 \\
\text { Mar } & 77 \\
\text { Mar } & 77 \\
\text { Mar } & 77\end{array}$ & $\begin{array}{l}28.8 \\
23.0 \\
30.5 \\
33.9 \\
19.5 \\
15.7 \\
31.7 \\
30.6 \\
25.1 \\
27.3 \\
26.5 \\
11.2 \\
17.6 \\
41.9 \\
15.2\end{array}$ & $\begin{array}{r}8.9 \\
11.6 \\
14.7 \\
5.9 \\
8.8 \\
6.0 \\
9.7 \\
8.9 \\
8.2 \\
8.6 \\
12.3 \\
10.2 \\
10.1 \\
13.0 \\
11.5\end{array}$ & $\begin{array}{l}11.8 \\
12.7 \\
15.5 \\
14.9 \\
10.0 \\
8.6 \\
11.1 \\
12.4 \\
10.8 \\
10.4 \\
13.3 \\
15.1 \\
13.2 \\
11.4 \\
13.9\end{array}$ & $\begin{array}{l}17.4 \\
18.1 \\
16.7 \\
18.1 \\
13.5 \\
12.7 \\
15.3 \\
18.9 \\
17.7 \\
16.2 \\
17.7 \\
22.9 \\
21.9 \\
13.6 \\
21.2\end{array}$ & $\begin{array}{l}33.1 \\
34.6 \\
22.6 \\
28.2 \\
48.2 \\
57.0 \\
32.3 \\
29.2 \\
38.3 \\
37.5 \\
30.2 \\
40.7 \\
37.1 \\
20.2 \\
38.2\end{array}$ \\
\hline \multicolumn{2}{|c|}{ Average } & 25.2 & 9.9 & 12.3 & 17.5 & 35.2 \\
\hline
\end{tabular}


bronchi, $11 \%$ to $13 \%$ by the secondary bronchi, 58 to $10 \%$ by the terminal bronchi, and $25 \%$ to $28 \%$ by the alveoli. The above percentages provide a guide to the interpretation of particulate size-distribution data. Particles greater than $7 \mu \mathrm{m}$ in diameter together with those in the submicron group account for nearly $60 \%$ to $70 \%$ of all inhaled particulates.

Most data pertaining to suspended particulates are obtained using a high-volume air flow and gravimetric technique. Although these data are not as informative as size distributions, they are easier to obtain dnd analyze; hence most governmental agencies use this method, especially in smaller urban areas. Table 4.3 gives monthly suspended-particulate data for Pella, Iowa from January 1976 through February 1977 as measured by the high-volume technique.

2. Unpaved roadway contribution

High-volume, aerodynamically-sized particle distributions were measured in five separate experiments that were conducted during August and September 1976. Measurements were taken at three gravel-road locations (one in Story county, Iowa and two in Mahaska County, Iowa) to estimate order-of-magnitude concentrations of suspended particles within $100 \mathrm{ft}$ of a gravel road. Experiments consisted of making 20-50 passes in a 4100lb station wagon driven at $40 \mathrm{mph}$ past a sampler $12-50 \mathrm{ft}$ from the road centerline. Measurements were taken dowliwind of dry unpaved surfaces during sunny afternoons with wind speeds of 5 
Table.4.3. Monthly ambient suspended-particulate data, Pella, Iowa - 216 Liberty St. (micrograms per cubic meter)

\begin{tabular}{lcccc}
\hline Month & $\begin{array}{c}\text { Arithmetic } \\
\text { mean }\end{array}$ & $\begin{array}{c}\text { Standard } \\
\text { deviation }\end{array}$ & $\begin{array}{c}\text { Geometric } \\
\text { mean }\end{array}$ & $\begin{array}{c}\text { Geometric } \\
\text { standard } \\
\text { deviation }\end{array}$ \\
\hline Jan 76 & 46.90 & 21.02 & 43.46 & 0.4294 \\
Feb 76 & 48.83 & 21.41 & 44.46 & 0.5343 \\
Mar 76 & 47.35 & 42.89 & 33.68 & 0.8846 \\
Apr 76 & 57.18 & 41.13 & 41.84 & 0.9736 \\
May 76 & 109.00 & N.A. & 109.00 & N.A. \\
Jun 76 & 74.25 & 17.50 & 72.83 & 0.2224 \\
Jul 76 & 63.85 & 3.78 & 63.77 & 0.0593 \\
Aug 76 & 83.64 & 13.88 & 83.64 & 0.1769 \\
Sep 76 & 74.22 & 34.21 & 68.32 & 0.4505 \\
Oct 76 & 70.08 & 11.22 & 69.34 & 0.1644 \\
Nov 76 & 70.76 & 15.14 & 69.26 & 0.2412 \\
Dec 76 & 40.68 & 8.31 & 40.03 & 0.1995 \\
Jan 77 & 36.54 & 10.29 & 35.27 & 0.3066 \\
Feb 77 & 35.27 & 4.03 & 35.12 & 0.1110 \\
\hline
\end{tabular}

to $10 \mathrm{mph}$. Also available were particle-size distribution data of dirt-road emissions in Morton County, Kansas and Wallace County, Kansas (US EPA, 1974); the Kansas dirt-road data shown in Figure 4.1 are similar to the Iowa gravel-road data, though biased toward smaller particles.

Figure 4.1 together with Table 4.4 shows that the Iowa gravel-road data contain a higher percentage of large particles 
Figure 4.1. Particle-size diameter graph of experimental suspended-particulate sizing data based on a particle density of $2.5 \mathrm{~g} / \mathrm{cm}^{3}$ 
THIS PAGE

\section{WAS INTENTIONALLY \\ LEFT BLANK}




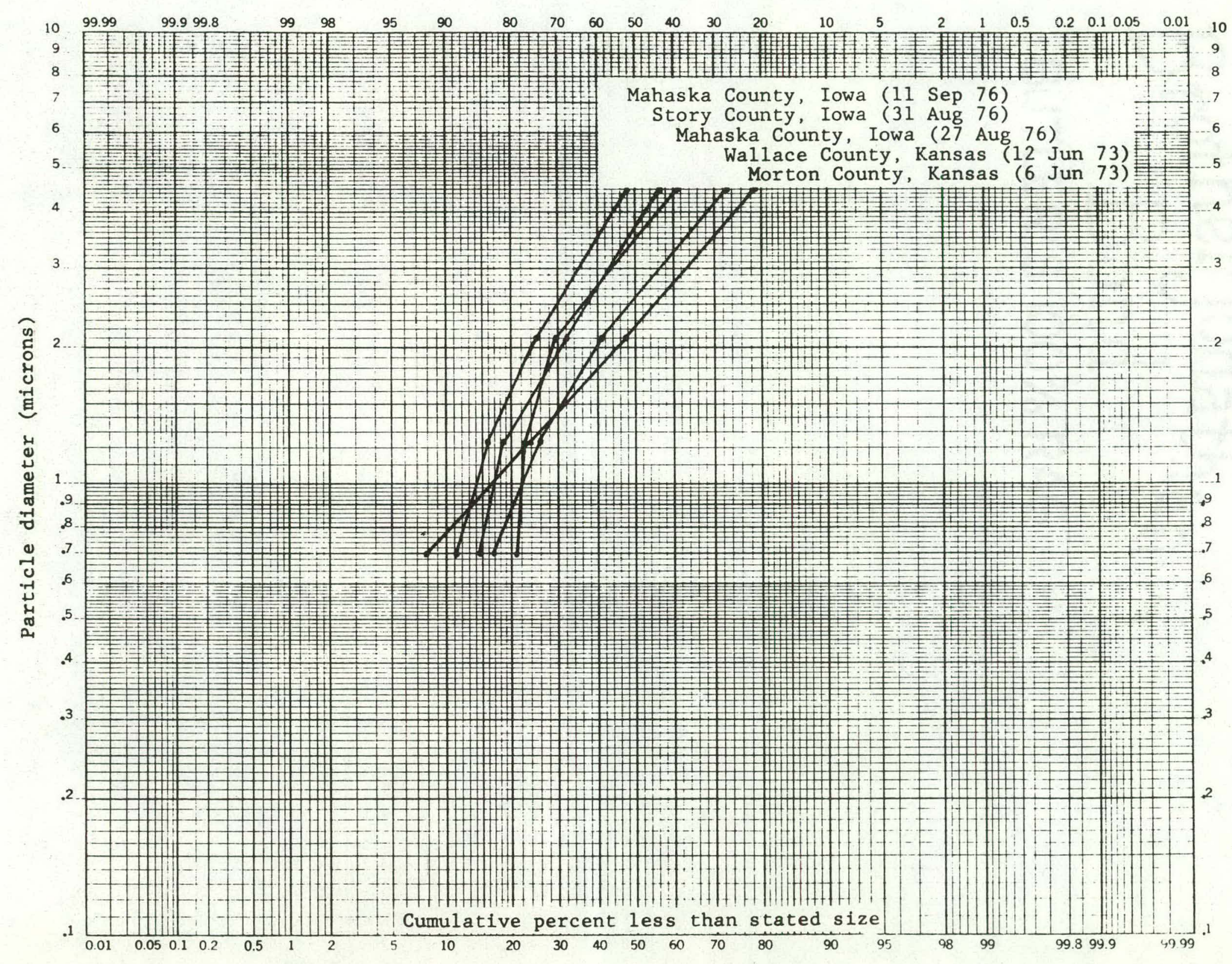


Table 4.4. Aerodynamic particulate-sizing data in percent during dry conditions

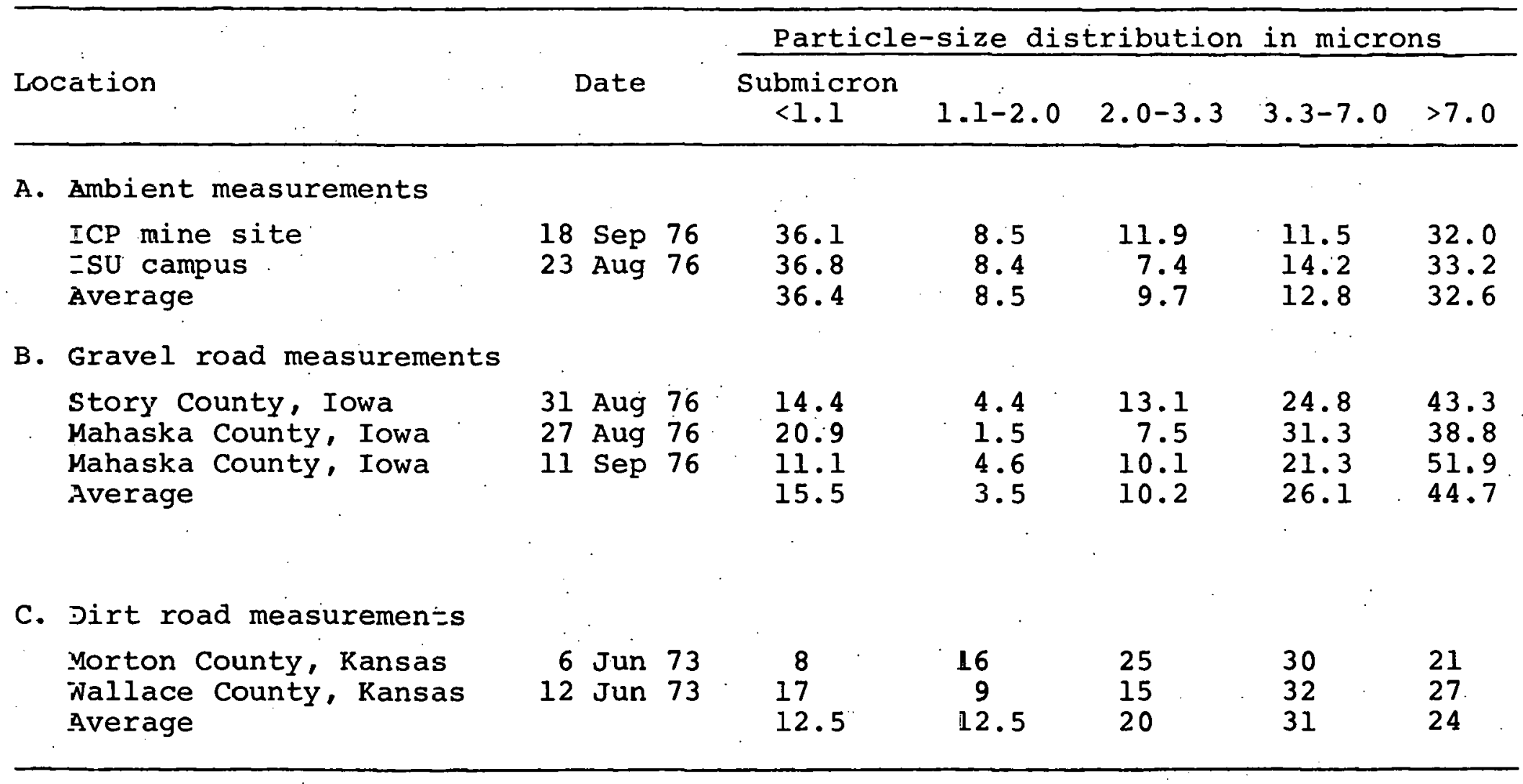


than the Kansas dirt-road data. These data were collected during dry conditions when dust concentrations were above normal; no samples were collected during wet periods. Roadway surfaces tend to dry off very rapidly if meteorological conditions are conducive or the traffic flow is moderate; the results are, therefore, representative of conditions that frequently exist. The percentage of particulates greater than or equal to $7 \mu \mathrm{m}$ is increased approximately 58 to $15 \%$ above normal ambient levels, and increases of 58 to $10 z$ are observed in the next smaller range. Consequently, smaller-size ranges show a decrease. This is expected because fewer large particles are required to shift the size spectra due to the greater mass per particle.

Table 4.5 shows the percentage of the total contribution below a graphically-determined aerodynamic particle diameter for the dirt- and gravel-road studies. Typically, $50 \%$ of the gravel-road particles generated by passing vehicles have aerodynamic diameters of approximately 5.4 to $7.5 \mu \mathrm{m}$ whereas $50 \%$ of the dirt-road particles generated by passing vehicles have aerodynamic diameters of approximately 3.5 to $4.0 \mu \mathrm{m}$ or less. Average point concentrations are extremely difficult to measure due to the rapidly changing plume characteristics as a function of space and time. Here gravel-road measurements also seem to be distributed log normally as evidenced by Figure 4.1. 
Table 4.5. Particulate-sizing data--aerodynamic particle diameter in microns

\begin{tabular}{|c|c|c|c|c|c|c|c|c|}
\hline \multirow[b]{2}{*}{ Losation } & \multirow[b]{2}{*}{. } & \multicolumn{3}{|c|}{ Percentage less =han } & for an & \multicolumn{3}{|c|}{ aerodynamic diameter } \\
\hline & & Date & 208 & 308 & 408 & $50 \%$ & $60 \%$ & $70 \%$ \\
\hline
\end{tabular}

A. Ambient measurements

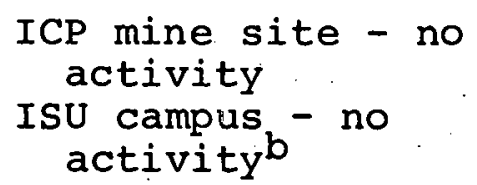

B. Gravel road measurements Story County, Iowa Mahaska County, Iowa Mahaska County, Iowa

C. Dirt road measuremerts Morton County, Kansas Wallace County, Kansas

$\begin{array}{lllllll}18 \text { Sep } 76 & \text { N.A. } & \sim 0.7^{\mathrm{a}} & 1.5 & 2.5 & 4.2 & \sim 8^{\mathrm{a}} \\ 23 \text { Aug } 76 & \text { N.A. } & \sim 0.7^{\mathrm{a}} & 1.4 & 2.9 & 5.0 & \sim 8.5^{\mathrm{a}}\end{array}$

$\begin{array}{lcccccc}\text { 31. Aug } 76 & 2.1 & 3.1 & 4.3 & 5.8 & \sim 7.6^{\mathrm{a}} & \text { N.A. } \\ 27 \text { Aug } 76 & \sim 0.7^{\mathrm{a}} & 3.3 & 4.3 & 5.4 & 6.9 & \text { N.A. } \\ 11 . \text { Sep } 76 & 2.6 & 3.9 & 5.5 & \sim 7.5^{\mathrm{a}} & \sim 10^{\mathrm{a}} & \text { N.A. }\end{array}$

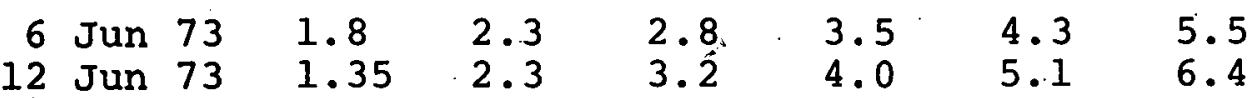

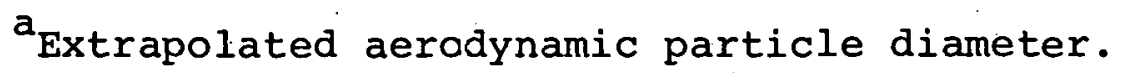

${ }^{b}$ Air pollution advisories were in effect for part of the sampling period. 
Dust concentrations from traffic on gravel roads are extremely variable over short distances. Dust plumes are observed to maintain their original shape for considerable distances downwind over open fields. In the vicinity of farmsteads, increased surface roughness (i.e., trees, shrubs, buildings) enhances mixing and slows horizontal transport, thereby increasing local deposition. No time-averaged concentrations are available for the Mahaska County gravel-road experiment on August 27, 1976 because of a faulty gasolinepowered yerieralur which stopped midwāy during the experiment. However it was possible to determine the particle-size distribution (without a knowledge of the sampling duration), but not the time-averaged concentration. Hereafter, any reference to Mahaska County, Iowa shall refer to the September 11, 1976 gravel-road experiment only. 


\section{DEPOSITION SENSITIVITY TESTS}

\section{A. Testing Criteria and Limitations}

In this chapter, the methodology described in chapter III is used to test the sensitivity of line-source-generated particulate-deposition amounts to atmospheric stability, roughness height, deposition height, source height, and wind speed. Also explored is the sensitivity of the relative deposition contribution for different particle-size ranges to the above five parameters. A cascade impactor at a downwind distance of $22 \mathrm{~m}$ is used to determine the particulate-size distribution, and this measured distribution is extrapolated back to the source. The particle-size-distribution statistics, as determined by the cascade impactor, are also assumed invariant. The five modeling parameters are tested to determine how each, with all possible combinations of the other parameters, affect the total deposition at the logarithmically-spaced distance of 4 , $8,16,32,64,128,256$, and $512 \mathrm{~m}$.

The chosen parameter values represent a wide range of observed, but not extreme, conditions. For example, the deposition-velocity algorithm described in section II.A.4 is not applicable for roughness heights in excess of about $0.1 \mathrm{~m}$. An order-of-magnitude variation in the roughness height should cover a wide range of conditions, consequently roughness height values of $0.01 \mathrm{~m}$ and $0.10 \mathrm{~m}$, corresponding to bare solid ground 
and mature root crops, respectively (Stern, 1976), are tested. These limits describe a rural environment, which is the intent of this study. Because emissions from unpaved roads originate at ground level, a source height of zero meters was the logical lower limit. However, vehicle-induced turbulence causes a nonzero effective source height. Observations reveal the initial particulate plume has an effective source height in the lowest two meters; thus a mean height of $1 \mathrm{~m}$ was chosen for a representative nonzero value. Although deposition heights are usually assumed to be at gruund-level, sehmel and Hodgcon (1976) consider a 1-m deposition height. These two values then form the lower and upper limits for the deposition heights tested. Wind speed values between $1 \mathrm{~m} / \mathrm{s}$ and $5 \mathrm{~m} / \mathrm{s}$ occur frequently and are representative of a wide range of conditions and hence are chosen for sensitivity testing. Furthermore, particleresuspension considerations are assumed negligible below the $5 \mathrm{~m} / \mathrm{s}$ upper limit. The log-linear wind profile is most reliable where departures from neutral conditions are small; thus, deposition sensitivity tests are limited to stability classes $B, D$ and $E$.

In Table 5.1 and Figures 5.1 through 5.32 particles are treated as equivalent spheres with a density of $2.5 \mathrm{~g} / \mathrm{cm}^{3}$. The particle-size intervals [i.e., $<1.1 \mu \mathrm{m}, 1.1 \mu \mathrm{m}$ to $2.0 \mu \mathrm{m}$, $2.0 \mu \mathrm{m}$ to $3.3 \mu \mathrm{m}, 3.3 \mu \mathrm{m}$ to $7.0 \mu \mathrm{m}$, and $7.0 \mu \mathrm{m}$ ] are assumed to have mass distributed in the ratio of $14.40: 4.41: 13.10$ : $24.77: 43.32$, respectively; these proportions approximately 
Table 5.1. Downwind-percentage contribution by particle-size range $(\mu \mathrm{m})$ and total downwind deposition $\left(\mu \mathrm{g} / \mathrm{m}^{2}\right)$

from an infinite instantaneous line source of $1.0 \mathrm{~g} / \mathrm{m}$ during. neutral conditions

\begin{tabular}{lrrrrrrrrrr}
\hline Modeling & Particle & \multicolumn{9}{c}{ Downwind distance } \\
parameters & size range & 4 & 8 & 16 & 32 & 64 & 128 & 256 & 512 \\
\hline $\mathrm{u}=1 \mathrm{~m} / \mathrm{s}$ & $<1.1$ & 1 & 1 & 1 & 1 & 2 & 3 & 4 & 8 \\
$\mathrm{~h}=0 \mathrm{~m}$ & $1.1-2.0$ & 1 & 1 & 1 & 1 & 1 & 2 & 2 & 4 \\
$\mathrm{z}_{\mathrm{d}}=0 \mathrm{~m}$ & $2.0-3.3$ & 3 & 3 & 3 & 4 & 5 & 7 & 10 & 15 \\
$\mathrm{z}_{\mathrm{o}}=0.01 \mathrm{~m}$ & $3.3-7.0$ & 10 & 11 & 12 & 14 & 16 & 20 & 27 & 37 \\
& $>7.0$ & 86 & 84 & 82 & 80 & 75 & 68 & 56 & 37 \\
\multicolumn{2}{c}{ Total deposition } & 378 & 237 & 142 & 80 & 41 & 20 & 8 & 3
\end{tabular}

$\begin{array}{lrrrrrrrrrr}\mathrm{u}=1 \mathrm{~m} / \mathrm{s} & <1.1 & 4 & 5 & 7 & 9 & 11 & 13 & - & - \\ \mathrm{h}=0 \mathrm{~m} & 1.1-2.0 & 2 & 2 & 3 & 3 & 4 & 4 & - & - \\ \mathrm{z}_{\mathrm{d}}=0 \mathrm{~m} & 2.0-3.3 & 7 & 9 & 10 & 11 & 12 & 12 & - & - \\ \mathrm{z}_{\mathrm{O}} & =0.10 \mathrm{~m} & 3.3-7.0 & 20 & 22 & 23 & 24 & 24 & 24 & - & - \\ & >7.0 & 67 & 62 & 57 & 53 & 50 & 47 & - & -\end{array}$

Total deposition $\quad \begin{array}{lllllllll}588 & 254 & 105 & 41 & 16 & 6 & -\end{array}$

$\begin{array}{lrrrrrrrrrr}\mathrm{u}=1 \mathrm{~m} / \mathrm{s} & <1.1 & 1 & 1 & 2 & 2 & 2 & 3 & 4 & 6 \\ \mathrm{~h}=0 \mathrm{~m} & 1.1-2.0 & 1 & 1 & 1 & 1 & 1 & 1 & 2 & 3 \\ \mathrm{z}_{\mathrm{d}}=1 \mathrm{~m} & 2.0-3.3 & 3 & 4 & 4 & 4 & 5 & 6 & 8 & 12 \\ \mathrm{z}_{\mathrm{O}}=0.01 \mathrm{~m} & 3.3-7.0 & 11 & 11 & 11 & 12 & 14 & 17 & 22 & 32 \\ & & >7.0 & 84 & 83 & 82 & 81 & 78 & 74 & 64 & 47\end{array}$
$\begin{array}{lllllllll}\text { Total deposition } & 41 & 67 & 69 & 54 & 35 & 20 & 10 & 4\end{array}$

$\begin{array}{rrrrrrrrrrr}\mathrm{u}=1 \mathrm{~m} / \mathrm{s} & <1.1 & 8 & 9 & 9 & 9 & 10 & 10 & 12 & 14 \\ \mathrm{~h}=0 \mathrm{~m} & 1.1-2.0 & 3 & 3 & 3 & 3 & 3 & 3 & 4 & 4 \\ \mathrm{z}_{\mathrm{d}}=1 \mathrm{~m} & 2.0-3.3 & 9 & 9 & 9 & 10 & 10 & 11 & 12 & 13 \\ \mathrm{z}_{\mathrm{O}}=0.10 \mathrm{~m} & 3.3-7.0 & 19 & 20 & 20 & 20 & 21 & 22 & 23 & 26 \\ & & >7.0 & 60 & 60 & 59 & 58 & 56 & 54 & 50 & 42 \\ & & & & & & \\ & \text { Total deposition } & 132 & 138 & 112 & 77 & 47 & 26 & 13 & 5\end{array}$


Table 5.1 (Continued)

\begin{tabular}{lcrrrrrrrrr}
\hline Modeling & Particle & \multicolumn{4}{c}{ Downwind distance } & \multicolumn{3}{c}{ (meters) } \\
parameters & size range & 4 & 8 & 16 & 32 & 64 & 128 & 256 & 512 \\
\hline $\mathrm{u}=1 \mathrm{~m} / \mathrm{s}$ & $<1.1$ & 1 & 1 & 1 & 1 & 2 & 3 & 4 & 7 \\
$\mathrm{~h}=1 \mathrm{~m}$ & $1.1-2.0$ & 1 & 1 & 1 & 1 & 1 & 2 & 2 & 4 \\
$\mathrm{z}_{\mathrm{d}}=0 \mathrm{~m}$ & $2.0-3.3$ & 3 & 3 & 4 & 4 & 5 & 7 & 10 & 15 \\
$\mathrm{z}_{0}=0.01 \mathrm{~m}$ & $3.3-7.0$ & 10 & 11 & 12 & 13 & 16 & 20 & 26 & 36 \\
& $>7.0$ & 85 & 84 & 83 & 80 & 76 & 70 & 57 & 38
\end{tabular}

Total deposition

$\begin{array}{llllllll}81 & 128 & 124 & 90 & 54 & 27 & 12 & 5\end{array}$

$\begin{array}{lrrrrrrrrr}\mathrm{u}=1 \mathrm{~m} / \mathrm{s} & <1.1 & 4 & 5 & 7 & 9 & 11 & 13 & - & - \\ \mathrm{h}=1 \mathrm{~m} & 1.1-2.0 & 2 & 2 & 3 & 3 & 4 & 4 & - & = \\ \mathrm{z}_{\mathrm{d}}=0 \mathrm{~m} & 2.0-3.3 & 8 & 9 & 10 & 11 & 12 & 12 & - & - \\ \mathrm{z}_{\mathrm{O}}=0.10 \mathrm{~m} & 3.3-7.0 & 20 & 22 & 23 & 24 & 24 & 24 & - & - \\ & >7.0 & 66 & 62 & 58 & 54 & 50 & 46 & - & -\end{array}$

Total deposition. $\quad 689 \quad 519 \quad 286 \quad 131 \quad 54 \quad 21 \quad$ -

\begin{tabular}{|c|c|c|c|c|c|c|c|c|c|}
\hline $1=1 \mathrm{~m} / \mathrm{s}$ & $<1.1$ & 2 & 2 & 2 & 2 & 2 & 3 & 4 & 6 \\
\hline$=1 \mathrm{~m}$ & $1.1-2.0$ & 1 & 1 & 1 & 1 & 1 & 1 & 2 & 3 \\
\hline $\mathrm{z}_{\mathrm{d}}=1 \mathrm{~m}$ & $2.0-3.3$ & 4 & 4 & 4 & 4 & 5 & 6 & 8 & 12 \\
\hline $0=0.01 \mathrm{~m}$ & $3.3-7.0$ & 11 & 11 & 12 & 12 & 14 & 16 & 22 & 31 \\
\hline & $>7.0$ & 83 & 82 & 82 & 81 & 78 & 74 & 65 & 48 \\
\hline
\end{tabular}

$\begin{array}{lllllllll}\text { Total deposition } & 140 & 101 & 78 & 60 & 42 & 25 & 12 & b\end{array}$

\begin{tabular}{|c|c|c|c|c|c|c|c|c|c|}
\hline $\mathrm{u}=1 \mathrm{~m} / \mathrm{s}$ & $<1.1$ & 9 & 9 & 9 & 9 & 10 & 10 & 12 & 14 \\
\hline $\mathrm{h}=1 \mathrm{~m}$ & $1.1-2.0$ & 3 & 3 & 3 & 3 & 3 & 3 & 4 & 4 \\
\hline$z_{d}=1 \mathrm{~m}$ & $2.0-3.3$ & 9 & 9 & 10 & 10 & 10 & 11 & 12 & 13 \\
\hline $0=0.10 \mathrm{~m}$ & $3.3-7.0$ & 20 & 20 & 20 & 20 & 21 & 22 & 23 & 26 \\
\hline & $>7.0$ & 60 & 60 & 59 & 58 & 57 & 54 & 50 & 42 \\
\hline
\end{tabular}
$\begin{array}{lllllllll}\text { Tulal deposition } & 192 & 150 & 120 & 87 & 56 & 32 & 16 & 7\end{array}$ 
Table 5.1 (Continued)

\begin{tabular}{|c|c|c|c|c|c|c|c|c|c|}
\hline $\begin{array}{l}\text { Modeling } \\
\text { parameters }\end{array}$ & $\begin{array}{c}\text { Particle } \\
\text { size range }\end{array}$ & 4 & $\begin{array}{c}\text { Dowr } \\
8\end{array}$ & $\begin{array}{r}\text { wind } \\
16\end{array}$ & $\begin{array}{c}\text { dist } \\
32\end{array}$ & $\begin{array}{l}\text { ance } \\
64\end{array}$ & $\begin{array}{l}\text { (met } \\
128\end{array}$ & $\begin{array}{l}\text { ers) } \\
256\end{array}$ & 512 \\
\hline $\mathrm{u}=5 \mathrm{~m} / \mathrm{s}$ & $<1.1$ & 1 & 1 & 1 & 1 & 2 & 2 & 4 & 5 \\
\hline $\mathrm{h}=0 \mathrm{~m}$ & $1.1-2.0$ & 1 & 1 & 1 & 1 & 1 & 2 & 2 & 3 \\
\hline $\mathrm{z}_{\mathrm{d}}=0 \mathrm{~m}$ & $2.0-3 \cdot 3$ & 3 & 3 & 4 & 5 & 6 & 8 & 11 & 14 \\
\hline \multirow[t]{2}{*}{$z_{0}=0.01 \mathrm{~m}$} & $3.3-7.0$ & 12 & 13 & 15 & 17 & 21 & 24 & 28 & 31 \\
\hline & $>7.0$ & 84 & 82 & 79 & 75 & 70 & 63 & 55 & 46 \\
\hline Total & sosition & 361 & 217 & 124 & 67 & 34 & 17 & 8 & 4 \\
\hline
\end{tabular}

$\begin{array}{lrrrrrrrrrr}\mathrm{u} & =5 \mathrm{~m} / \mathrm{s} & <1.1 & 2 & 4 & 5 & 7 & 10 & - & - & - \\ \mathrm{h}=0 \mathrm{~m} & 1.1-2.0 & 1 & 2 & 3 & 3 & 4 & - & - & - \\ \mathrm{z}_{\mathrm{d}}=0 \mathrm{~m} & 2.0-3.3 & 7 & 9 & 10 & 11 & 12 & - & - & - \\ \mathrm{z}_{\mathrm{o}}=0.10 \mathrm{~m} & 3.3-7.0 & 22 & 24 & 25 & 25 & 24 & - & - & - \\ & >7.0 & 67 & 62 & 57 & 53 & 50 & - & - & -\end{array}$

Total deposition $\begin{array}{lllllllll}474 & 196 & 78 & 31 & 12 & - & -\end{array}$

$\begin{array}{lrrrrrrrrr}\mathrm{u}=5 \mathrm{~m} / \mathrm{s} & <1.1 & 2 & 2 & 2 & 2 & 3 & 3 & 3 & 4 \\ \mathrm{~h}=0 \mathrm{~m} & 1.1-2.0 & 1 & 1 & 2 & 2 & 2 & 2 & 2 & 2 \\ \mathrm{z}_{\mathrm{d}}=1 \mathrm{~m} ; & 2.0-3.3 & 7 & 7 & 7 & 7 & 8 & 8 & 9 & 10 \\ \mathrm{z}_{\mathrm{o}}=0.01 \mathrm{~m} & 3.3-7.0 & 20 & 20 & 20 & 21 & 21 & 22 & 23 & 24 \\ & >7.0 & 70 & 69 & 69 & 68 & 67 & 65 & 63 & 60\end{array}$
$\begin{array}{lllllllll}\text { Total deposition. } & 24 & 39 & 42 & 35 & 25 & 16 & 10 & 5\end{array}$

$\begin{array}{lrrrrrrrrrr}\mathrm{u}=5 \mathrm{~m} / \mathrm{s} & <1.1 & 10 & 10 & 10 & 10 & 11 & 11 & 12 & 13 \\ \mathrm{~h}=0 \mathrm{~m} & 1.1-2.0 & 4 & 4 & 4 & 4 & 4 & 4 & 4 & 4 \\ \mathrm{z}_{\mathrm{d}}=1 \mathrm{~m} & 2.0-3.3 & 12 & 12 & 12 & 12 & 12 & 12 & 12 & 13 \\ \mathrm{z}_{\mathrm{o}}=0.10 \mathrm{~m} & 3.3-7.0 & 24 & 24 & 24 & 24 & 24 & 24 & 24 & 24 \\ & >7.0 & 51 & 50 & 50 & 50 & 49 & 48 & 47 & 46\end{array}$
$\begin{array}{llllllllll}\text { Total deposition } & 109 & 115 & 94 & 66 & 42 & 24 & 13 & 6\end{array}$ 
Table 5.1 (Continued)

\begin{tabular}{|c|c|c|c|c|c|c|c|c|c|}
\hline $\begin{array}{l}\text { Modeling } \\
\text { parameters }\end{array}$ & $\begin{array}{l}\text { Particle } \\
\text { size range }\end{array}$ & 4 & & \multicolumn{2}{|c|}{$\begin{array}{c}\text { distance } \\
3264\end{array}$} & \multicolumn{2}{|c|}{ (meters) } & 51 \\
\hline $\mathrm{u}=5 \mathrm{~m} / \mathrm{s}$ & $<1.1$ & 1 & 1 & 1 & 1 & 2 & 2 & 3 & \\
\hline $\mathrm{h}=1 \mathrm{~m}$ & $1.1-2.0$ & 1 & 1 & 1 & 1 & 1 & 2 & 2 & \\
\hline $\mathrm{z}_{\mathrm{d}}=0 \mathrm{~m}$ & $2.0-3.3$ & 3 & 4 & 4 & 5 & 6 & 8 & 10 & \\
\hline \multirow[t]{2}{*}{$z_{0}=0.01 \mathrm{~m}$} & $3.3-7.0$ & 13 & 14 & 15 & 17 & 20 & 23 & 27 & 3 \\
\hline & $>7.0$ & 83 & 82 & 79 & 76 & 71 & 65 & 57 & \\
\hline Total & leposition & 73 & 112 & 106 & 75 & 44 & 23 & 1.1 & \\
\hline $\mathrm{u}=5 \mathrm{~m} / \mathrm{s}$ & $<1.1$ & 3 & 4 & 5 & 7 & 10 & - & - & - \\
\hline$h-1 \mathrm{~m}$ & $1.1-3.0$ & 3 & 3 & 3 & 3 & $z$ & - & - & - \\
\hline $\mathrm{z}_{\mathrm{d}}=0 \mathrm{~m}$ & $2.0-3.3$ & 7 & 9 & 10 & 11 & 12 & - & - & - \\
\hline \multirow{2}{*}{$z_{0}=0.10 \mathrm{~m}$} & $3.3-7.0$ & 21 & 23 & 25 & 25 & 25 & - & - & - \\
\hline & $>7.0$ & 67 & 63 & 57 & 53 & 49 & - & - & - \\
\hline Total & SOSION & 094 & 497 & 265 & 120 & 50 & - & - & \\
\hline
\end{tabular}

\begin{tabular}{|c|c|c|c|c|c|c|c|c|c|}
\hline$\alpha=5 \mathrm{~m} / \mathrm{s}$ & $<1.1$ & 2 & 2 & 2 & 2 & 2 & 3 & 3 & 4 \\
\hline $\mathrm{n}=1 \mathrm{~m}$ & $1.1-2.0$ & 2 & 2 & 2 & 2 & 2 & 2 & 2 & 2 \\
\hline$z_{d}=1 \mathrm{~m}$ & $2.0-3.3$ & 7 & 7 & 7 & 7 & 8 & 8 & 9 & 10 \\
\hline$z_{0}=0.01 \mathrm{~m}$ & $3.3-7.0$ & 20 & 20 & 20 & 21 & 21 & 22 & 23 & 24 \\
\hline & $>7.0$ & 69 & 69 & 69 & 68 & 67 & 65 & 63 & 60 \\
\hline
\end{tabular}

$\begin{array}{lllllllll}\text { Tutal deposition } & 73 & 53 & 42 & 34 & 26 & 18 & 11 & 6\end{array}$

$\begin{array}{lrrrrrrrrr}\mathrm{u}=5 \mathrm{~m} / \mathrm{s} & <1.1 & 10 & 10 & 10 & 10 & 11 & 11 & 12 & 13 \\ \mathrm{~h}=1 \mathrm{~m} & 1.1-2.0 & 4 & 4 & 4 & 4 & 4 & 4 & 4 & 4 \\ \mathrm{z}_{\mathrm{d}}=1 \mathrm{~m} & 2.0-3.3 & 12 & 12 & 12 & 12 & 12 & 12 & 12 & 13 \\ \mathrm{z}_{\mathrm{O}}=0.10 \mathrm{~m} & 3.3-7.0 & 24 & 24 & 24 & 24 & 24 & 24 & 24 & 24 \\ & >7.0 & 51 & 50 & 50 & 50 & 49 & 48 & 47 & 46\end{array}$

$\begin{array}{lllllllll}\text { Total deposition } & 151 & 119 & 95 & 70 & 47 & 28 & 15 & 7\end{array}$ 
correspond to the story County data for aerodynamic particle diameters of unit density.

The calculated depositions for the no-background assumptions were compared to calculated depositions assuming a $260 \mu \mathrm{g} / \mathrm{m}^{3}$ background. The $260 \mu \mathrm{g} / \mathrm{m}^{3}$ background corresponds to the present 24-hour-average primary standard for suspended particulate matter as specified in the National Ambient Air Quality standards. The assumed $260 \mu \mathrm{g} / \mathrm{m}^{3}$ background was divided among the particle-size ranges (represented by $<1.1$, 1. 1-2.0, 2.0-3.3,3.3-7.0, and $>7.0 \mu \mathrm{m})$ ill Lhe rat10 of $30: 3:$ 10:15:40, respectively. These proportions approximately correspond to the average ambient particulate-sizing data given in Tables 4.1 and 4.2 . For a $260 \mu \mathrm{g} / \mathrm{m}^{3}$ background, the zerobackground assumption causes an error of about $10 \%$ or less in the deposition calculations. Since normal background concentrations are usually $25 \%$ to 508 of the primary standard (see Table 4.3), the error from the zero-ambient-concentration assumption should be about $5 \%$ or less. The final algorithm includes a correction for the actual ambient concentration, if it is known.

Due to machine limitations, on the dual system IBM 360 model 65 and ITEL AS/5, it was impossible to calculate the deposition at several large downwind distances, especially for large particles (greater thain $7 \mu \mathrm{m}$ ) over rough surfaces, see Table 5.1. This problem arises in Equation 3.1 when the 
exponential function in the third term increases almost as rapidly as the complementary error function decreases. The net result is an approximate balance between the two functions, with the latter dominating. Obviously, deposition calculations become erroneous when either function experiences underflow or overflow conditions; this is very apparent when deposition is plotted as a function of downwind distance. Underflow (which usually precedes overflow) occurs when the complementary error function argument exceeds approximately 13.3, resulting in a sudden increase by several urders of magnitide of the calculated deposition.

A study of the bracketed term in Equation 3.1 revealed that the sum of the first two terms is approximately equal to the third term; hence a relatively small number results from the difference of two large numbers. When the third term becomes zero an artificial increase appears. A large argument of the complementary error function results from large deposition velocities associated with rough surfaces; although sufficiently large source and deposition heights can also contribute to the argument. It is fortunate that underflow conditions occur well beyond the deposition peak, making it possible to extrapolate the results into regions where machine limitations give exroneous results:

When a significant portion of the total particulate-size distribution experiences a large gravitational fall velocity, 
an apparent violation of mass conservation may exist for certain source-deposition surface geometries. Normal atmospheric-turbulence levels allow upward diffusion of smaller particles, but the greater fall velocity of large particles may overshadow their vertical transport. Since large particles comprise a significant percentage of the total plume mass (see Tables 4.1 and 4.2 ), a significant amount of mass may not be deposited on a deposition surface when its height exceeds the source height. This is especially likely over smooth surfaces, which lack the additional impetus of moohanically induced turbulence. In summary, the validity and applicability of mass conservation principles are dependent upon the particle-size distribution and source-deposition height geometry.

Recapping, deposition sensitivity tests are performed on atmospheric stability, surface roughness, deposition height, source height, and wind speed for the conditions ranging from moderately unstable to slightly stable, $0.01 \mathrm{~m}$ to $0.10 \mathrm{~m}, 0 \mathrm{~m}$ to $1 \mathrm{~m}, 0 \mathrm{~m}$ to $1 \mathrm{~m}$, and $1 \mathrm{~m} / \mathrm{s}$ to $5 \mathrm{~m} / \mathrm{s}$, respectively. Figures 5.1 through 5.32 show the downwind deposition, for various combinations of the five modeling parameters, which results from an infinite instantaneous line source emission of $1.0 \mathrm{~g} / \mathrm{m}$. Results and discussions are based on deposition calculations at logarithmically-spaced downwind distances ranging from $4 \mathrm{~m}$ to $512 \mathrm{~m}$, inclusive. Table 5.1 shows the percentagecontribution varlabllity for different particle-size ranges 
for each modeling parameter over a range of conditions typifying a rural environment.

\section{B. Response to Atmospheric Stability}

Atmospheric stability does not appear directly in the diffusion-deposition model, but it influences the friction velocity, which in turn effects the deposition velocity and rate of deposition. It will be shown, using Figures 5.1 through 5.32; that the overall deposition sensitivity to stability is weak when compared to surface roughness, deposition height, and source height; whereas only wind speed seems to have a comparable influence. Some of the general effects displayed by atmospheric stability are also observed for other sensitivity parameters, and a discussion is given in the following paragraphs.

When the deposition height and source height are different (see Figures 5.2, 5.3, 5.6 and 5.7), greater instability is initially moro cffeclive in transporting the plume to the deposition surface. Consequently, there is more deposition close to the infinite instantaneous line source during unstable conditions than during stable conditions.

When the deposition height and source height are the same, it is expected that greater deposition should occur close to the source under stable conditions, because the plume will diffuse less rapidly away from the common height. Figures 5.1, 
5.4 and 5.5 are in agreement with this for smooth surfaces. Here, the thermally induced turbulence (due to atmospheric instability) is distinguishable from the normally dominate mechanically induced turbulence (due to surface roughness). Cases of apparent disagreement with this discussion, such as Figure 5.8, result from the overbearing effect of mechanically induced turbulence implicit in other modeling parameters (such as roughness height and wind speed, which are discussed in sections V.C and V.F, respectively).

From conservation of mass, the relative cuntribution for stability classes $B, D$ and $E$ at small downwind distances is expected to be opposite that of large distances; however some of the figures do not contain a crossover point in the range of $4 \mathrm{~m}$ to $512 \mathrm{~m}$. Several factors could result in a crossover point outside these limits. First, if the stability dependence is weak (see Figure 5.1) then the crossover point may be postponed for a considerable distance. Second, less deposition at small distances must be compensated by more deposition downwind; here a pcak depusttion value in excess of approximately $10^{-4} \mathrm{~g} / \mathrm{m}^{2}$ per unit source strength of $1.0 \mathrm{~g} / \mathrm{m}$ apparently increases the likelihood of a crossover point before $512 \mathrm{~m}$ (see Figure 5.2). Third, a steep deposition fall off rate (see Figures 5.1 and 5.5) could produce a crossover point either less than $4 \mathrm{~m}$ or beyond the point of machine underflow. The question as to which region contains the crossover point is 
indeterminate because of previously described machine limitations; however, a speculation is offered. At small downwind distances, greater instability should more rapidly disperse the plume causing relatively less deposition close-in, resulting in a crossover point further downwind. Figure 5.5 for a roughness height of $0.10 \mathrm{~m}$ lends support by showing a slight convergence at the $D$ and $E$ lines at $64 \mathrm{~m}$. This question could be resolved if calculated depositions were available beyond $64 \mathrm{~m}$.

Overall, Figures 5.1 through 5.8 show the sensitivity of deposition to atmospheric stability for various conditions. The graphs show deposition difference between stability classes $B$ and $E$ averaging about 20\%, with a maximum of about a factor of two. This factor of two is considerably below the order-ofmagnitude variations caused by other parameters. In brief, deposition amounts are relatively insensitive to atmospheric stability.

Next, consider the relative contribution of different particle sizes for different stability classes. It is fortunate that, for a given set of conditions, downwind differences in the relative contributions of different-sized particles for stability classes B, D and E differs by a maximum of only 38 , and usually less than 18. This allows considerable simplification when considering the deposition sensitivity to variations in the particle-size spectrum for 
other modeling parameters. With only one stability case requiring consideration, the neutral case (see Table 5.1) was chosen.

In summary, the deposition sensitivity to atmospheric stability is limited to about a factor of two, but usually is only. about 20\%. Furthermore, atmospheric stability has a negligible effect on the relative contribution of different sized particles to the downwind deposition. Consequently, only the neutral case (shown in Table 5.1 ) requires consideration when examining the depnsitinn sensitivity to otliei mudeling parameters.

\section{Response to Roughness Height}

Although the roughness height does not appear explicitly in the diffusion-deposition model, it significantly influences the deposition by controlling the near-ground-level turbulence via the friction velocity and, in turn, the deposition velocity and rate of deposition.

A study of Figures 5.1 through 5.8 shows two pronounced features. First, deposition close to the source is always greater over rough surfaces (i.e. the dashed lines) than over smooth surfaces (i.e. the solid lines). This probably results from more efficient particle transport to and capture by the rough surface. As for stability, roughness height line-crossover points are required by the mass conservation principle. 


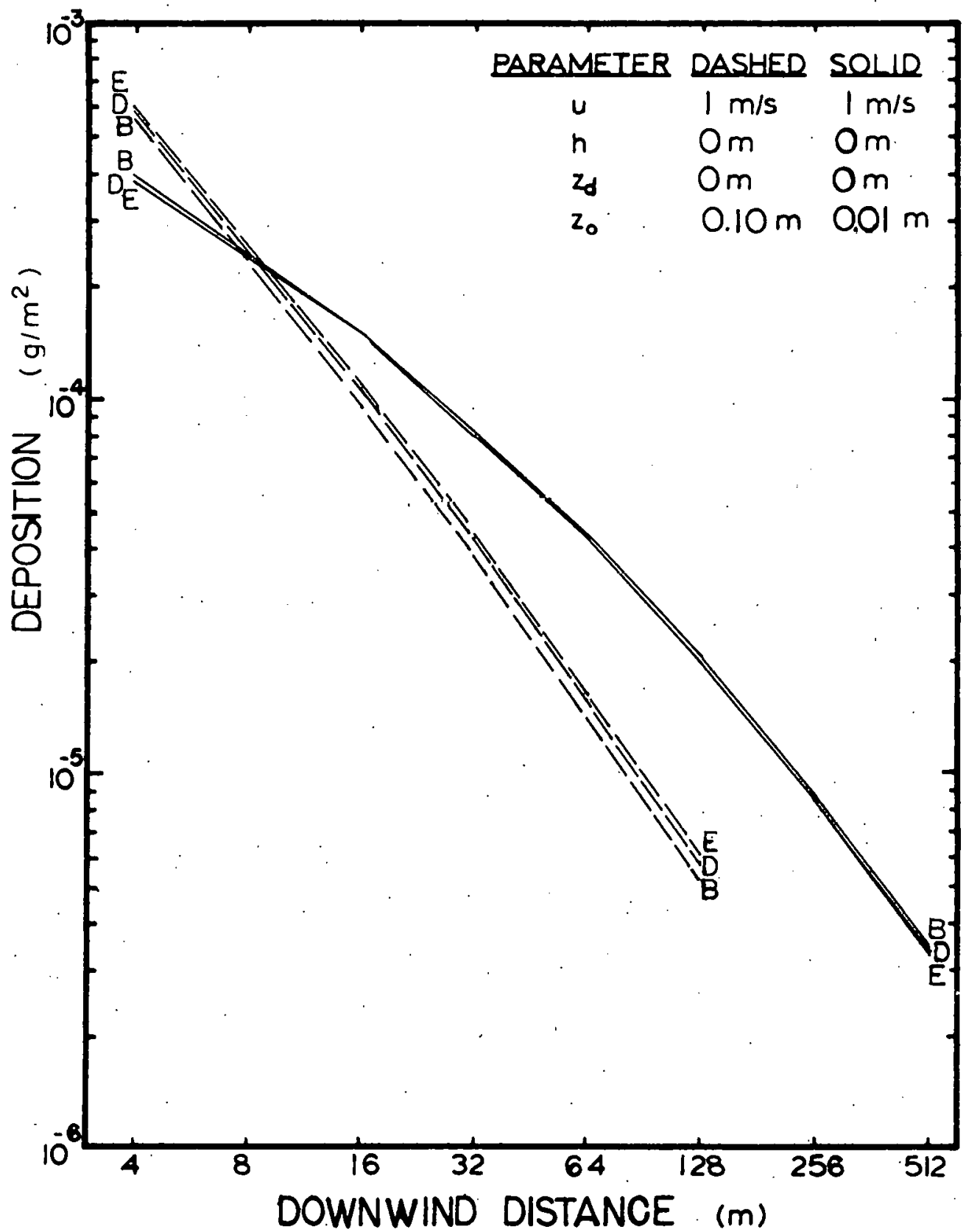

Figure 5.1. Downwind-deposition sensitivity to roughness height and atmospheric stability from an infinite instantaneous line. source. of $1.0 \mathrm{~g} / \mathrm{m}$ 


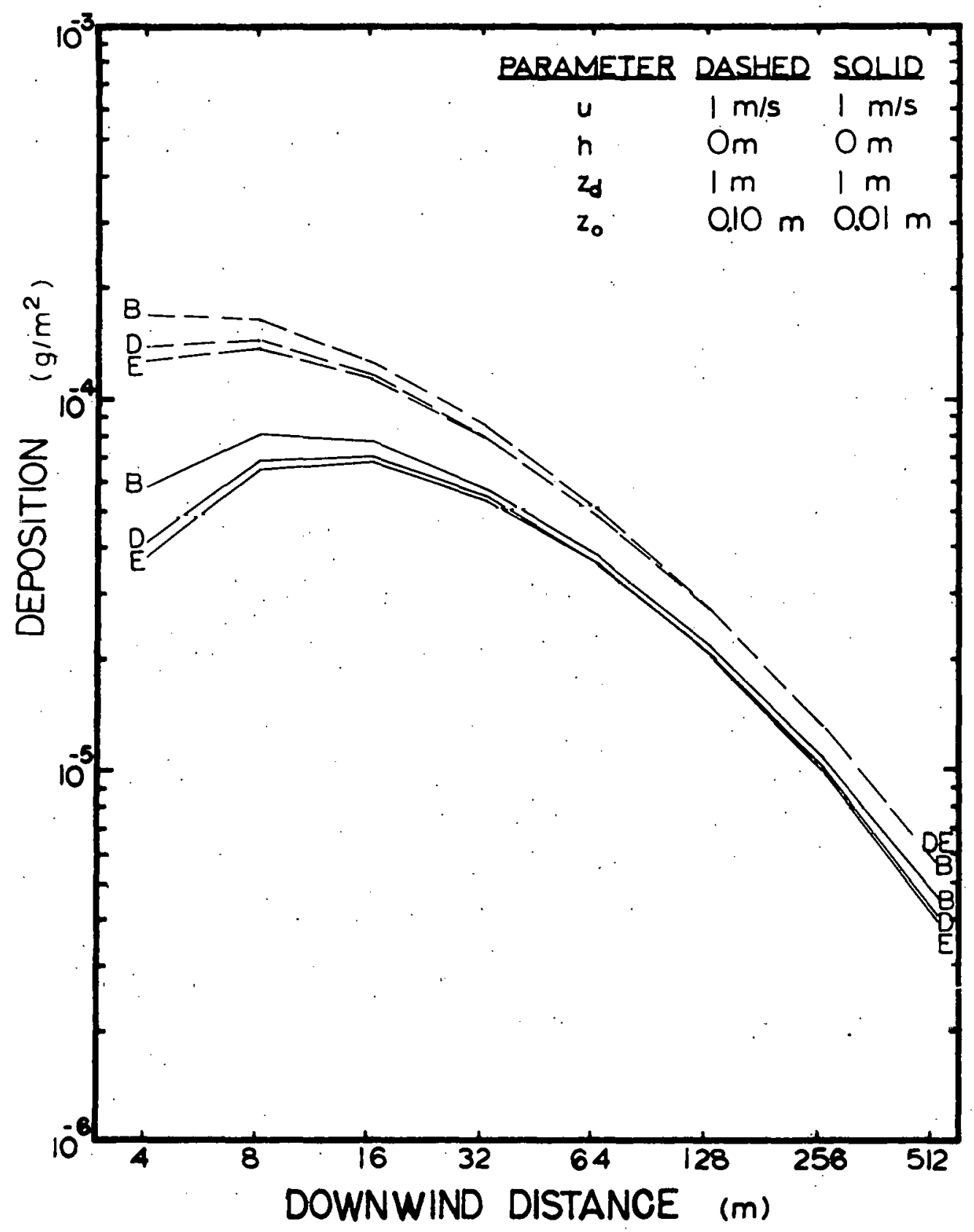

Figure 5.2. Downwind-deposition sensitivity to roughness height and atmospheric stability from an infinite instantaneous line source of $1.0 \mathrm{~g} / \mathrm{m}$ 


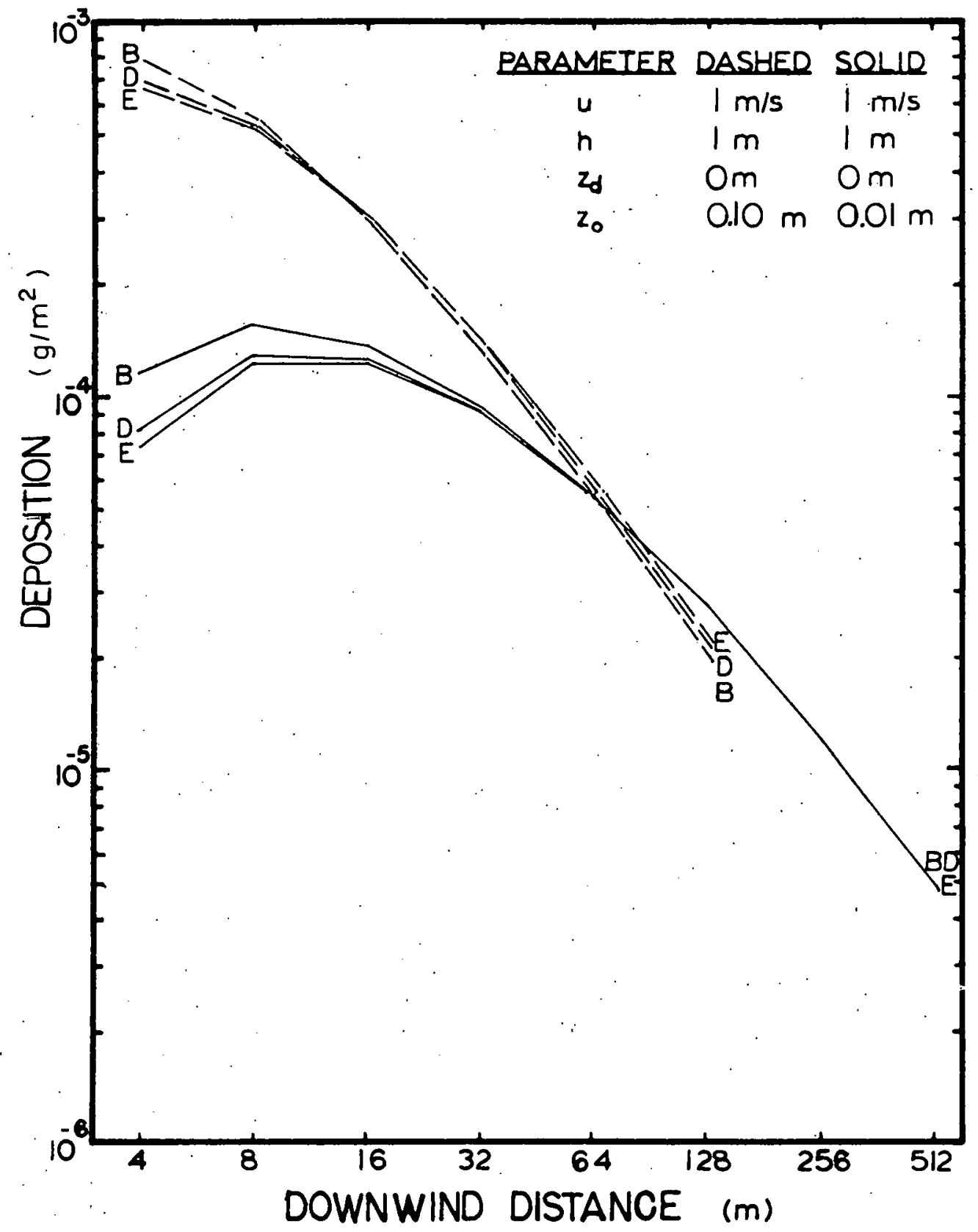

Figure 5.3. Downwind-deposition sensitivity to roughness height and atmospheric stability from an infinite instantaneous line source of $1.0 \mathrm{~g} / \mathrm{m}$ 


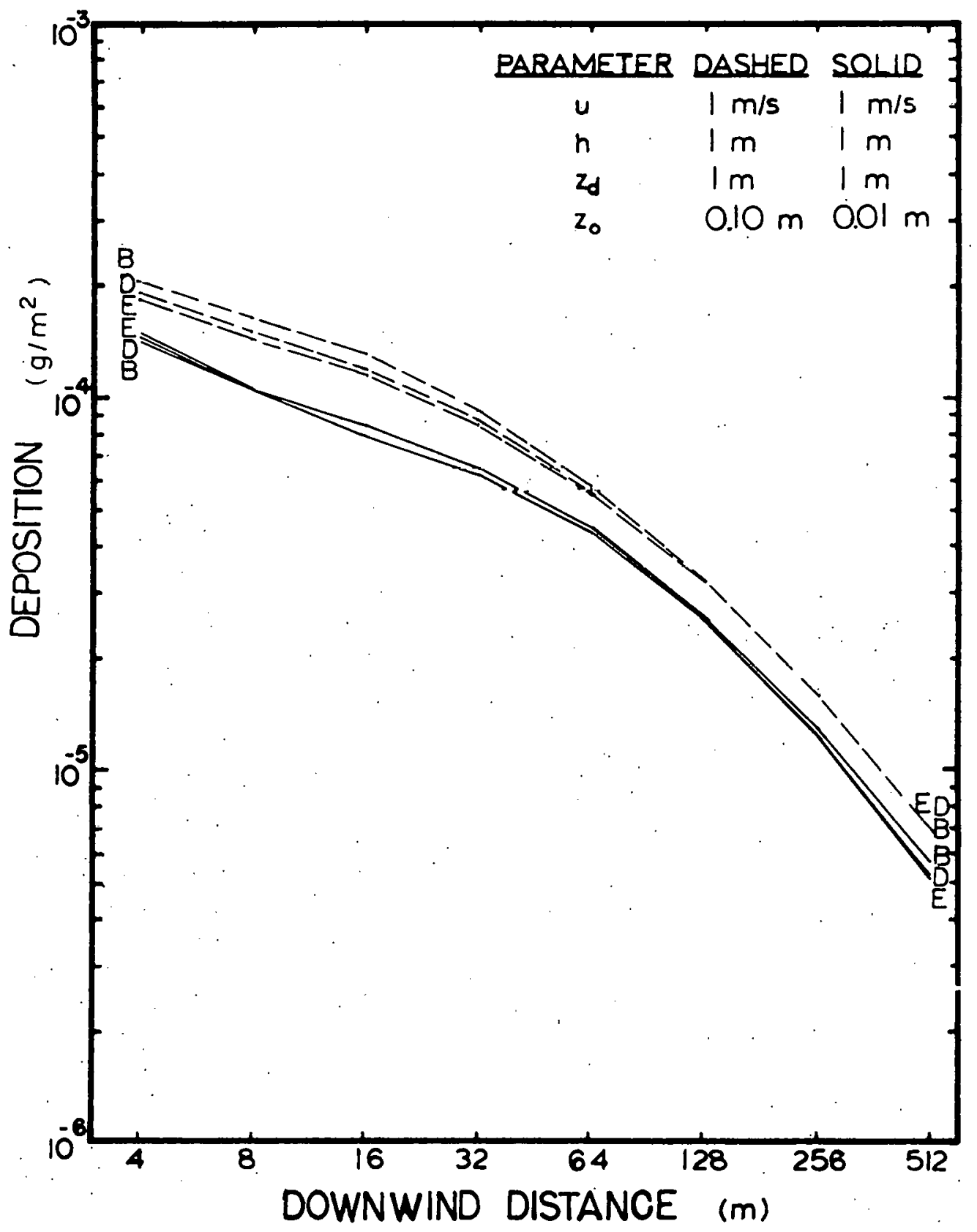

Figure 5.4. Downwind-deposition sensitivity to roughness height and atmospheric stability from an infinite instantaneous line source of $1 . n \mathrm{~g} / \mathrm{m}$ 


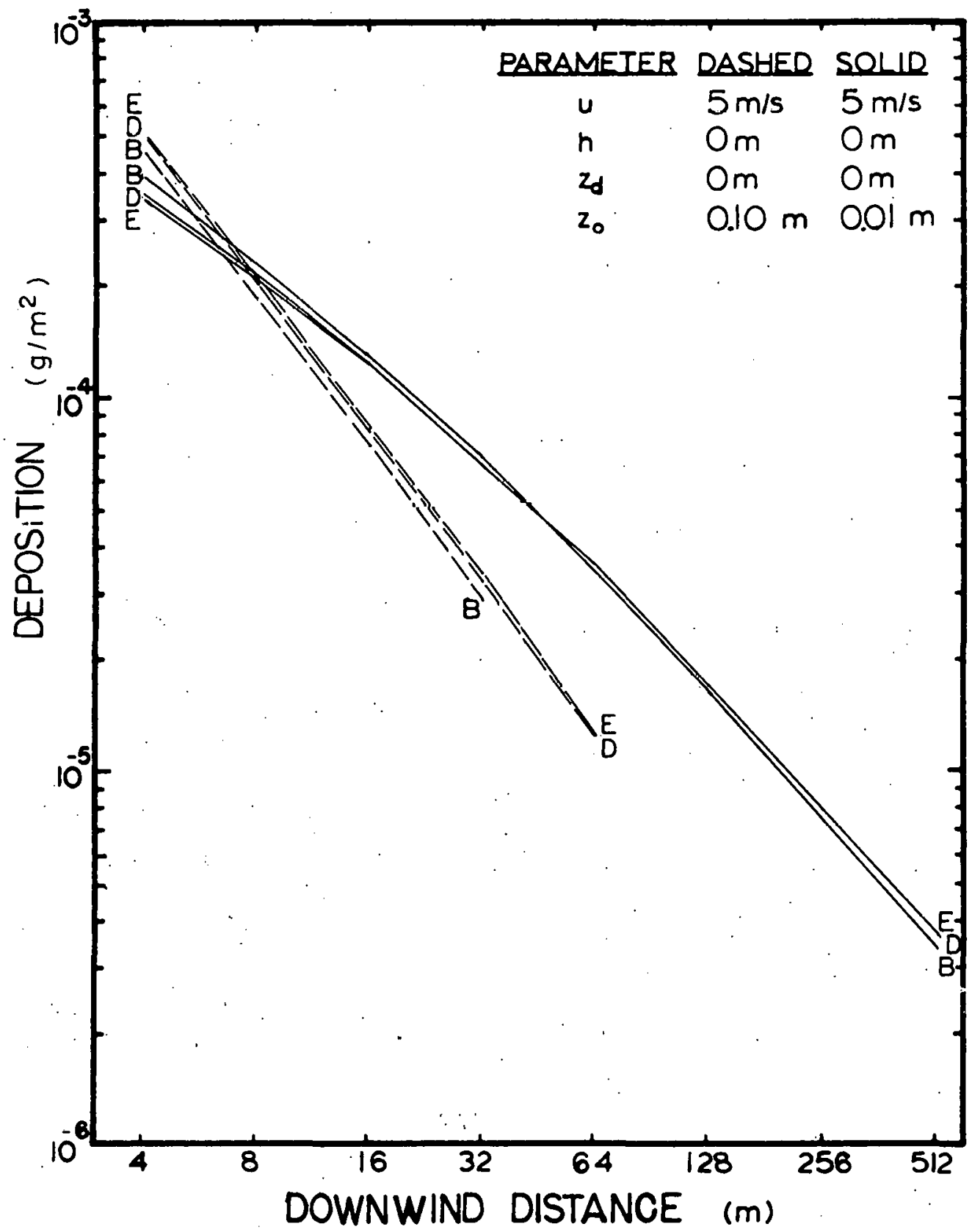

Figure 5.5. Downwind-deposition sensitivity to roughness height and atmospheric stability from an infinite instantaneous $1 \mathrm{ine}$ source of $1.0 \mathrm{~g} / \mathrm{m}$ 


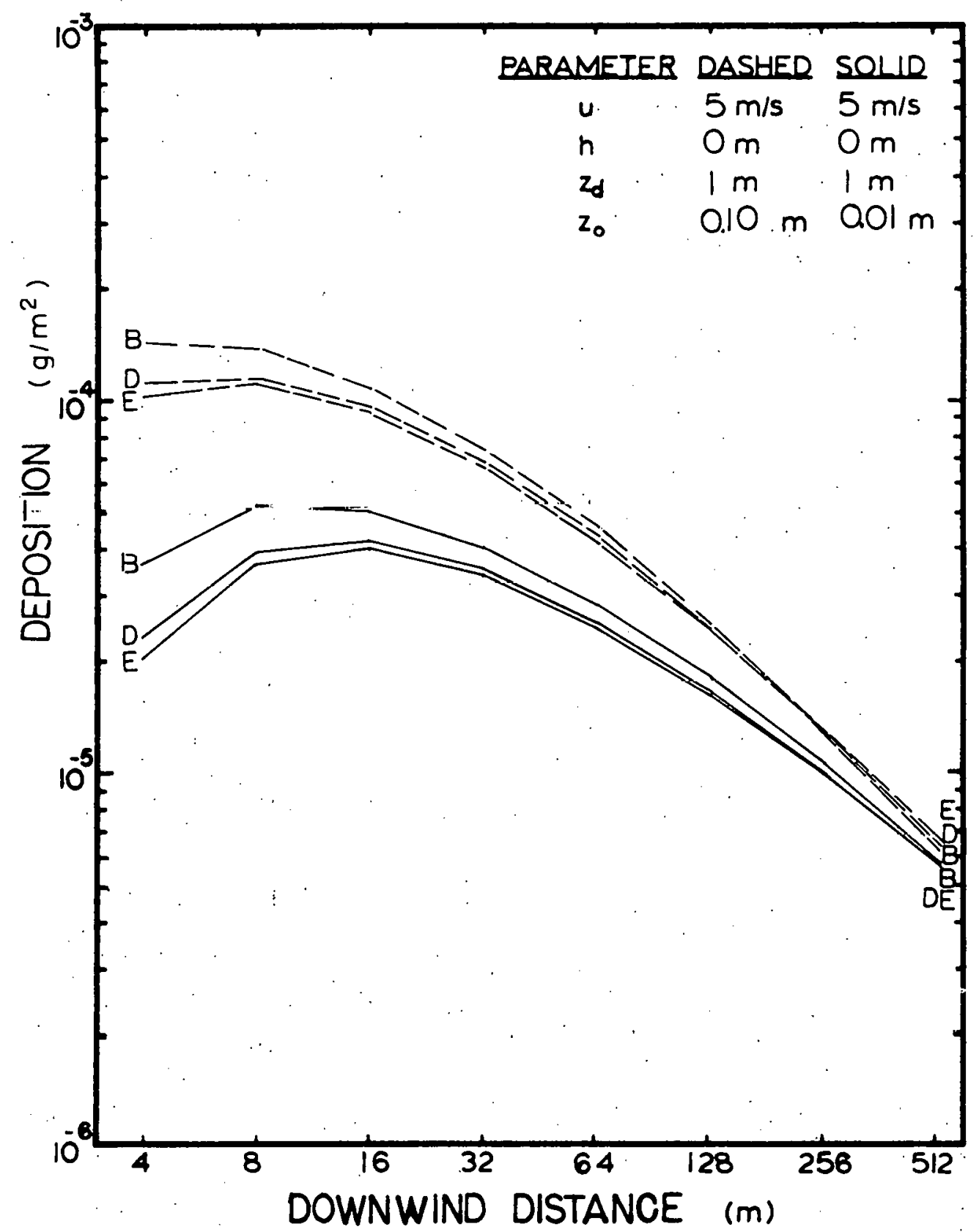

Figure 5.6. Downwind-deposition sensitivity to roughness height and atmospheric stability from an infinite instantanenus $1 \mathrm{ine}$ source of $1.0 \mathrm{~g} / \mathrm{m}$ 


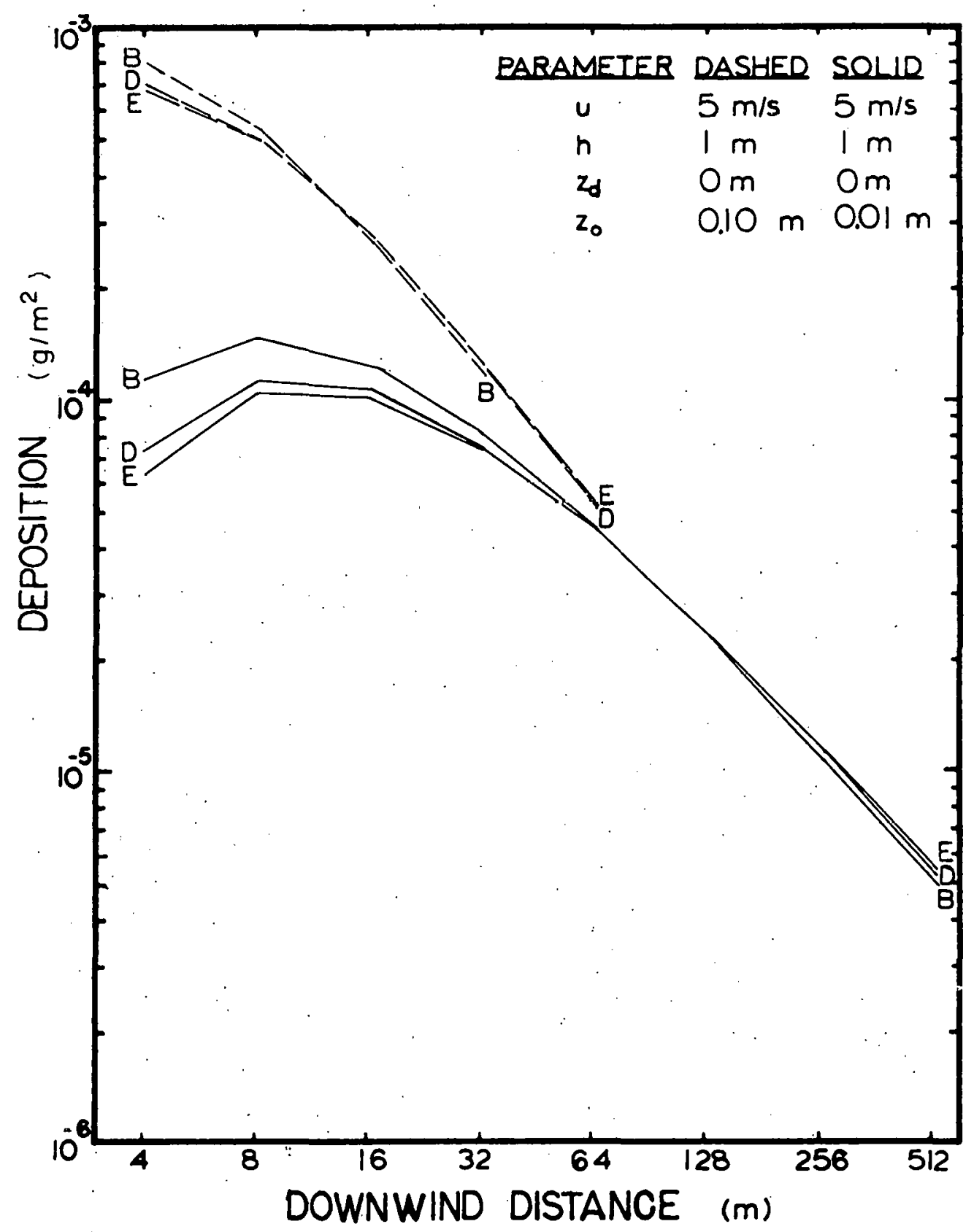

Figure 5.7. Downwind-deposition sensitivity to roughness height and atmospheric stability from an infinite instantaneous line sourre of $1.0 \mathrm{~g} / \mathrm{m}$ 


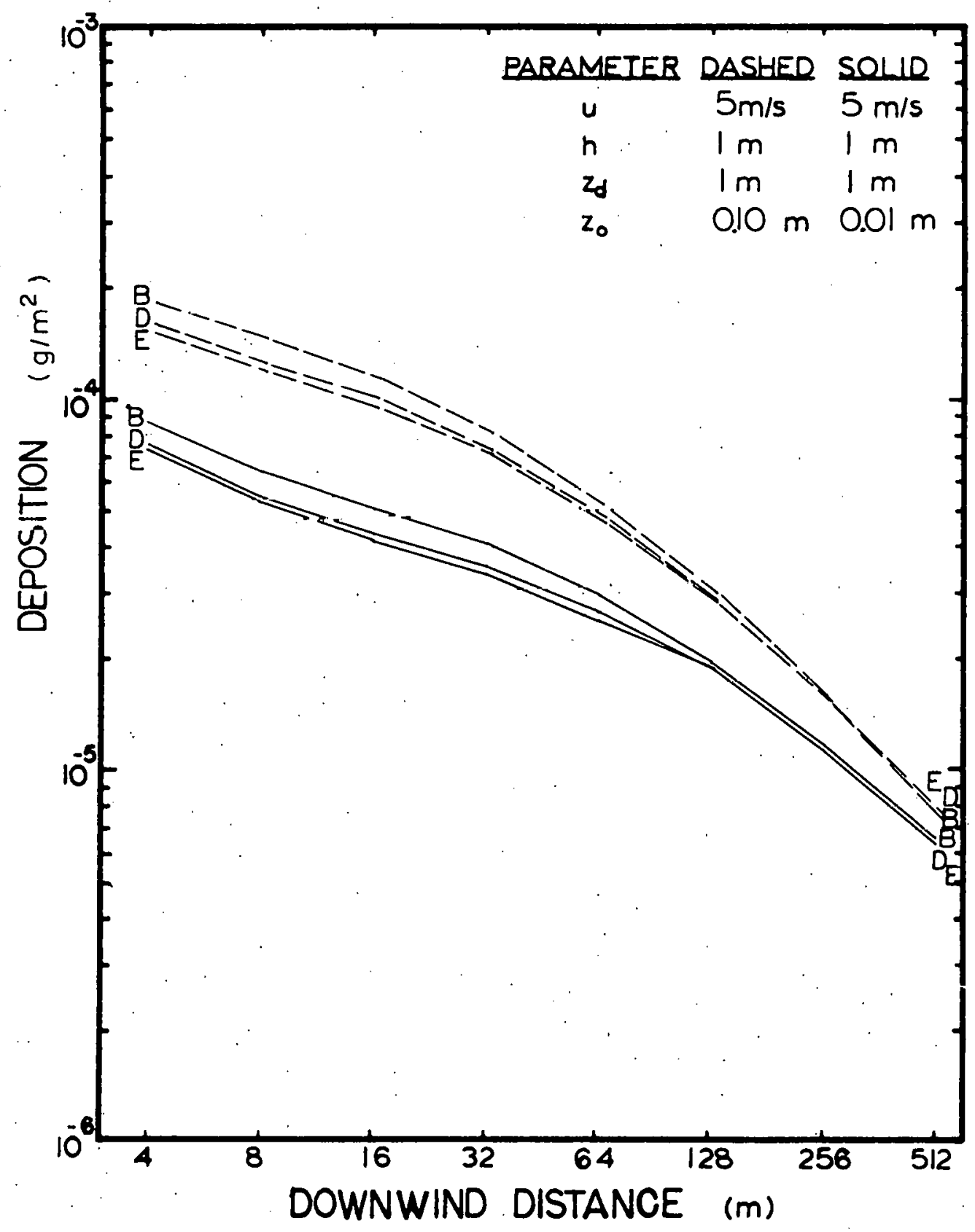

Figurc 5.8. Downwind-deposition sensitivity to roughness height and atmospheric stability from an infinite instantaneous line source of $1.0 \mathrm{~g} / \mathrm{m}$ 
So too, there exist cases when the lines do not cross within the $4 \mathrm{~m}$ to $512 \mathrm{~m}$ range, probably for the reasons previously discussed in section IV.A.

The second pronounced feature of Figure 5.1 through 5.8 is the much greater deposition sensitivity to surface roughness than to atmospheric stability. Recalling from section II.A.3, where for a near-ground-level source the thermally induced turbulence is much smaller than the mechanically induced turbulence, it should be no surprise that the deposition sensitivity due to atmospheric stability is less than that due to surface roughness. It can be seen in sections II.A.3 and II.A.4 that increasing the surface roughness causes a larger friction velocity, which enhances the very influencial deposition velocity resulting in more deposition. Deposition differences due to different roughness heights may be in excess of one order of magnitude, but usually differences are only half this amount. Therefore, deposition is very sensitive to roughness height.

An examination of Table 5.1 reveals that the percentage contribution of large particles to the total deposition is less over rough surfaces than over smooth surfaces. A tentative explanation is that, over smooth surfaces, the settling velocity is of primary importance in depositing the larger particles, while the smaller particles are allowed to diffuse vertically. Over a rough surface there is a greater amount of 
low-level turbulence near the deposition surface, which probably reduces the importance of the settling term. This, in turn, reduces the selective size-dependent-deposition contribution due to large particles; therefore all sizes of particles have a more equal chance of becoming deposited over rough surfaces.

Since the roughness height is a major factor in determining the low-level turbulence, and is independent of the deposition height and source height, it is not surprising to find that the percentaqe partirlo-eise conlribution for a given roughness height is only slightly dependent upon the source height and deposition height. Roughness height enters the diffusiondeposition model by way of the stability-dependent log-linear wind profile. However, the stability influence is minimal very close to the ground, and so too is its effect on the relative particle-size contribution to the total deposition for a given roughness height. Wind speed has the distinction of directly altering the deposition by way of the friction velocity, while also cuntrolling the plume advection. The net result is a superpositioning of the two opposing effects. Thus Table 5.1 shows that increasing the roughness height serves to increase the percentage of small particles at large distances, whereas a decrease is exhibited during stronger winds.

In summary, the roughness height is a very fundamental parameter having considerable impact on the downwind deposition, 
evidenced by the order of magnitude variations it produces. The relative particle-size contribution is remarkably insensitive to the roughness height for different source-deposition height geometries, but displays greater sensitivity to roughness height when accompanied by changes in wind speed and, to a lesser extent, atmospheric stability. In addition, situations differing only in roughness height display the common feature that the relative contribution of the small particles is consistently greater over rough surfaces than over smooth curfaoco.

\section{Response to Deposition Height}

The deposition height enters the diffusion-deposition model indirectly by way of the deposition velocity, which, in turn, ultimately controls the amount of material deposited. So while the deposition height may not appear explicitly, its impact is observed in a very critical parameter.

An examination of Figures 5.9 through 5.16 reveals two pronounced features. First, deposition close-in is usually greater for a ground-level deposition height (i.e. the solid line) than for a 1-m deposition height (i.e. the dashed lines); this is likely caused by particle settling toward the lower surface. Notable exceptions are Figures 5.11 and 5.15 which have a source height and deposition height both at $1 \mathrm{~m}$. Here the common $1-\mathrm{m}$ height allows the deposition at $1 \mathrm{~m}$ to exceed 


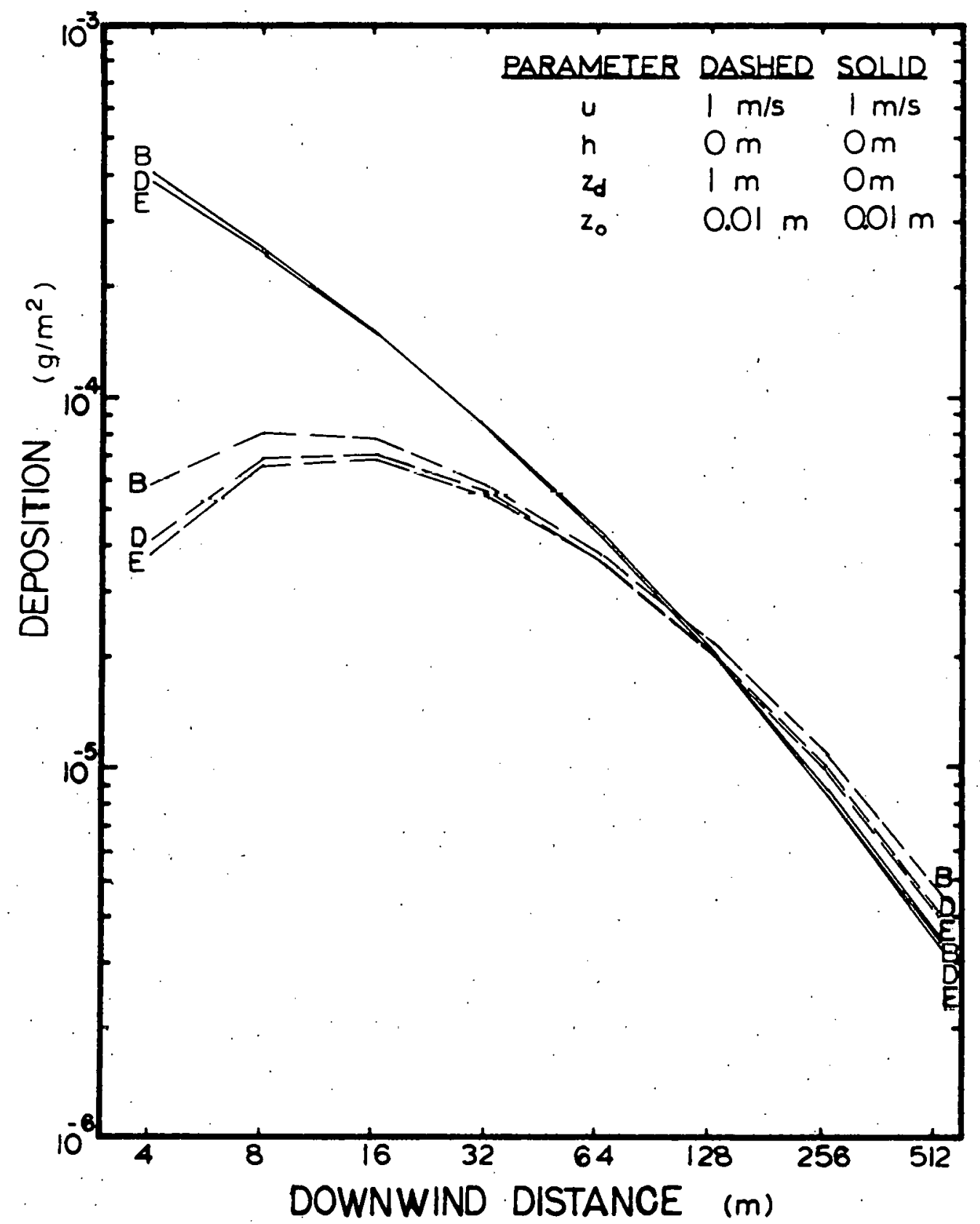

Figure 5.9. Downwind-deposition sensitivity to deposition height and atmospheric stability from an infinite instantaneous line oouree of $1.0 \mathrm{y} / \mathrm{ll}$ 


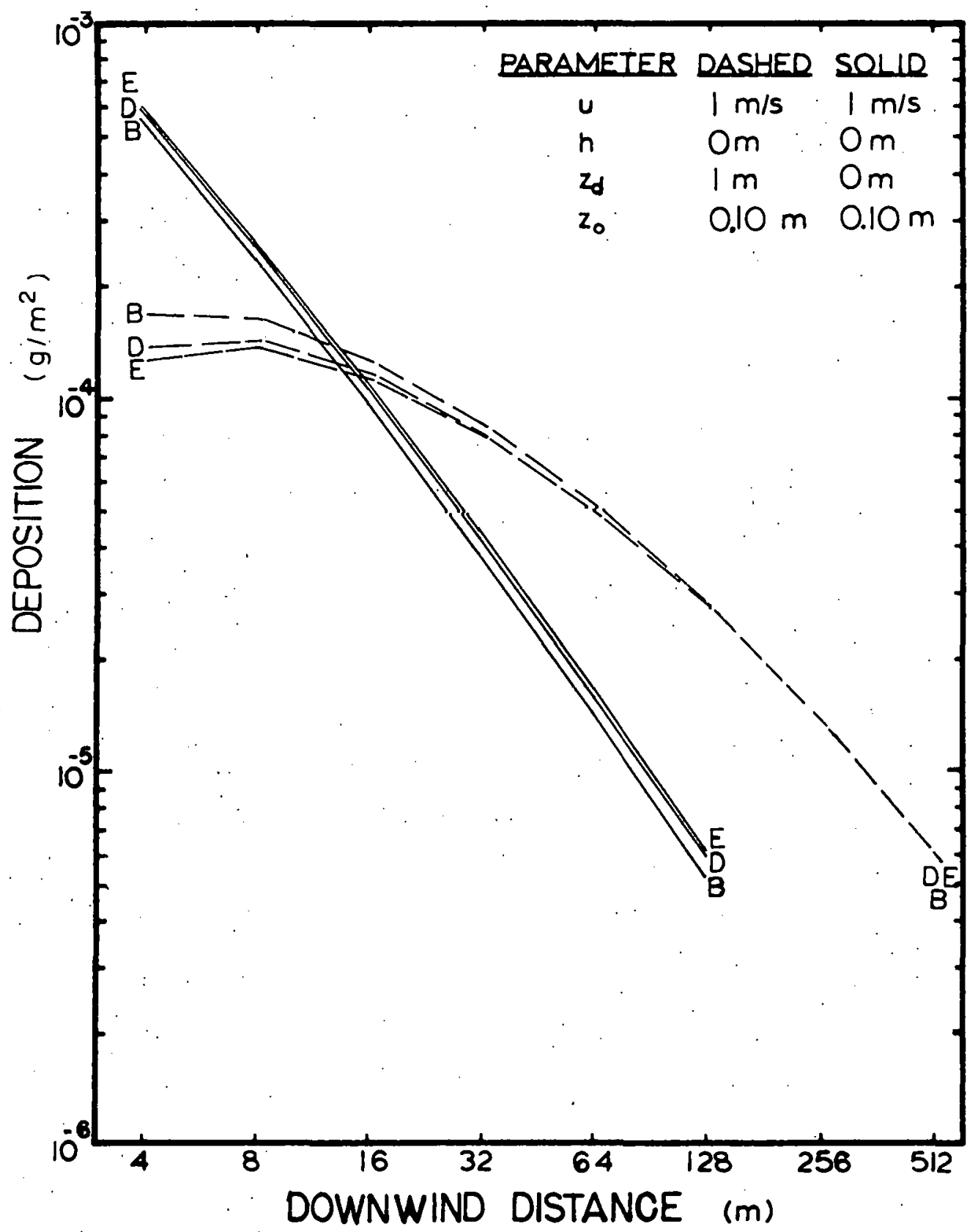

Figure 5.10. Downwind-deposition sensitivity to deposition height and atmospheric stability from an infinite instantaneous line source of $1.0 \mathrm{~g} / \mathrm{m}$ 


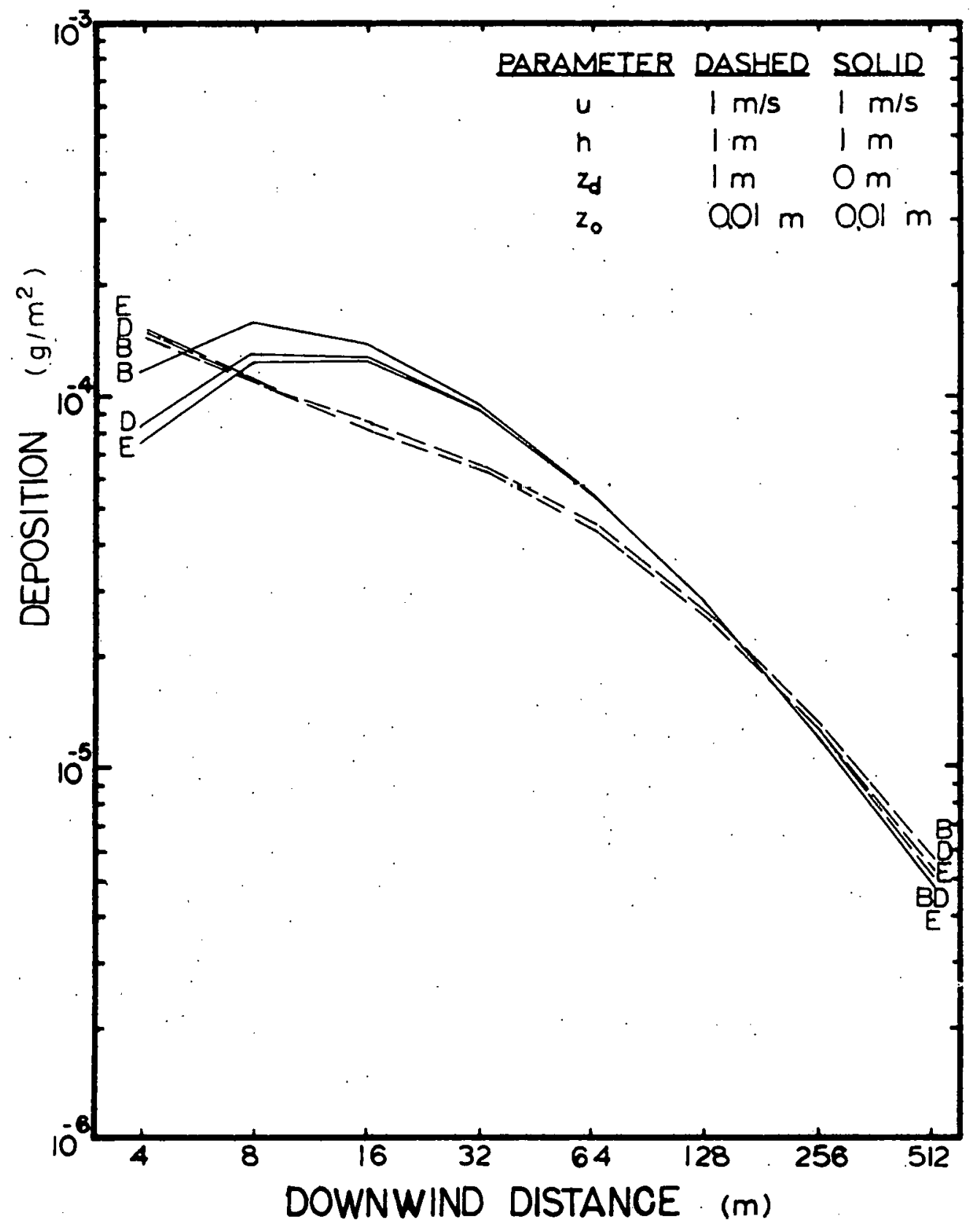

Figure 5.11. Downwind-deposition sensitivity to deposition height and atmospheric stability from an infinito instantaneous line soürce of $1.0 \mathrm{~g} / \mathrm{m}$ 


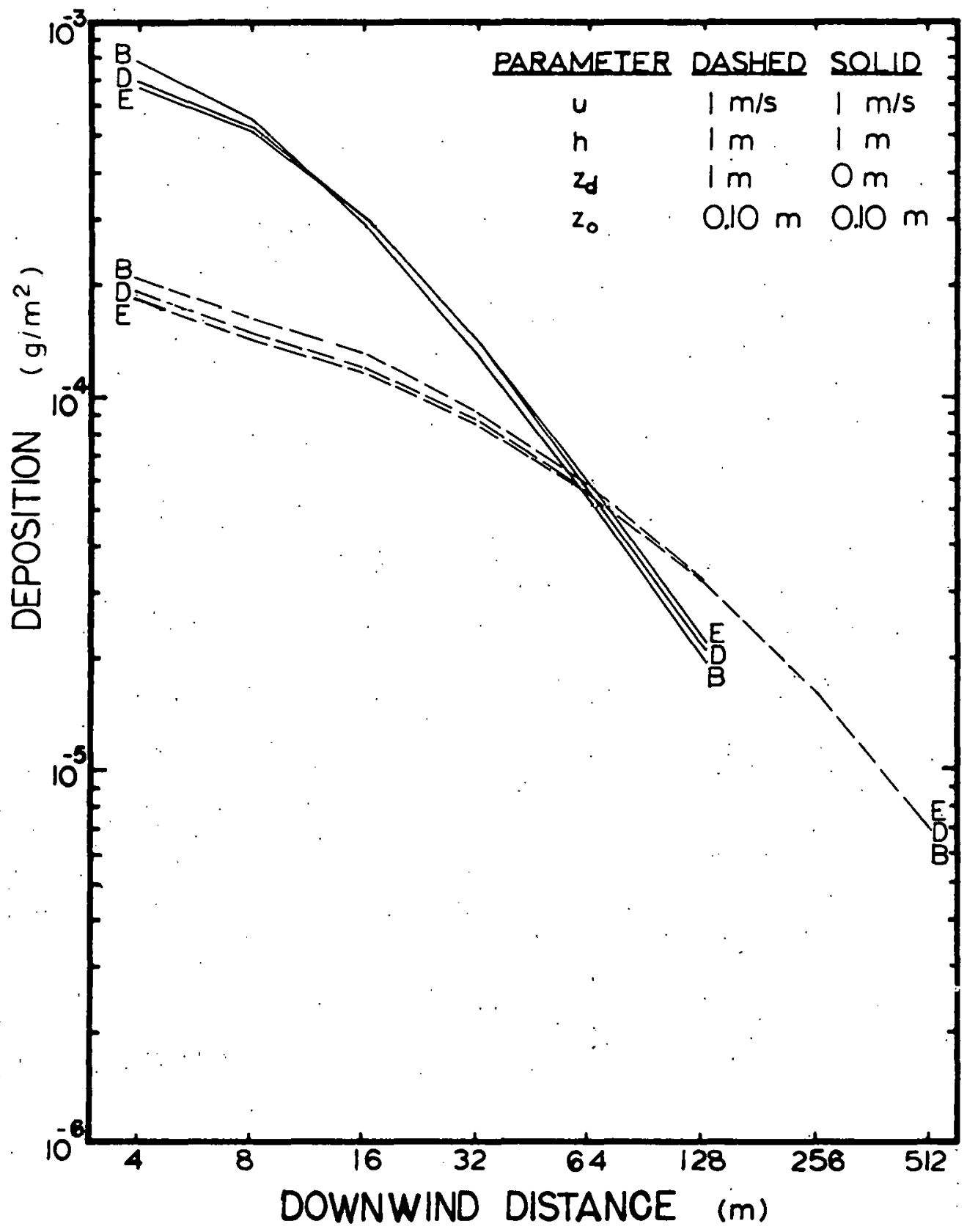

Figure 5.12. Downwind-aeposttion sensitivity to deposition height and atmospheric stability from an infinite instantaneous line source of $1.0 \mathrm{~g} / \mathrm{m}$. 


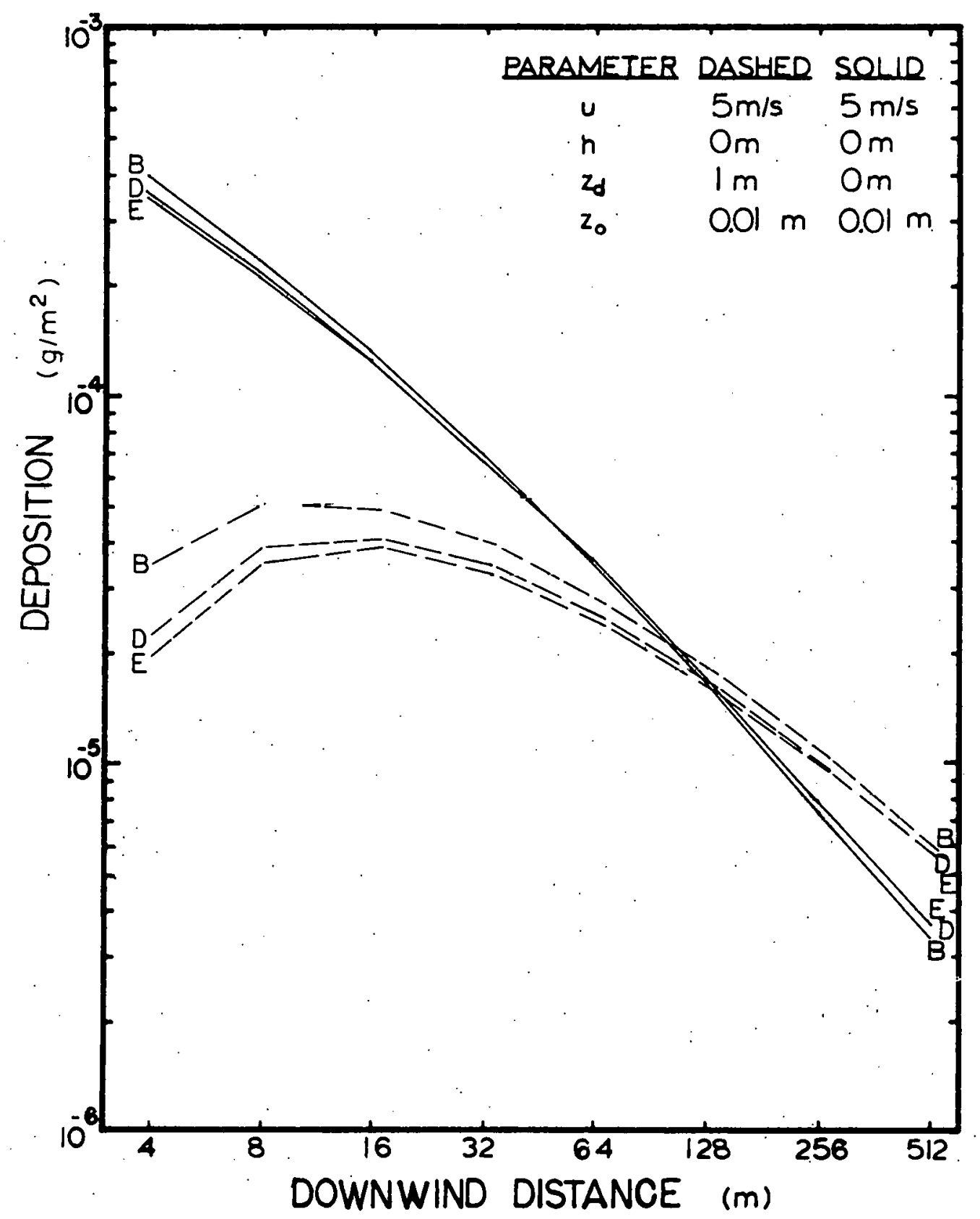

Figure 5.13. Downwind-deposition sensitivity to deposition height and atmospheric stability from an infinite instantaneoue line source uf $1.0 \mathrm{~g} / \mathrm{m}$ 


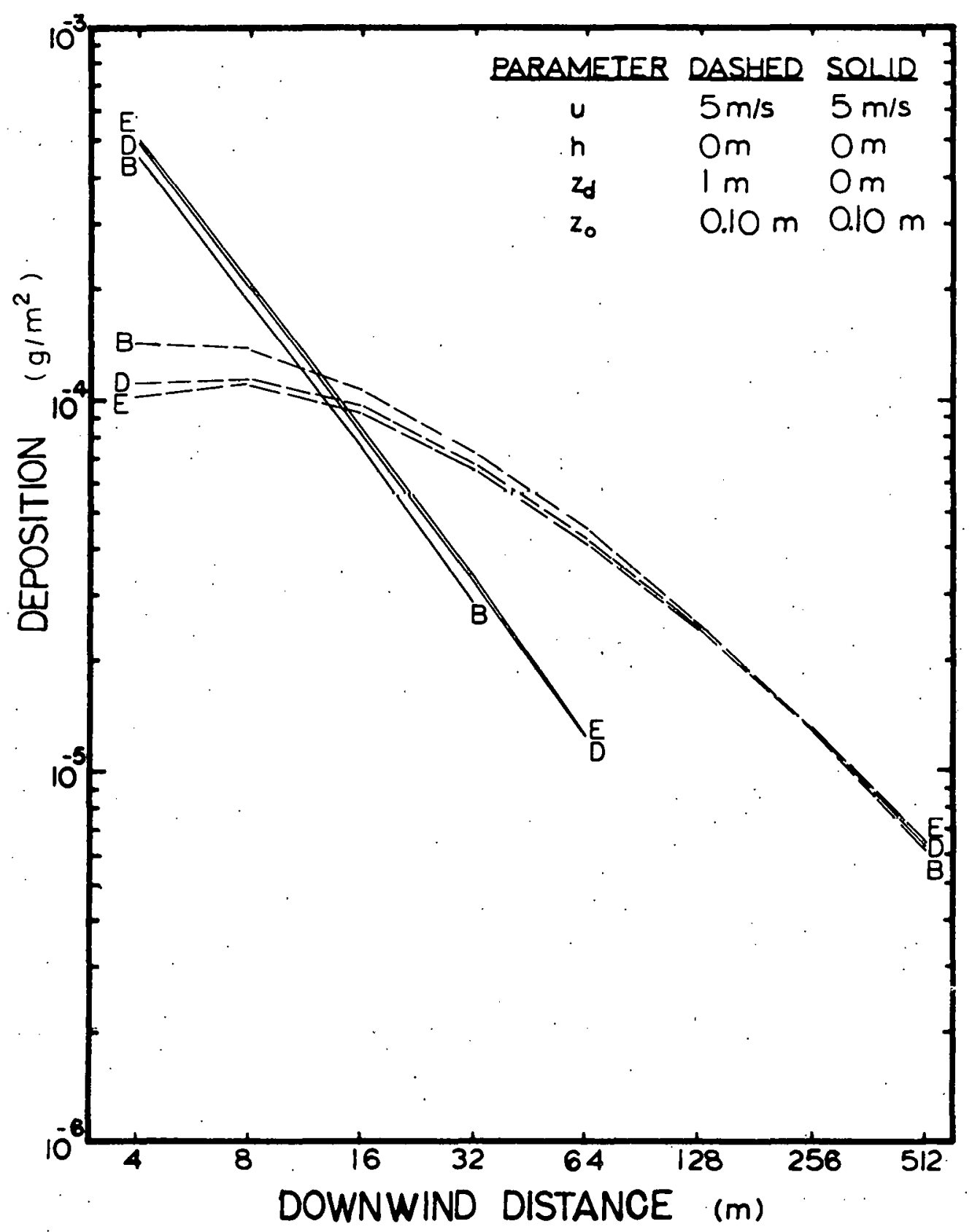

Figure 5.14. Downwind-deposition sensitivity to deposition height and atmospheric stability from an infinite instantanenils line souroo of $1.0 \mathrm{~g} / \mathrm{m}$ 


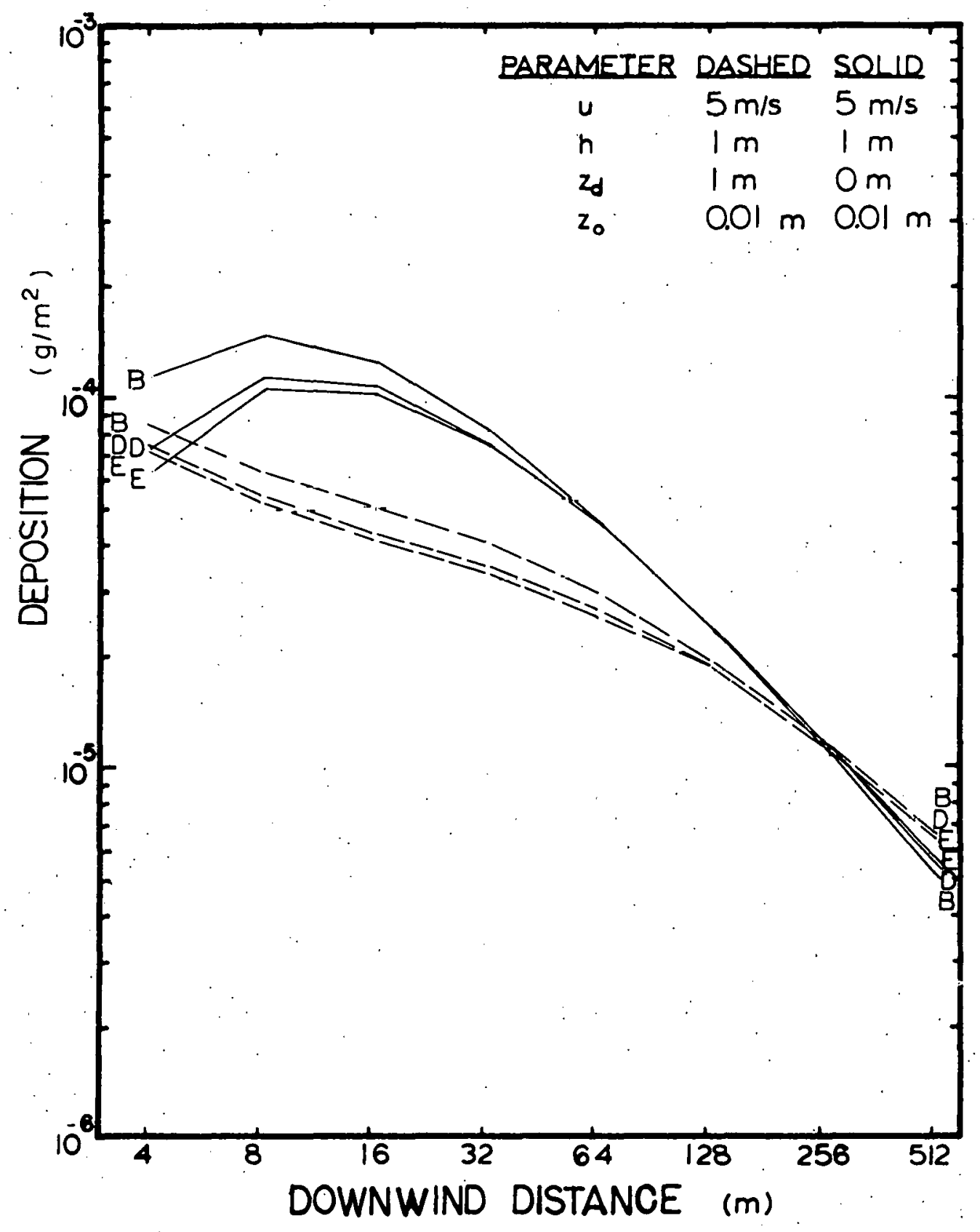

Figure 5.15. Downwind-deposition sensitivity to deposition height and atmospheric stability from an infinite instantaneous line source of $1.0 \mathrm{~g} / \mathrm{m}$ 


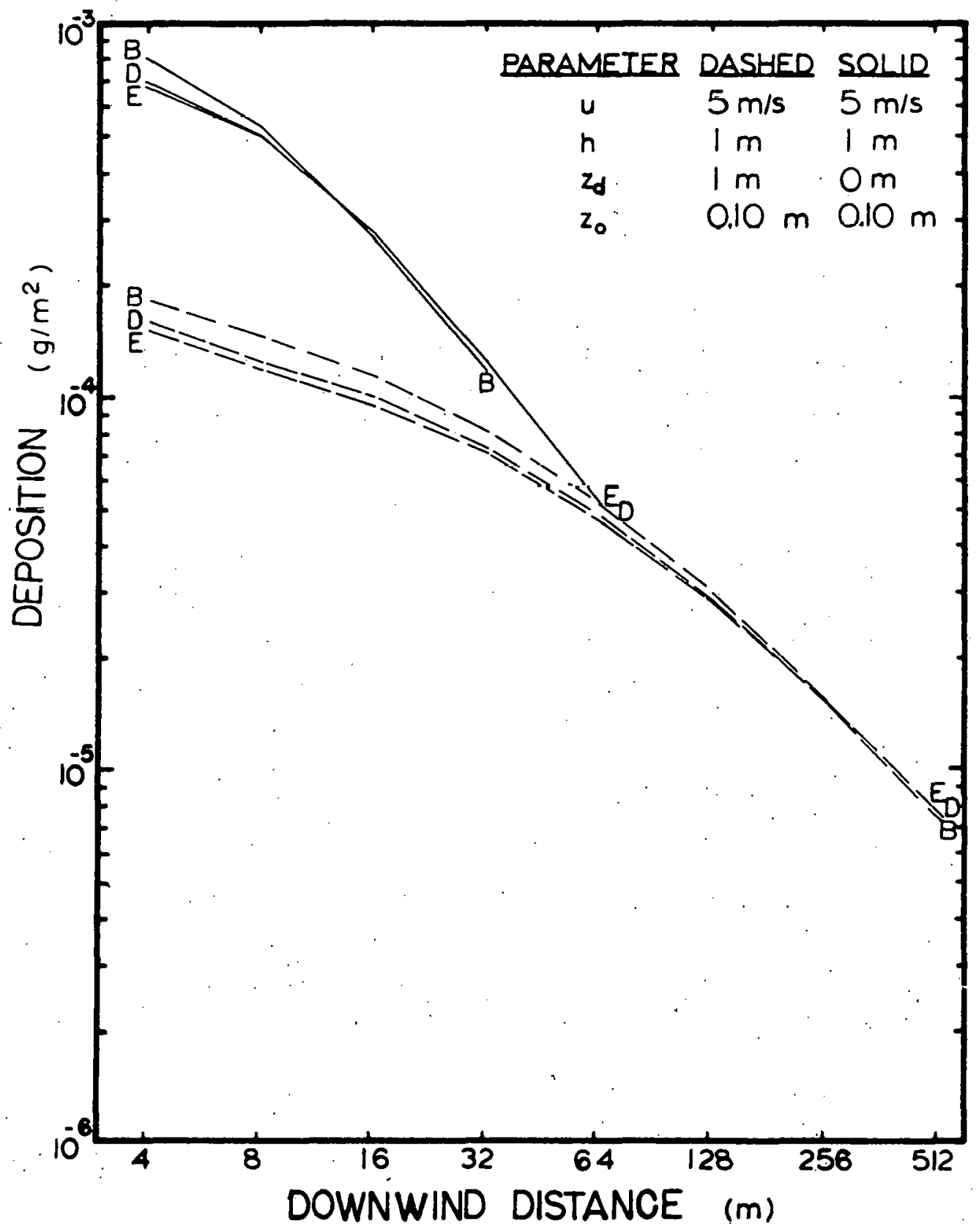

Figure 5.16. Downwind-deposition sensitivity to deposition height and atmospheric stability from an infinite instantaneous line source of $1.0 \mathrm{~g} / \mathrm{m}$ 
that at ground level in the first several meters (i.e. the particles have not fallen appreciably in the first several meters). Once the particles have had sufficient time to fall an appreciable distance, the lines cross and follow the usual pattern.

The second pronounced feature of Figures 5.9 through 5.16 is that, as for atmospheric stability and roughness height, the crossing of the deposition lines occurs because of mass conservation. Here all eight cases seem to have their crossover points between $4 \mathrm{~m}$ and $512 \mathrm{~m}$. Furthermure, the deposition sensitivity to deposition height is considerably greater than for atmospheric stability. As for roughness height, deposition differences due to different deposition heights may be in excess of one order of magnitude.

The data in Table 5.1 indicate that at small distances from the infinite instantaneous line source, the percentage of large particles contributing to the total deposition is usually greater for a ground-level deposition height. This is reasonable since the relatively large effect of settling (compared to diffusion) assists the particles in reaching the lower surface. Further downwind the reverse occurs, in that the percentage of large particles contributing to the total deposition is relatively greater at $1 \mathrm{~m}$ than at ground level. A tentative explanation for this unexpected result is the initial upwind depletion of large particles for a ground-level deposition 
surface. It is also plausible that the percentage contribution to the total deposition due to small particles should behave in a manner opposite that of large particles. The data in Table 5.1 seem to be in agreement with this.

It is noteworthy that these effects are amplified for. greater surface roughness and are diminished for increased wind speed. For example, consider a ground-level source in a mean wind of $1 \mathrm{~m} / \mathrm{s}$. When the roughness height is $0.01 \mathrm{~m}$, the percentage of deposition due to submicron particles $(<1.1 \mu \mathrm{m})$ at $4 \mathrm{~m}$ and $512 \mathrm{~m}$ range 3 from 18 to $8 \%$ and 18 to 68 for a deposition height at ground level and $1 \mathrm{~m}$, respectively; however, when the roughness height is $0.10 \mathrm{~m}$, the percentage of submicron particles at $4 \mathrm{~m}$ and $128 \mathrm{~m}$ ranges from 48 to $13 \%$ and $8 \%$ to $10 \%$ for a deposition height at ground level and $1 \mathrm{~m}$, respectively. When the roughness height is $0.01 \mathrm{~m}$, the percent of deposition due to large particles $(>7.0 \mu \mathrm{m})$ at $4 \mathrm{~m}$ and $512 \mathrm{~m}$ ranges from $86 \%$ to 378 and 848 to 478 for a deposition height at ground level and $1 \mathrm{~m}$, respectively; however, when the roughness height is $0.10 \mathrm{~m}$, the percentages of large particles at $4 \mathrm{~m}$ and $128 \mathrm{~m}$ range from $67 \%$ to $47 \%$ and $60 \%$ to 548 for a deposition height at ground level and $I \mathrm{~m}$, respectively.

The above seems to indicate that, regardless of particle. size or roughness height; the $\mathrm{l}=\mathrm{m}$ dcposition-lieight percentages always lie within the corresponding percentage range of the ground-level deposition surface; this is more marked for rough 
surfaces. This implies that smooth surfaces have a lesser effect on the downwind particle-size-deposition percentages, which is plausible since rougher surfaces should be more efficient only for close-in particle transport to the deposition surface, well before the depletion of large particles becomes significant.

The reason for the previously mentioned diminished effects during windy periods (at some downwind distance) is apparently related to the greater plume advection. Here the greater wind speed reduces the intepartion time between lie particulate plume and the upwind deposition surface, resulting in less change per unit distance.

In summary, deposition is very sensitive to the deposition height as evidenced by the order of magnitude variation displayed in Figures 5.9 through 5.16. The relative contribution of different particle sizes is more sensitive to deposition height over rough surfaces than smooth surfaces; similarly, it is more sensitive to deposition height during calm periods Lhan during windy conditions.

\section{E. Response to Source Height}

The height of the infinite instantaneous line source is the only parameter of the source-receptor geometry that is permitted to vary. The data in Figures 5.17 through 5.24 suggest llat deposition sensitivity to different source heights 


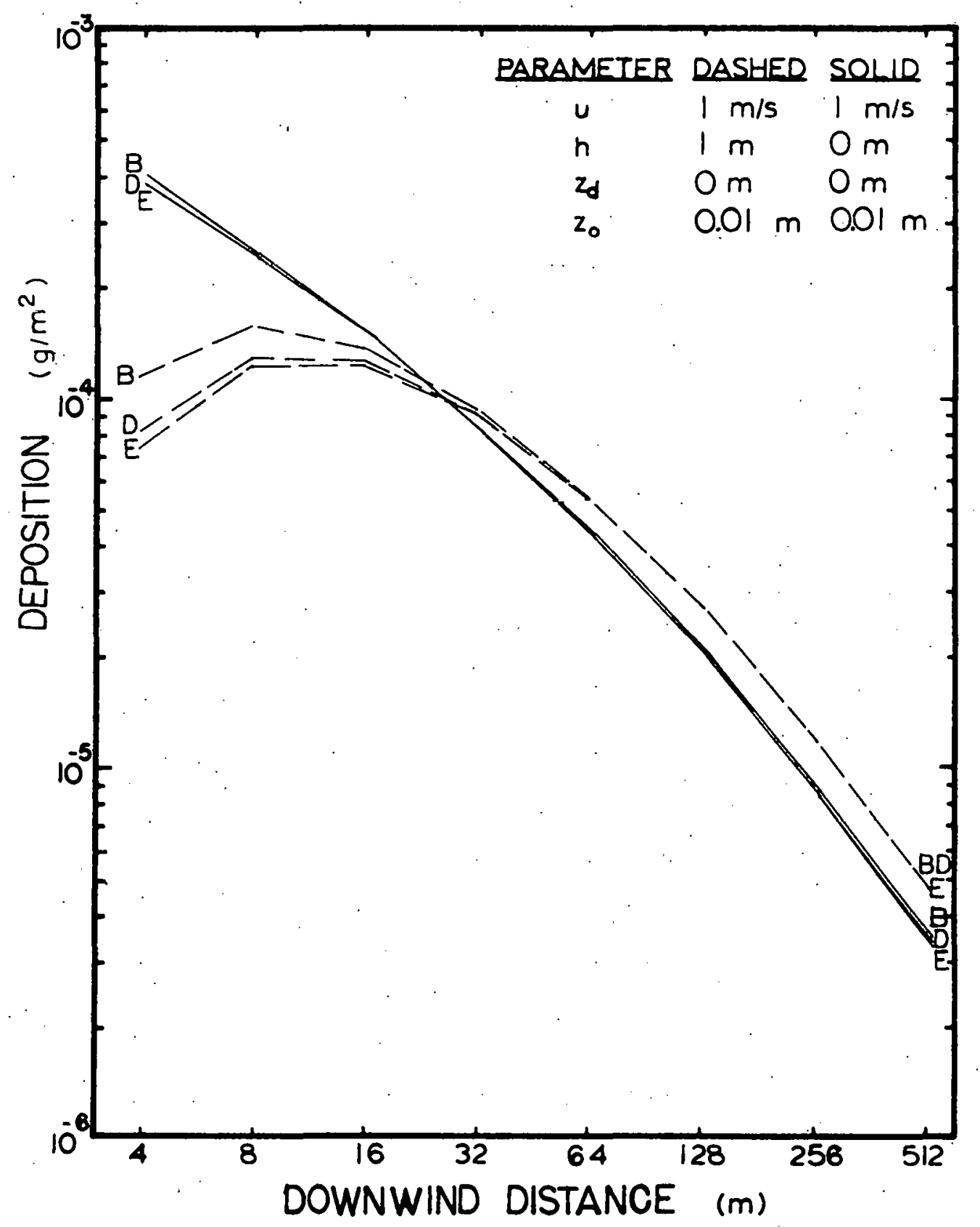

F1gure 5.17. Downwind-deposition sensitivity to source height and atmospheric stability from an infinite instantaneous $1 \mathrm{ine}$ source of $1.0 \mathrm{~g} / \mathrm{m}$ 


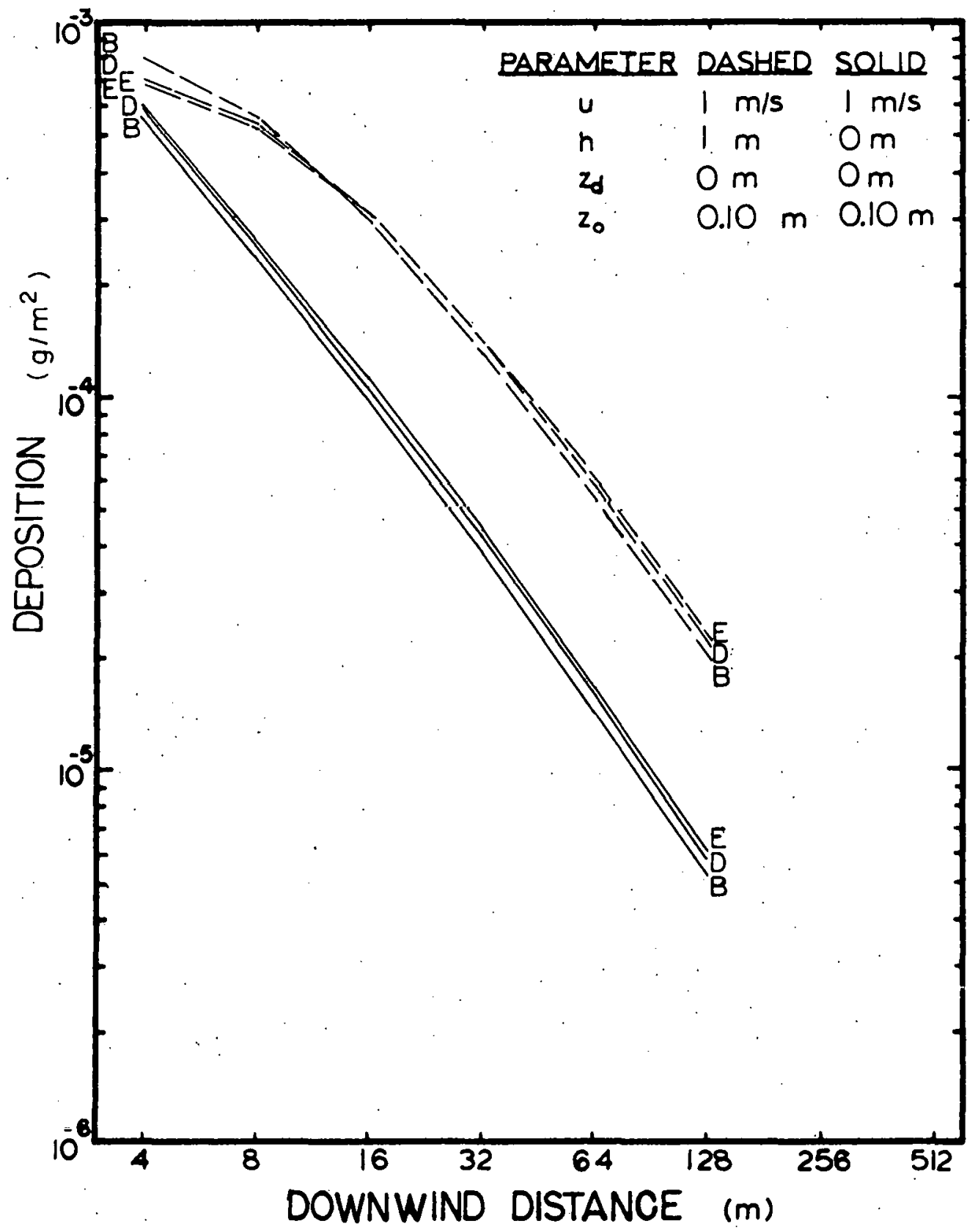

Figure 5.18. Downwind-deposition sensitivity to source height and atmospheric stability from an infinite instantaneous line solurre of $1.0 \mathrm{~g} / \mathrm{m}$ 


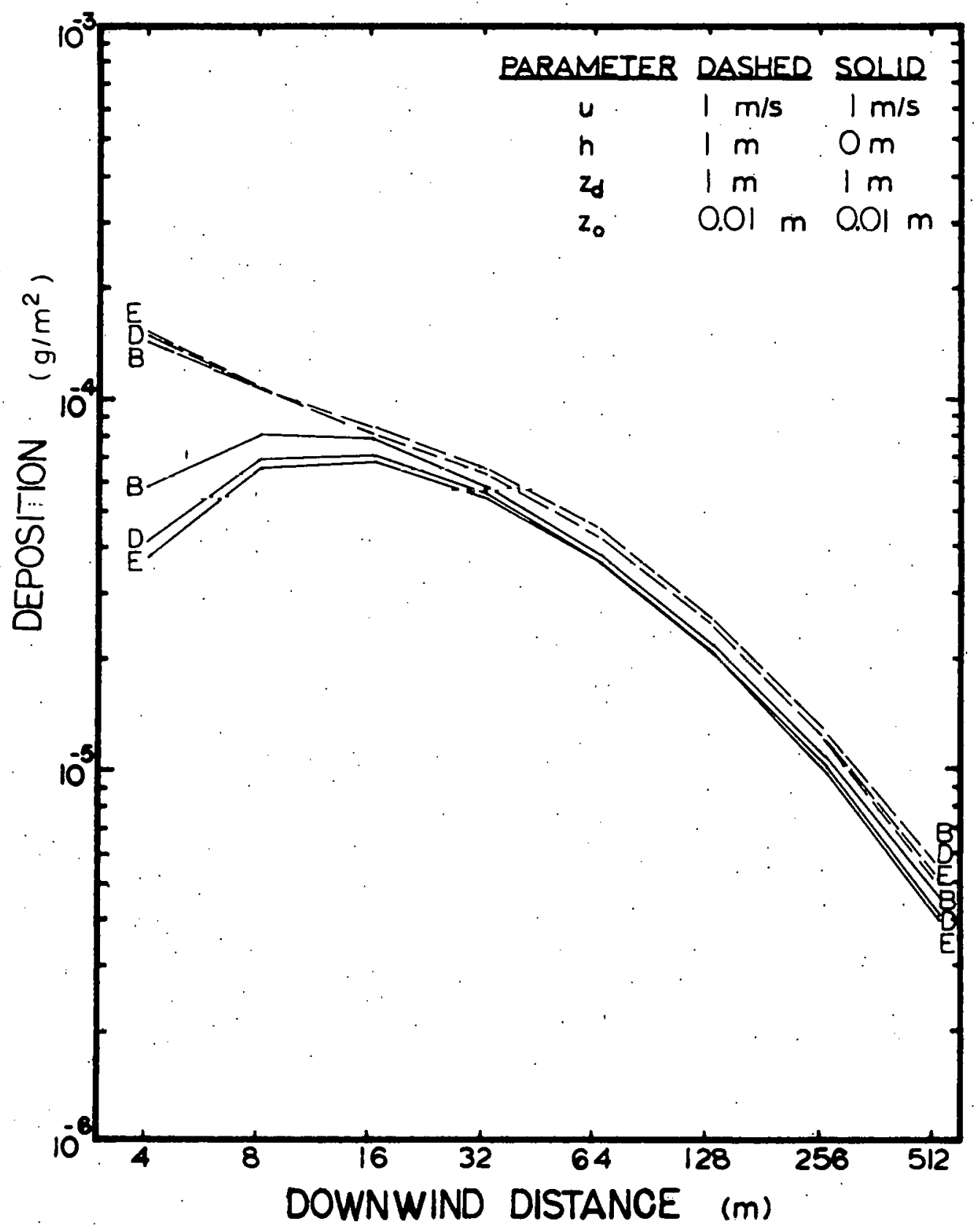

Figure 5.19. Downwind-deposition sensitivity to source height and atmospheric stability from an infinite instantancous line source of $1.0 \mathrm{~g} / \mathrm{m}$ 


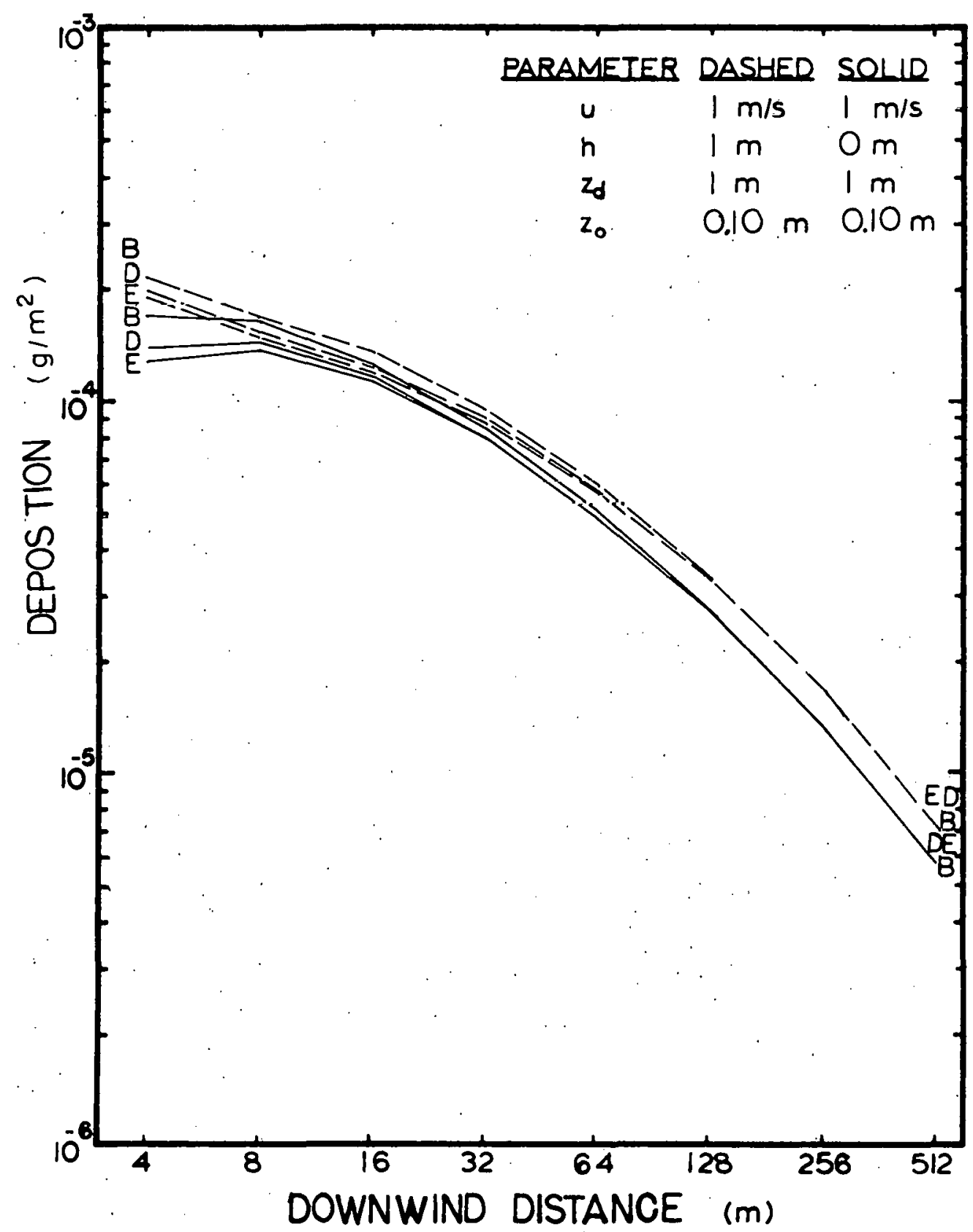

Figure 5.20. Downwind-deposition sensitivity to source height and atmospheric stability from an infinite instantaneous line source of $1: 0 \mathrm{~g} / \mathrm{m}$ 


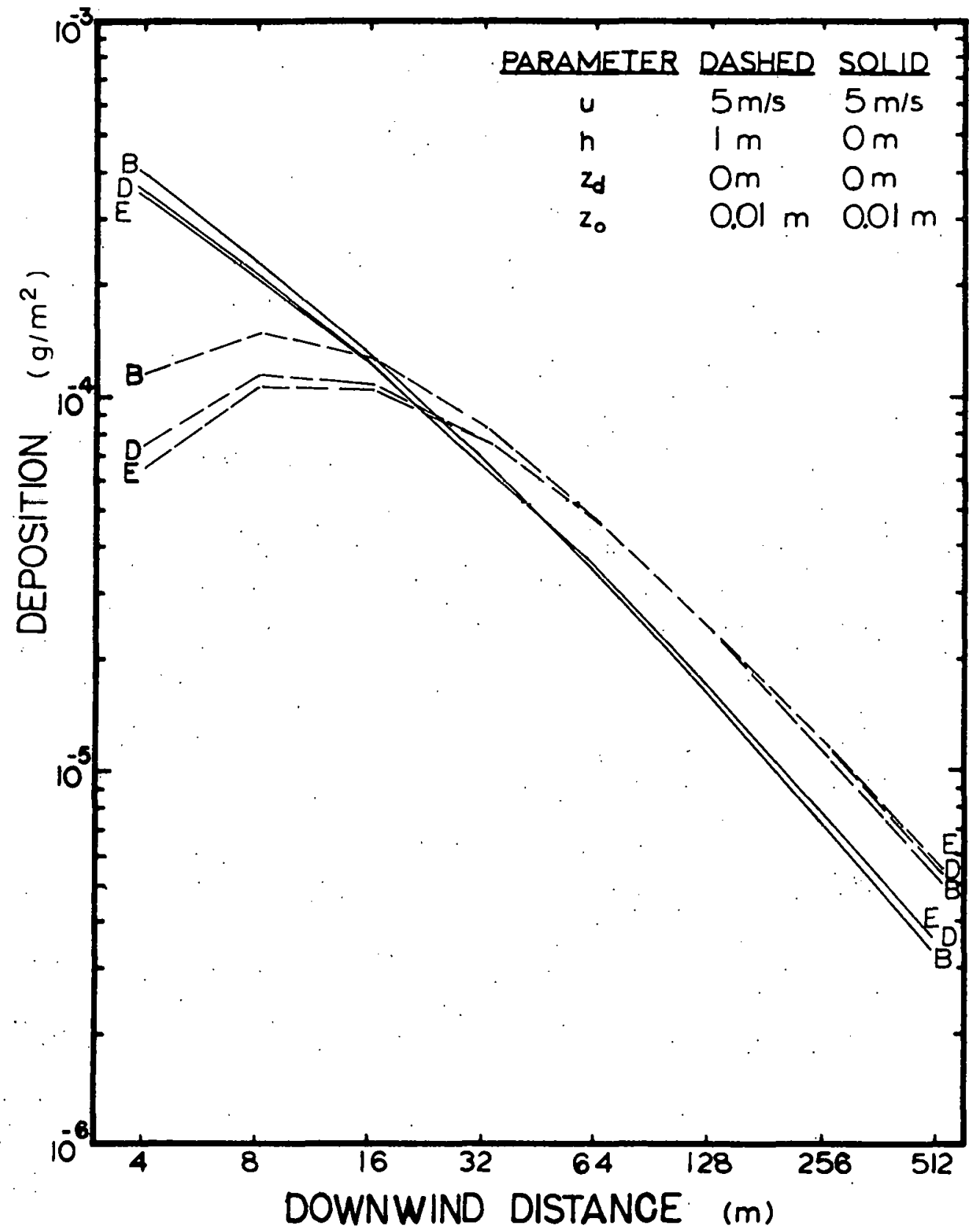

Flgure 5.21. Downwind-deposition sensitivity to source height and atmospheric stability from an infinite instantaneous 1 ine source of $1.0 \mathrm{~g} / \mathrm{m}$ 


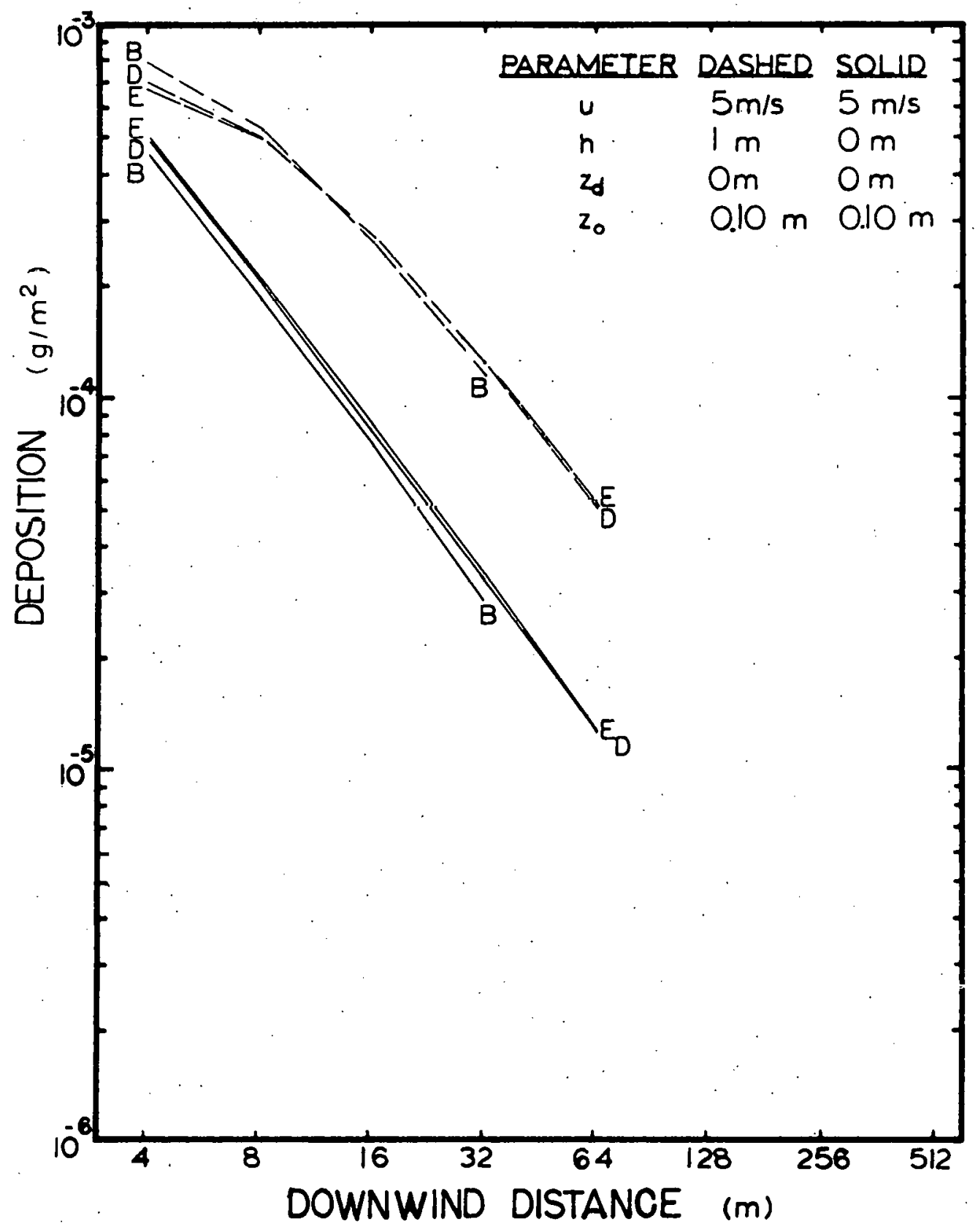

Figure 5.22. Downwind-deposition sensitivity to source height and atmospheric stability from an infinite instantaneous line source of $1.0 \mathrm{~g}, \mathrm{~m}$ 


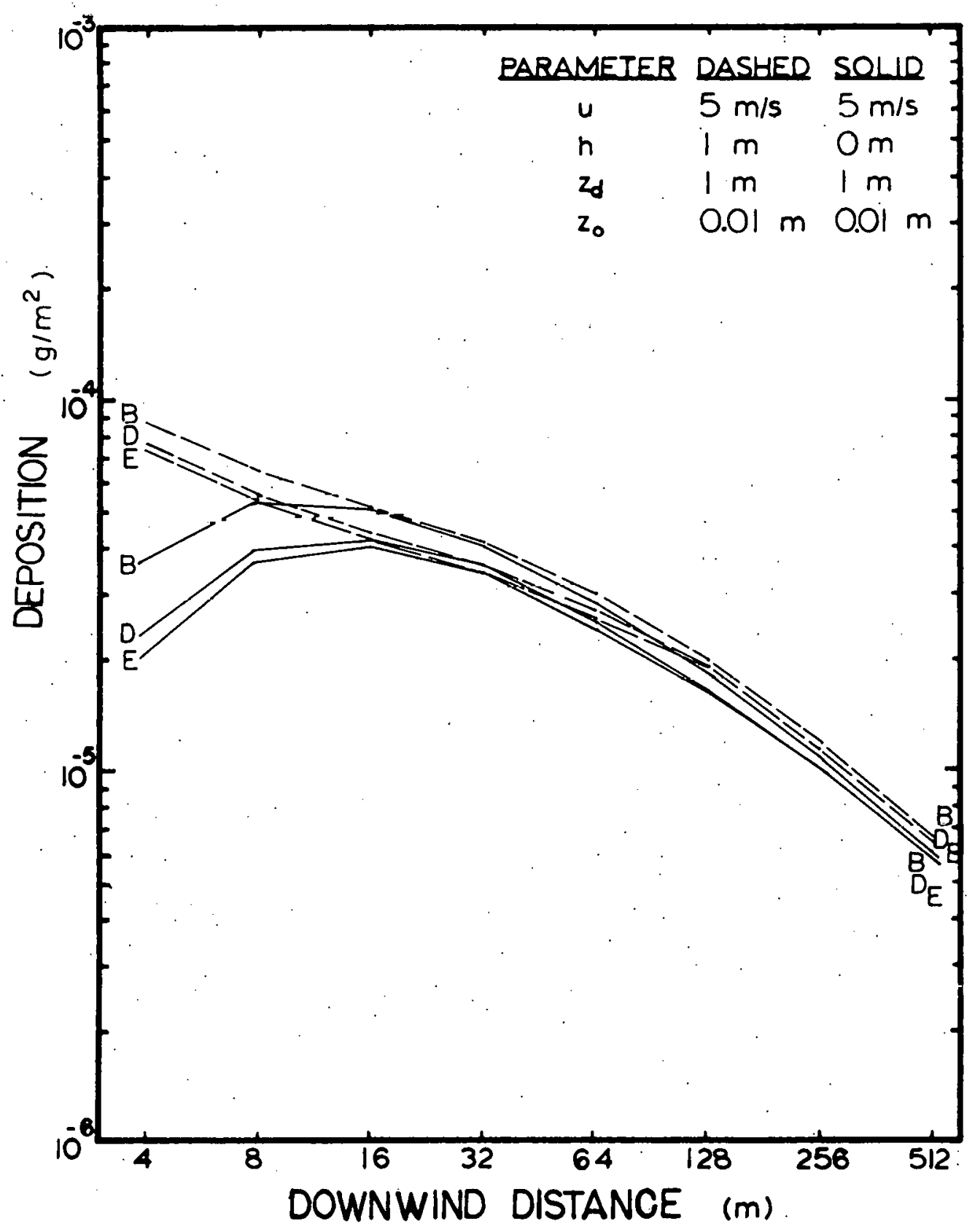

Figure 5.23. Downwind-deposition sensitivity to source height and atmospheric stability. from an infinite instantaneous line souroc of $1.0 \mathrm{~g} / \mathrm{m}$ 


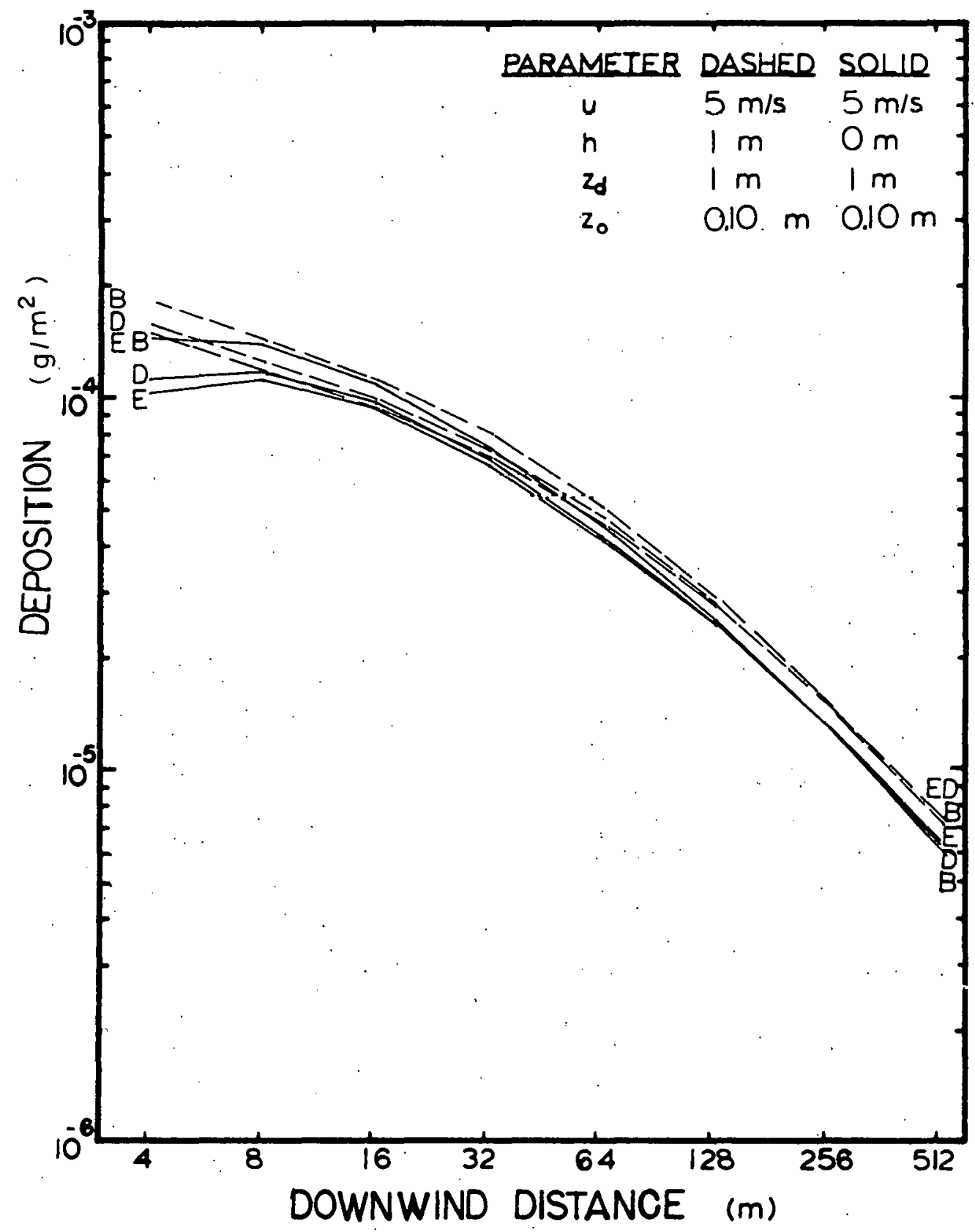

Figure 5.24. Downwind-deposition sensitivity to source height and atmospheric stability from an infinite instantanoous linc source of 1.0 y/lil 
be considered as two separate cases--that for a ground-level deposition surface and that for an elevated deposition surface.

For a ground-level deposition surface, we must also consider the effects of surface roughness. Over smooth surfaces (see Figures 5.17 and 5.21), deposition differences due to different source heights vary from an order of magnitude at $4 \mathrm{~m}$ to zero at the crossover point, with differences typically averaging a factor of two or less. Over rough surfaces (see Figures 5.18 and 5.22), order-of-magnitude differences predullindte, with the crossover polnt occurring at less than $4 \mathrm{~m}$. This is to be expected from continuity considerations since the increased surface roughness should accelerate the deposition process and, in turn, move the crossover point to smaller downwind distances.

Figures 5.19, 5.20, 5.23 and 5.24 show that, for a $1-m$ deposition height close to the source, the effects of source height with respect to the deposition sensitivity are approximately a factor of three greater for smooth surfaces than for rough surfaces, with downwind differences in both cases approaching $30 \%$. At large distances deposition is greater for a l-m deposition height than for a ground-level deposition surface. This is probably due to the downwind-deposition source-height lines which do not cross on account of the sourcedeposition height geometry discussed in section IV.A. 
From $0 \mathrm{~m}$ to $1 \mathrm{~m}$ the source height does not seem to significantly affect the percentage contribution of different sized particles. This is shown in Table 5.1, which reveals that the maximum difference in the percentage contribution at any downwind distance is about $2 \%$, but usually is within $1 \%$. Two tentative explanations are offered. First, the maximum difference between the deposition height and the source height was limited to $\mathrm{lm}$. If the difference between the two heights was significantly increased, then the present uniformity (i.e. the 2 if ifference) might not exist. secundly, the maximum source height was limited to $1 \mathrm{~m}$. If it were considerably higher, then the importance of the particle fall velocity and atmospheric stability could result in significant differences in the relative contributions. However, increasing the source height might void the present surface-layer treatment and require additional study of surface layer and planetary boundary-layer interactions. Therefore, the line-source height was limited to relatively low values to insure the validity of surface-layer concepts.

In summary, deposition sensitivity to source height is less for elevated deposition surfaces than for ground-leveldeposition surfaces. Under the range of conditions tested, these differences usually approach about $30 \%$ further downwind, the exception being: a ground-level deposition surface with a 0.01 -m roughness height, which displays an order-of-magnitude 
difference at large distances. The maximum difference in the relative contribution of different particle sizes for different source heights is about 28 , but most differences are within 18 .

\section{F. Response to Wind Speed}

Wind speed is a fundamental meteorological parameter that enters into the diffusion-deposition model by way of (1) the advection term, (2) the determination of atmospheric stability, and (3) the friction velocity. A brief glance of Figures 5.25 through 5.32 reveals that deposition usually is quite insensitive to wind speed, except over smooth surfaces when the source height and deposition height are at $1 \mathrm{~m}$ (see Figures 5.27 and 5.31); these exceptions will be discussed later in this section.

The relative insensitivity of deposition to wind speed (excluding Figures 5.27 and 5.31) results from a balance between two factors, namely the advection effect and roughness effect. The interaction time between the particulate plume and deposition surface at some specified location is merely a response to the advection component. As the wind speed increases, the amount of time the plume may interact with the deposition surface decreases; thus, an inverse relationship exists for the advection term.

The roughness effect might also be termed the depositionvelocity effect, because it, being a function of the surface roughness, ultimately controls the rate of deposition. 


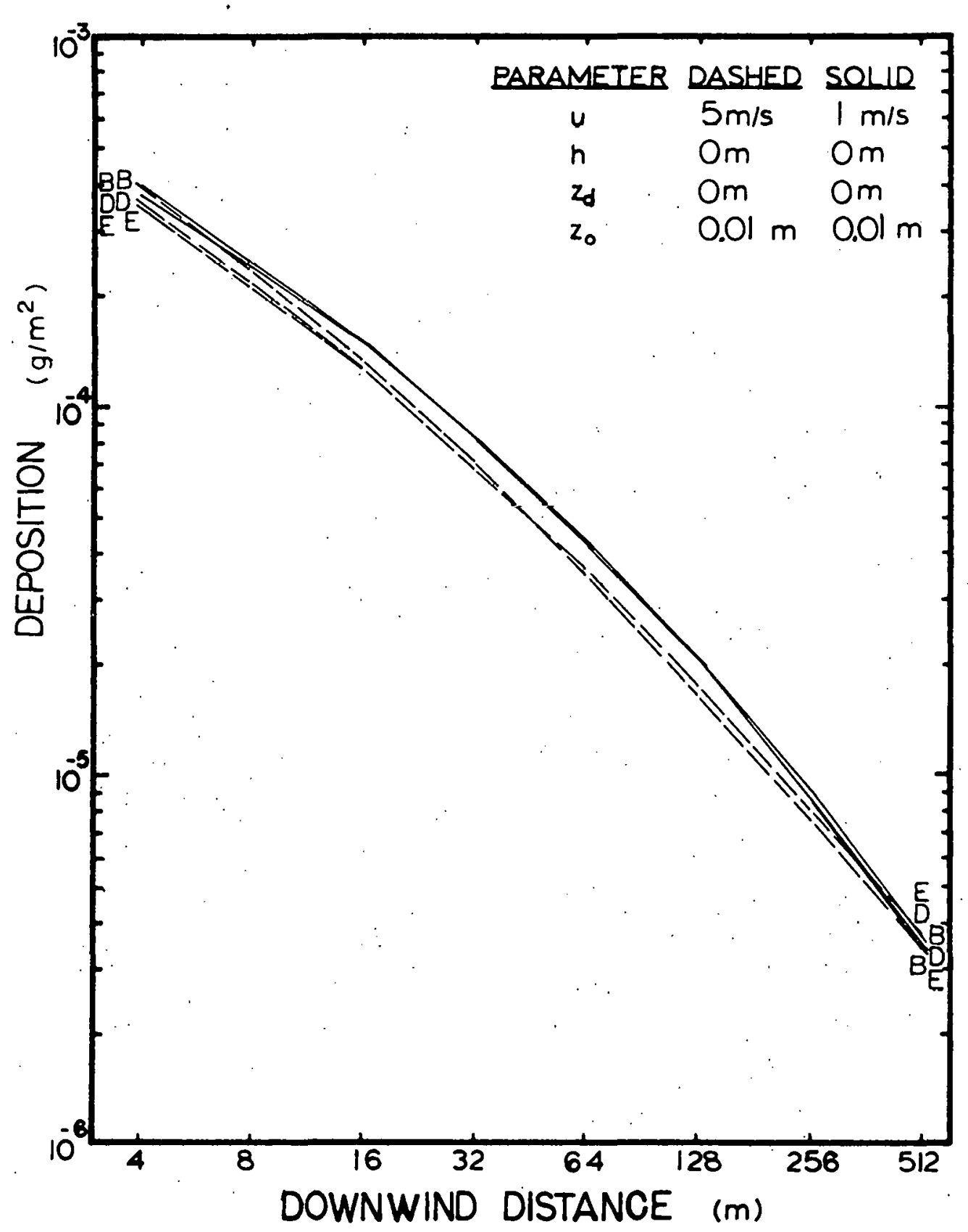

Flgure 5.25. Downwind-deposition sensitivity to wind speed and atmospheric stability from an infinite instantancous line source of $1.0 \mathrm{~g} / \mathrm{m}$ 


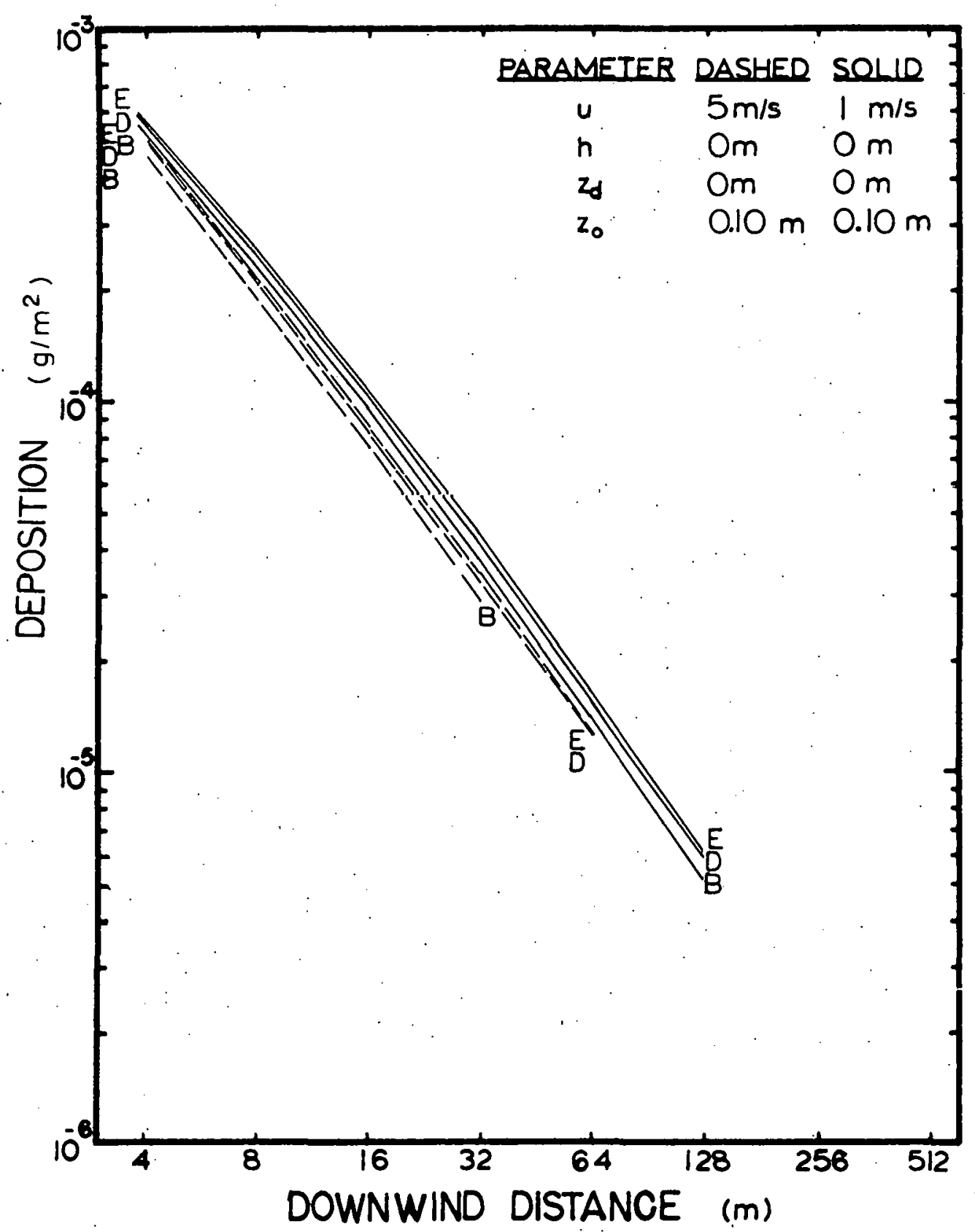

Figure 5.26. Downwind-deposition sensitivity to wind speed and atmospheric stability from an infinite instantaneous lise suurce of $1.0 \mathrm{~g} / \mathrm{m}$ 


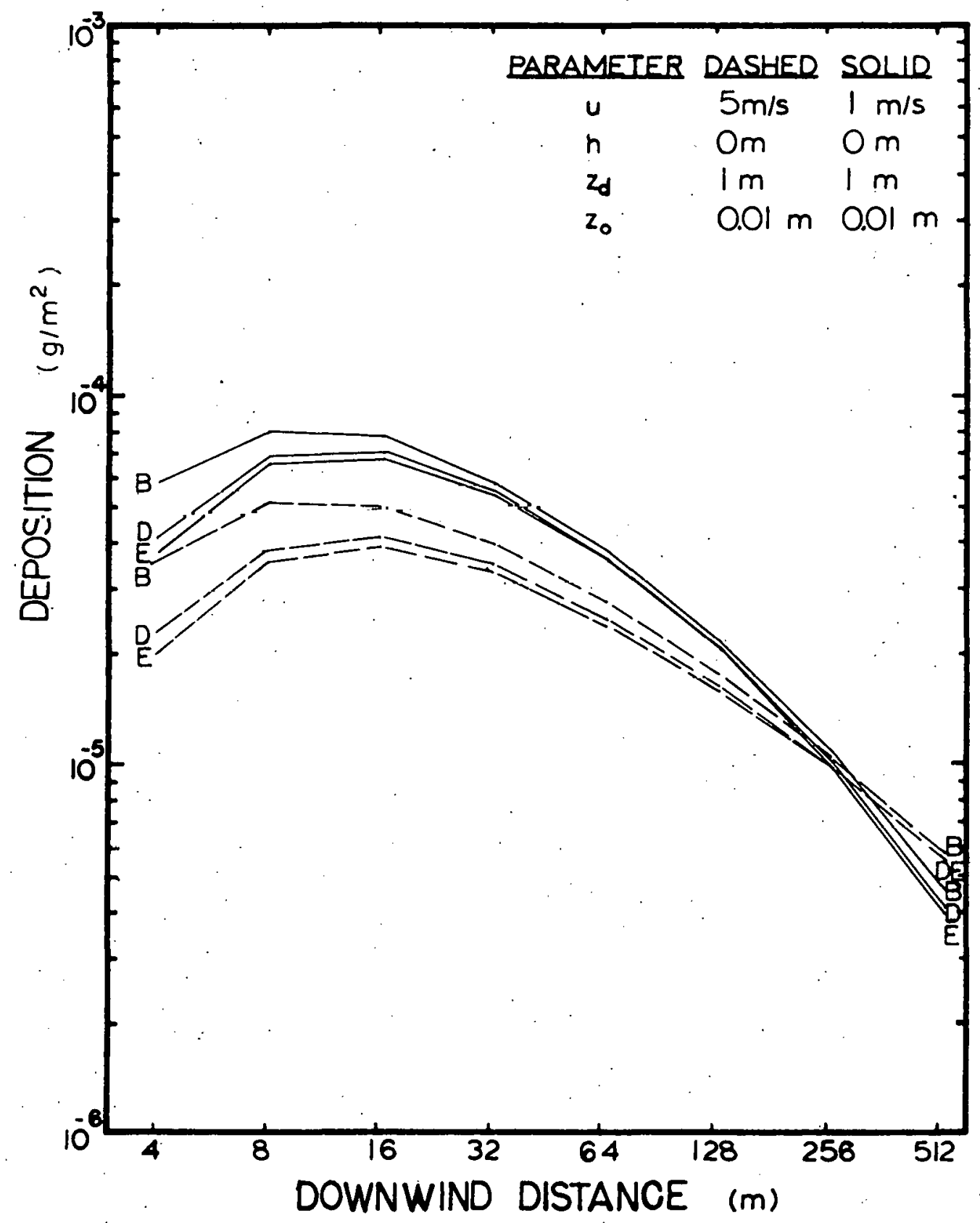

Figure 5.27. Downwind-deposition sensitivity to wind speed and atmospheric stability from an infinite instantaneous line source of $1.0 \mathrm{~g} / \mathrm{m}$ 


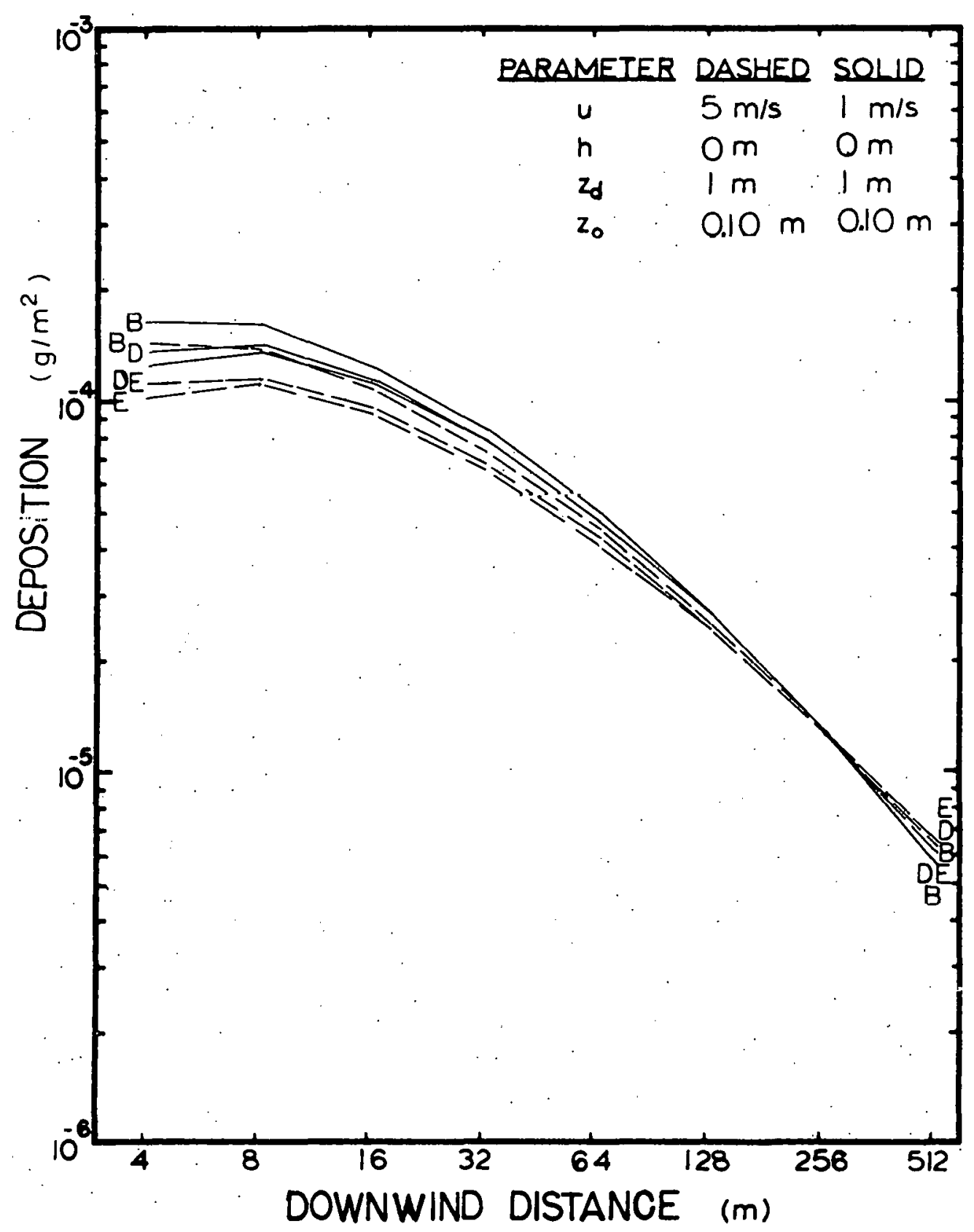

Figure 5.28. Downwind-deposition sensitivity to wind speed and atmospheric stability from an infinite instantaneous lilie source of $\overline{1} .0 \mathrm{~g} / \mathrm{m}$ 


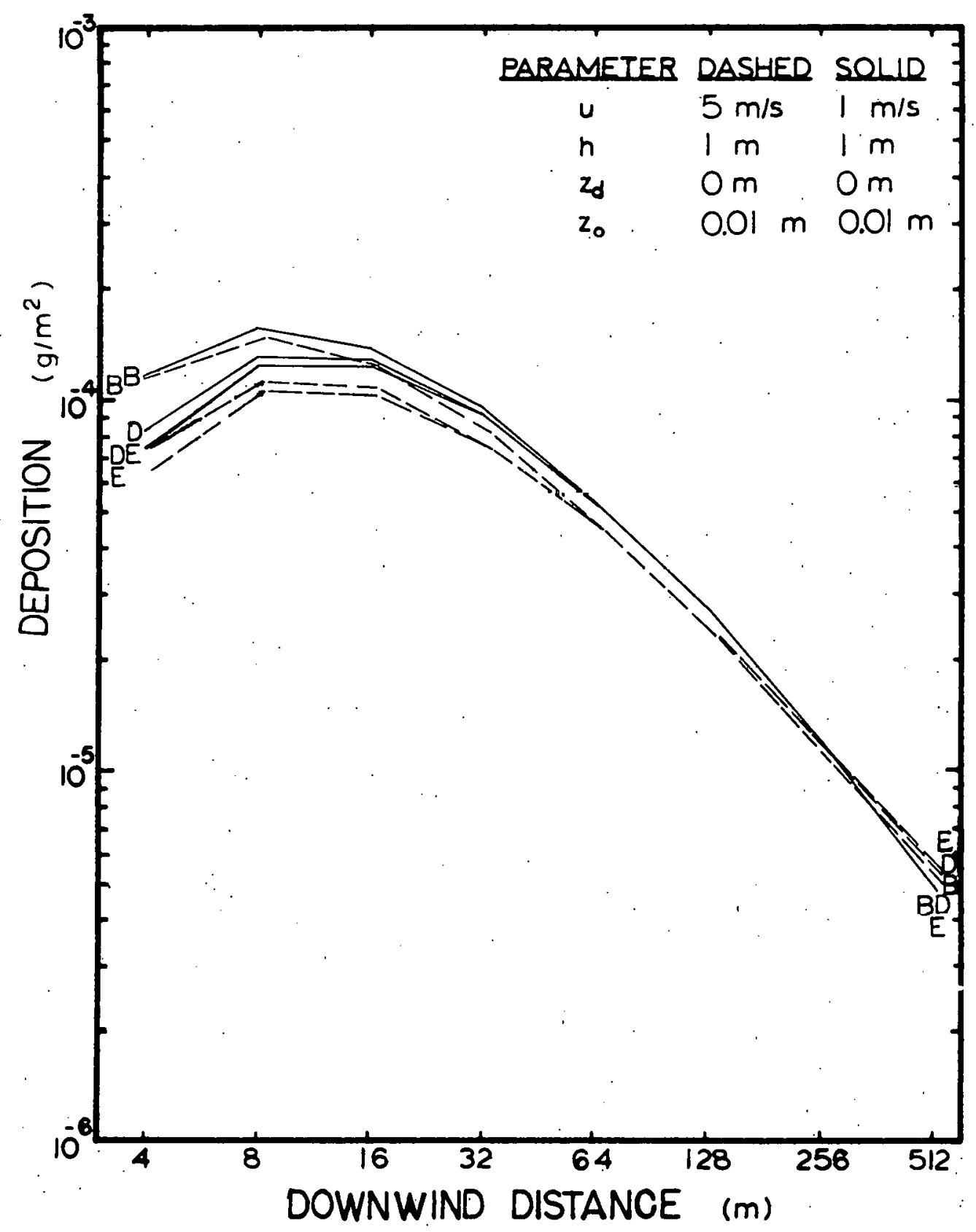

Figure 5.29. Downwind-deposition sensitivity to wind speed and atmospheric stability from an infinite instantaneuis line suurce of $1.0 \mathrm{~g} / \mathrm{m}$ 


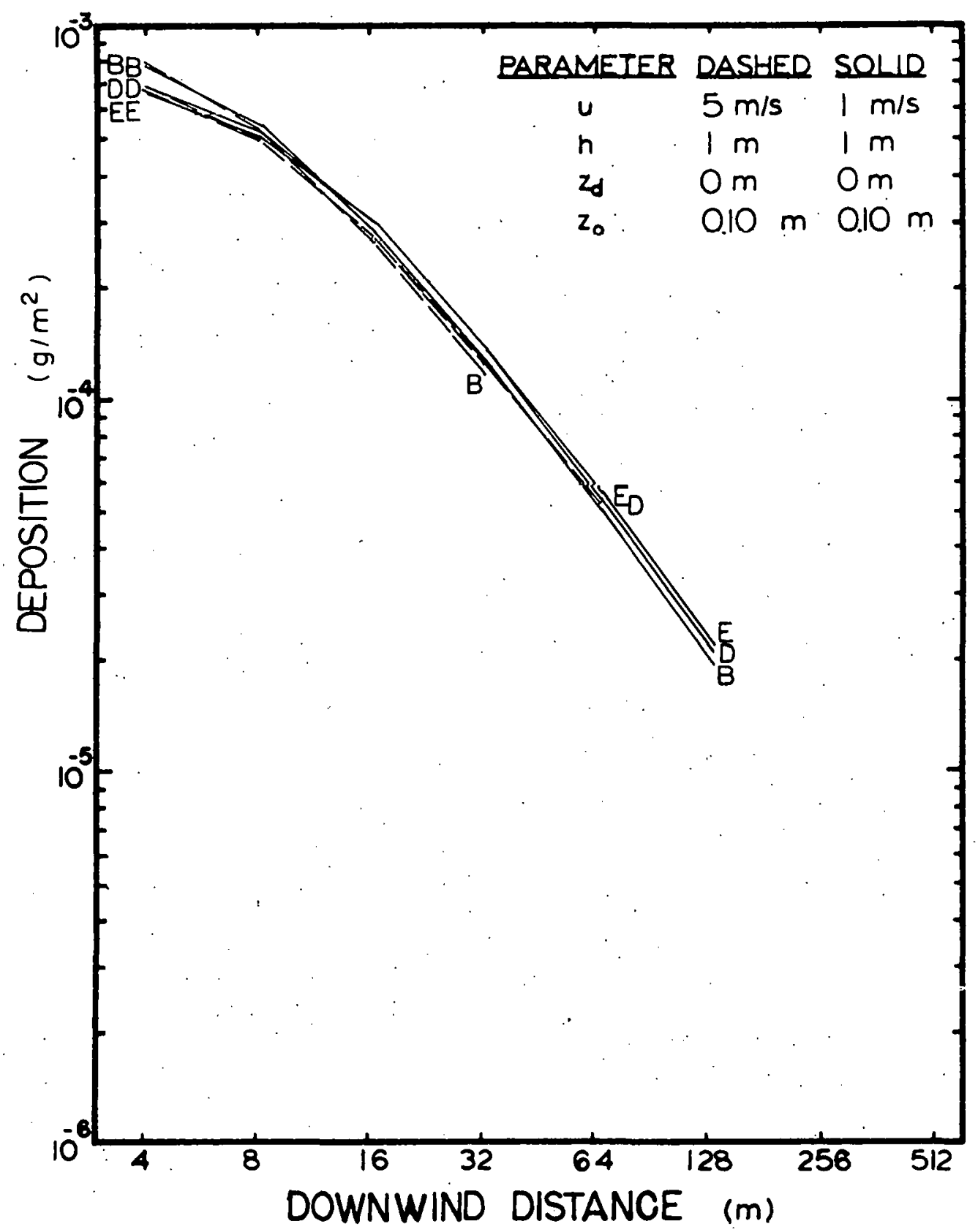

Figure 5.30. Downwind-deposition sensitivity to wind speed and atmospheric stability from an infinite instantaneous line source of $1.0 \mathrm{~g} / \mathrm{m}$ 


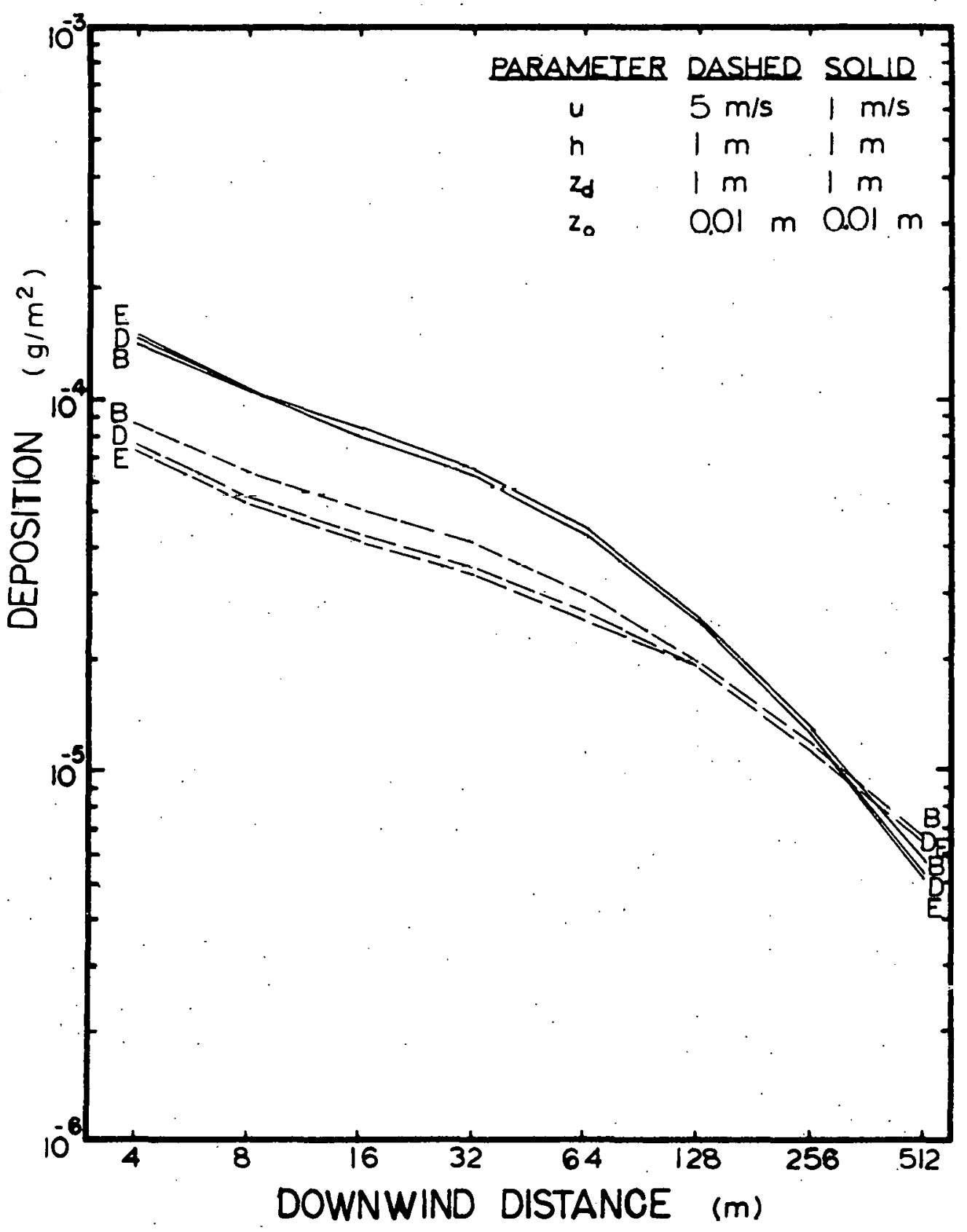

Figure 5.31. Downwind-deposition sensitivity to wind speed and atmospheric stability from an infinite. instantalievis line source of $1.0 \mathrm{~g} / \mathrm{m}$ 


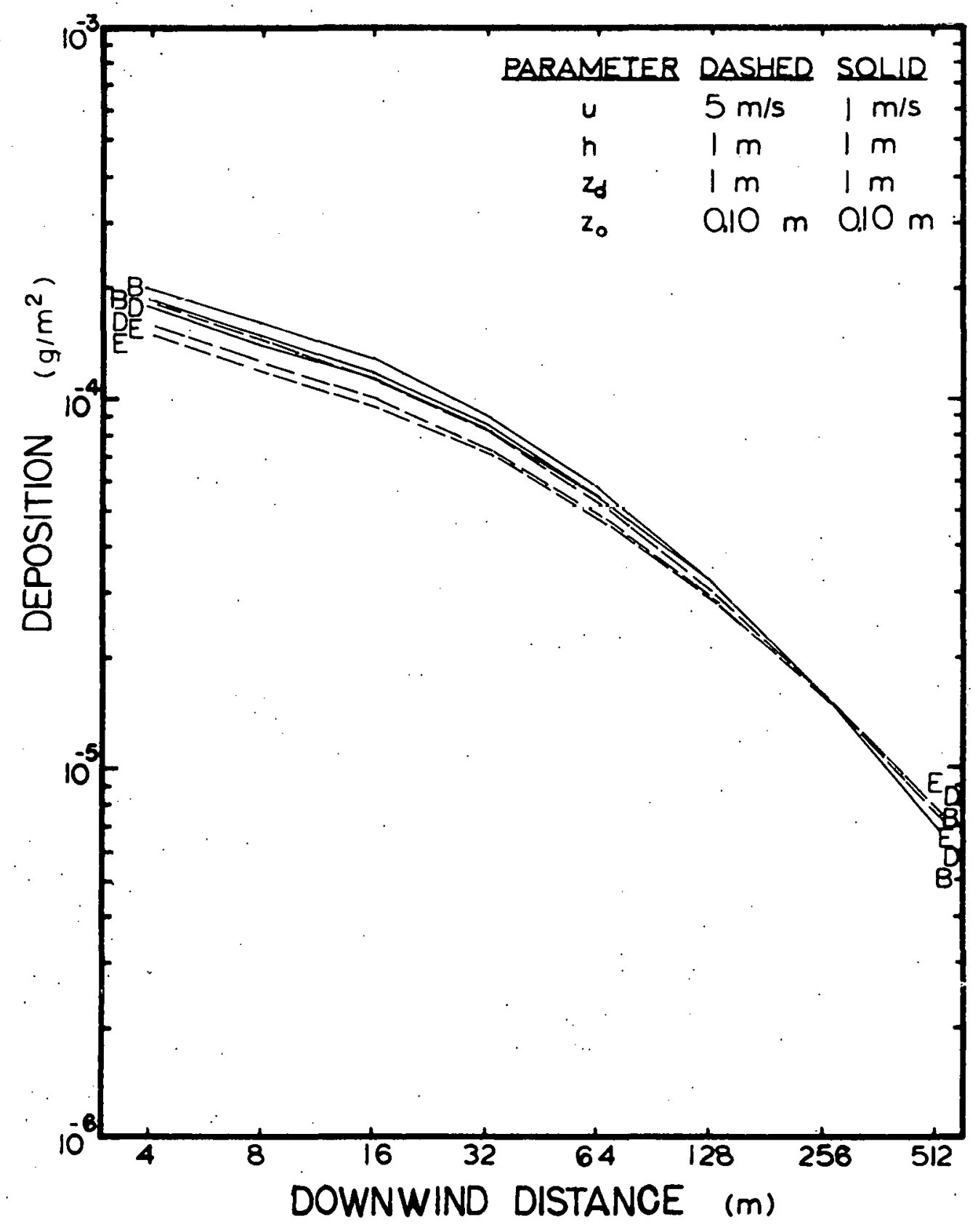

Figure 5.32. Downwind-deposition sensitivity to wind speed and atmospheric stability from an infinite instantaneous line source of $1.0 \mathrm{~g} / \mathrm{m}$ 
Consider an experimental situation where the roughness height and wind speed measurement height are fixed, and where the log-linear wind profile assumption is sufficiently accurate. It is observed that increasing the wind speed causes a greater friction velocity, which enhances the deposition velocity resulting in more deposition. Thus, the roughness effect accounts for a direct relationship between the wind speed and the rate of deposition.

When the advection effect and roughness effect are iundined, the net result is a relatively low deposition sensitivity to wind speed. However, isolating or reducing either effect increases the deposition sensitivity to wind speed. For example, consider Figures 5.27 and 5.31 for a $1-m$ deposition height and a $1-m$ source height over a smooth surface. It is observed that, close to the infinite instantaneous line source, the deposition is noticeably greater for a wind speed of $1 \mathrm{~m} / \mathrm{s}$; this coincides with a region where the advection effect dominates. Close to the source, the slower-moving plume has more time to interact with the deposition surface, and thus its deposition is greater than the $5 \mathrm{~m} / \mathrm{s}$ plume by about a factor of two. However at approximately $256 \mathrm{~m}$ the $1 \mathrm{~m} / \mathrm{s}$ plume has experienced considerable depletion, and beyond this point the deposition from the $5 \mathrm{~m} / \mathrm{s}$ plume exceeds that of the $1 \mathrm{~m} / \mathrm{s}$ plume. It is noteworthy that while it is possible. to reduce the roughness effect in wind-speed-sensitivity tests 
(by increasing the source and deposition heights), it is impossible to eliminate the advection effect.

Most of Figures 5.25 through 5.32 display the familiar and expected deposition line crossover somewhere between $4 \mathrm{~m}$ and $512 \mathrm{~m}$. The notable exception is Figure 5.26 for groundlevel source and deposition heights over a rough surface. Because of the close proximity of the lines and lack of results beyond the point of machine underflow, it is impossible from the data in Figure 5.26 to determine whether the lines cross before $4 \mathrm{~m}$. or beyond the point of machine underflow. The latter is believed more likely, because of the greater interaction time, which is available to the $1 \mathrm{~m} / \mathrm{s}$ plume.

The influences of wind speed on the percentage contribution of different particle sizes is next shown by considering its effect on deposition, both at ground level and at $1 \mathrm{~m}$. Table 5.1 shows that, for a l-m deposition height at small downwind distances, the percentage contribution of particles less than $7.0 \mu \mathrm{m}$ is less for a wind speed of $\mathrm{lm} / \mathrm{s}$ than for $5 \mathrm{~m} / \mathrm{s}$, while the percentage contribution of particles larger than $7.0 \mu \mathrm{m}$ is greater for a wind speed of $1 \mathrm{~m} / \mathrm{s}$ than for $5 \mathrm{~m} / \mathrm{s}$; at large downwind distances the opposite wind speed relation is observed. This is reasonable since, close-in, the relatively massive particles have more time to interact with the 1-m deposition height, hence their contribution to the total deposition should be relatively greater for slower wind 
speeds at small downwind distances and relatively less further downwind.

A ground-level-deposition height is seen to have the same particle-size percentage features as the l-m deposition height, except that the percentage of less-than-2- $\mu$ m particles close-in is greater for a $1 \mathrm{~m} / \mathrm{s}$ wind speed than for a $5 \mathrm{~m} / \mathrm{s}$ wind speed. This deviation from the case of a $1-m$ deposition height is compensated by particles in the 3.3 to $7.0-\mu \mathrm{m}$ size range. The physical significance of this is unknown. For both deposition heights, the faster-moving plume experiences less change per unit distance due to a shorter interaction time per unit distance.

In summary, the deposition is relatively insensitive to wind speed, except over smooth surfaces when the source height and deposition height are at $1 \mathrm{~m}$, where a factor-of-two difference exists. The percentage contribution to the total deposition from large particles close-in is greater for a $1 \mathrm{~m} / \mathrm{s}$ wind speed than for a $5 \mathrm{~m} / \mathrm{s}$ wind speed, whereas at large distances the percentage contribution of large particles is less for a $1 \mathrm{~m} / \mathrm{s}$ wind speed than for a $5 \mathrm{~m} / \mathrm{s}$ wind speed. Furthermore, a $5 \mathrm{~m} / \mathrm{s}$ plume experiences less charge per unit distance than a $1 \mathrm{~m} / \mathrm{s}$ plume because of the shorter interaction time per unit distance. 


\section{G. Sensitivity Synopsis}

In sections V.B through V.F the sensitivity of deposition calculations was considered for various modeling parameters. Table 5.2 gives an overview of the deposition sensitivity to atmospheric stability, roughness height, deposition height, source height, and wind speed. Order-of-magnitude depositionsensitivity estimates are given for both maximum observed differences and typically observed differences for each of the five modeling parameters, whereas the sensitivity of the relative particle-size contribution is subjectively evaluated for the same variables.

Atmospheric stability, followed closely by wind speed and source height (excluding a ground-level deposition height over a rough surface), is usually observed to have the least influence on the total deposition for the range of conditions tested. Roughness height and deposition height have a considerable impact on the deposition amounts, as evidenced by the 0.7 order-of-magnitude differences that frequently occur. Total deposition apparently is most sensitive to source height for a ground-level deposition surface with a large roughness height.

In general, Table 5.2 shows that a large total deposition sensitivity (e.g., 0.7 orders of magnitude) tends to be associated with a moderate or high relative particle-size 
Table 5.2. An assessment of the total deposition seasitivity and relative particlesize contribution sensitivity to various modeling parameters from an infinite instantaneous line source of $1.3 \mathrm{~g} / \mathrm{m}$

\begin{tabular}{|c|c|c|c|}
\hline \multirow[b]{2}{*}{$\begin{array}{l}\text { Modeling } \\
\text { parameter }\end{array}$} & \multicolumn{2}{|c|}{$\begin{array}{l}\text { Total deposition } \\
\text { sensitivity } \\
\text { (orders of magnitude) } \\
\end{array}$} & \multirow{2}{*}{$\begin{array}{l}\begin{array}{c}\text { Relative particle- } \\
\text { size contribution } \\
\text { sensitivity }\end{array} \\
\begin{array}{l}\text { Subjective } \\
\text { evaluation }\end{array}\end{array}$} \\
\hline & $\begin{array}{c}\text { Maximum } \\
\text { difference }\end{array}$ & $\begin{array}{l}\text { Typical } \\
\text { difference }\end{array}$ & \\
\hline Atmospheric stability & .3 & .1 & Minor \\
\hline $0.01 \mathrm{~m}, 0.10 \mathrm{~m})$ & 1.0 & .7 & Major \\
\hline Deposition height & 1.0 & .7 & Moderate \\
\hline $\begin{array}{l}\text { Source height } \\
\left.\text { excluding } \mathbf{z}_{\mathrm{d}}=0 \mathrm{~m}, \mathrm{z}_{\mathrm{o}}=0.10 \mathrm{~m}, 1 \mathrm{~m}\right) \\
\text { exclusively } \mathbf{z}_{\mathrm{d}}=0 \mathrm{~m}, \mathrm{z}_{\mathrm{o}}=0.10 \mathrm{~m}\end{array}$ & $\begin{array}{l}1.0 \\
1.0\end{array}$ & $\begin{array}{r}.2 \\
1.0\end{array}$ & $\begin{array}{l}\text { Minor } \\
\text { Minor }\end{array}$ \\
\hline $\begin{array}{l}\text { Wind speed } \\
\quad \begin{array}{l}(1 \mathrm{~m} / \mathrm{s}, 5 \mathrm{~m} / \mathrm{s}) \\
\text { excluding } z_{d}=h=1 \mathrm{~m}, z_{o}=0.01 \mathrm{~m} \\
\text { exclusively } z_{d}=h=1 \mathrm{~m}, z_{o}=0.01 \mathrm{~m}\end{array}\end{array}$ &. .2 & $\begin{array}{l}.1 \\
.3\end{array}$ & $\begin{array}{l}\text { Moderate } \\
\text { Moderate }\end{array}$ \\
\hline
\end{tabular}


contributici sensitivity (e.g., moderate or major). A notable exception is the deposition sensitivity to source height for a ground-level deposition height over a rough surface. Here, order-of-magnitude differences are typical, but the impact on the relative particle-size contribution is minor. This is in contrast with the deposition sensitivity to wind speed, which has significantly less variation in the total deposition, but experiences moderate variations in the relative contribution by different particle-size ranges. 
VI. APPIICATIONS OF THE QUANTIFICATION METHODOLOGY

A. Particulate Deposition from Dry Unpaved Roadways

Ground-level downwind-deposition estimates and their corresponding maximum number of allowable vehicle passes were calculated using the Story County, Mahaska County, Morton County and Wallace County data. Each location had a different source-receptor geometry, and different meteorological and terrain conditions. The surface roughness for the Kansas locations was unknown, so it was assumed to be approximately the same as for the Iowa locations, namely about $0.05 \mathrm{~m}$. For simplicity, a zero-background concentration, and a maximum contract between the deposition particles and the deposition surface were assumed

The calculations for Story County, Mahaska County, Morton County and Wallace County yielded, respectively, a 4-m total deposition of $1010,16600,104$ and $1430 \mu \mathrm{g} / \mathrm{m}^{2}$-pass which corresponds to 49, 4, 270 and 21 allowable vehicle passes, respectively, before exceeding the $0.7 \%$ EAC standard; these are equivalent to $12,1,68$ and 5 vehicle passes per day before exceeding the $0.17 \% \mathrm{EAC} /$ day standard. At $256 \mathrm{~m}$ downwind the respective deposition is $27,352,5$ and $104 \mu \mathrm{g} / \mathrm{m}^{2}$-pass which corresponds to 621, 65, 3200 and 103 allowable vehicle passes, respectively, before exceeding the $0.7 \%$ EAC standard; these are equivalent to $155,16,800$ and 26 vehicle passes per day before exceeding thc 0.17 EnC/day standard. 
Since a given mass of small particles will have a greater EAC than large particles (due to the greater surface-area to volume ratio), the particle-size dependence of the EAC causes a nonlinear relationship to exist between the total mass deposition and the total EAC and, in turn, the number of allowable vehicle passes before exceeding some standard. This explains why different total deposition values of 352 and $104 \mu \mathrm{g} / \mathrm{m}^{2}$-pass (at $256 \mathrm{~m}$ for a gravel road and dirt road, respectively) both result in more nearly the same number of allowable vehicle passes (65 and 103, respectively). In short, large particles contribute relatively more to the total deposition while small particles contribute relatively more to the total effective area coverage.

\section{B. Particulate Deposition due to Ambient Conditions}

For comparison purposes, we examine the particulate deposition due to typical ambient conditions for two cases: (1) Those conditions coincident with the four site experiments, and (2) a reference case which typifies flat terrain covered by prairie grass. The latter, which acts as a point of comparison, defines a 'reference case' that describes the particulate deposition experienced by flat terrain for $u_{*}=50 \mathrm{~cm} / \mathrm{s}, z_{0}=$ $3 \mathrm{~cm}$, and $\bar{x}_{a}=50 \mu \mathrm{g} / \mathrm{m}^{3}$. 
The four field experiments had a calculated friction velocity of approximately $50 \mathrm{~cm} / \mathrm{s}$ and a roughnes.s height of about $5 \mathrm{~cm}$. Due to a lack of experimental data at the site locations, a $100 \mu \mathrm{g} / \mathrm{m}^{3}$ ambient concentration was assumed; this factor of two above the reference case concentration is incorporated because of the exceptionally dry conditions which existed during the field experiments. As will be seen shortly, this factor-of-two difference in the ambient concentrations has a minor influence on the daily particulate deposition in comparison with the differense resulting from a less than factorof-two variation in the roughness height. Next, we briefly consider the conditions representing the reference case.

According to sutton (1953), $z_{0}$ is usually independent of $U$, and $u_{\star} / U$ is constant over a wide variety of surfaces (snow, grassland, root crops) for $U$ (measured at $5 \mathrm{~m}$ ) varying from about $20-500 \mathrm{~cm} / \mathrm{s}$. The values of $u_{*}$ vary from $3-128$ of the mean wind speed, the lower values being associated with smooth surfaces (Sutton, 1953). Thus, the reference case represents a mean wind speed of approximately $10 \mathrm{mph}$. This moderate velocity promotes rapid surface drying, while still maintaining a negligible resuspension rate. If, however, wind velocities are considerably greater than $10 \mathrm{mph}$, then the accuracy of the procedure diminishes because of particle resuspension. A roughness height of $3 \mathrm{~cm}$ is characteristic of flat open country (3tern, 1976); this also typifies a dense $10 \mathrm{~cm}$ stand of grass 
or a thin $50 \mathrm{~cm}$ stand of grass. Finally, an ambient concentration of $50 \mu \mathrm{g} / \mathrm{m}^{3}$ is typical of many rural environments. ${ }^{1}$

The particulate-deposition calculations for the four site locations and the reference case assumed that the ambient particle-size distribution was divided into proportions similar to the Des Moines, Iowa and Iowa City, Iowa particulate-sizing data given in Tables 4.1 and 4.2 , respectively. Statistics on the suspended-particulate and particulate-deposition distributions for the site and reference cases are summarized in Table 6.1 .

Table 6.1 shows a total daily actual area coverage for the site and reference conditions of 10.91 and $3.63 \% /$ day, respectively; this corresponds to a total daily effective area coverage of 0.55 and $0.18 \% /$ day (here we have followed the approach of Hancock et al. (1976), where it is assumed that the effective area coverage is about 58 of the actual area coverage). Therefore, the number of days required before exceeding the 0.78 EAC standard is 1.28 days (i.e., approximately 30 hours) for the site conditions, and 3.86 days (i.e., approximately 92.6 hours) for the reference case. Here we observe a difference of a factor of 1.5 (corrected for ambient concentration differences) between roughness heights of $3 \mathrm{~cm}$ and $5 \mathrm{~cm}$. We conclude that

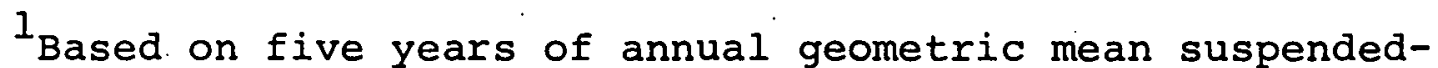
particulate data for several rural locations within the state of Iowa. (Iowa Department of Environmental Quality, Des Moines, Iowa. Private communication. 1977). 
Table 6.1. Particulate deposition due to ambient conditions

(Site conditions: $u_{\star}=50 \mathrm{~cm} / \mathrm{s}, z_{0}=5 \mathrm{~cm}$, and $\bar{x}_{a}=100 \mu \mathrm{g} / \mathrm{m}^{3}$ )

\begin{tabular}{|c|c|c|c|c|c|}
\hline & \multicolumn{5}{|c|}{ Particle-size-diameter range (um) } \\
\hline & $<0.7$ & $0.7-1.25$ & $1.25-2.1$ & $2.1-4.5$ & $>4.5$ \\
\hline \multicolumn{6}{|l|}{ Suspended-particulate statistics } \\
\hline $\begin{array}{l}\text { Percent of total mass } \\
\text { Geometric mean (mass) diameter ( } \mu \mathrm{m}) \\
\text { Deposition velocity (cm/sec) }\end{array}$ & $\begin{array}{l}30.0 \\
0.24 \\
1.0\end{array}$ & $\begin{array}{l}5.0 \\
0.94 \\
1.5\end{array}$ & $\begin{array}{l}10.0 \\
1.62 \\
2.0\end{array}$ & $\begin{array}{l}15.0 \\
3.06 \\
2.5\end{array}$ & $\begin{array}{l}40.0 \\
13.62 \\
4.0\end{array}$ \\
\hline \multicolumn{6}{|l|}{ Particulate-deposition statistics } \\
\hline $\begin{array}{l}\text { Daily deposition }\left(\mathrm{g} / \mathrm{m}^{2} \text {-day) } \times 10^{2}\right. \\
\text { Geometric mean (area) diameter }(\mu \mathrm{m}) \\
\text { Daily actual area coverage }(\mathrm{q} / \text { day })\end{array}$ & $\begin{array}{r}2.59 \\
.19 \\
8.21\end{array}$ & $\begin{array}{l}.65 \\
.93 \\
.42\end{array}$ & $\begin{array}{r}1.73 \\
1.60 \\
.65\end{array}$ & $\begin{array}{r}3.24 \\
2.97 \\
.65\end{array}$ & $\begin{array}{r}13.82 \\
8.46 \\
.98\end{array}$ \\
\hline \multicolumn{6}{|c|}{ Reference case: $u_{*}=50 \mathrm{~cm} / \mathrm{s}, z_{0}=3 \mathrm{~cm}$, and $\bar{x}_{a}=50 \mu \mathrm{g} / \mathrm{m}^{3}$} \\
\hline Suspended-particulate statistics & & & & & \\
\hline $\begin{array}{l}\text { Percent of total mass } \\
\text { Geometric mean (mass) diameter }(\mu \mathrm{m}) \\
\text { Deposition velocity }(\mathrm{cm} / \mathrm{sec})\end{array}$ & $\begin{array}{c}30.0 \\
0.24 \\
.7\end{array}$ & $\begin{array}{l}5.0 \\
0.9 \leq \\
1.0\end{array}$ & $\begin{array}{l}10.0 \\
1.62 \\
1.4\end{array}$ & $\begin{array}{l}15.0 \\
3.06 \\
2.0\end{array}$ & $\begin{array}{l}40.0 \\
13.62 \\
3.5\end{array}$ \\
\hline Particulate-deposition statistics & & & & & \\
\hline $\begin{array}{l}\text { Daily deposition }\left(\mathrm{g} / \mathrm{m}^{2}-\text { day }\right) \times 10^{2} \\
\text { Geometric mean (area) diameter }(\mu \mathrm{m}) \\
\text { Daily astual area coverage ( } 8 / \text { day })\end{array}$ & $\begin{array}{r}.91 \\
.21 \\
2.59\end{array}$ & $\begin{array}{l}.22 \\
.93 \\
.14\end{array}$ & $\begin{array}{r}.60 \\
1.61 \\
.22\end{array}$ & $\begin{array}{r}1.30 \\
2.9 .8 \\
.26\end{array}$ & $\begin{array}{r}6.05 \\
8.68 \\
.42\end{array}$ \\
\hline
\end{tabular}


the particulate deposition due to ambient conditions is very sensitive to the associated roughness height. This is not unexpected in light of the high deposition sensitivity to roughness height for an infinite instantaneous line source discussed in section V.C.

In comparing these results with those from section VI.A, it is seen that the 1.5-hour actual area coverage due to ambient deposition is comparable to $49,4,270$ and 21 vehicle passes at $4 \mathrm{~m}$ downwind of an infinite instantaneous line source fnr the Story County, Mahaska county, Morton County and Wallace County data, respectively. This implies that 49, 4, 270 and 21 vehicle passes per hour at these locations have the same effect as a $100 \mu \mathrm{g} / \mathrm{m}^{3}$ background concentration for $z_{0}=$ $5 \mathrm{~cm}$ and $u_{\star}=50 \mathrm{~cm} / \mathrm{sec}$. For similar conditions at $256 \mathrm{~m}$ downwind, the number of vehicle passes per hour required to equal the ambient contribution are $621,65,3200$ and 103. Recall, these data are for a $4100 \mathrm{lb}$ vehicle driven at approximately $40 \mathrm{mph}$.

If the roadway were traveled by much heavier vehicles, say haul trucks, the road emissions might be as high as ten times greater. If the particle-size-distribution proportions remain the same, then only $4.9,0.4,27$ and 2.1 vehicles passes per hour would match the ambient contribution of $4 \mathrm{~m}$, while at 256 $\mathrm{m}$ downwind $62.1,6.5,320$ and 10.3 vehicle passes per hour would equal the ambient contribution. 
In short; these data seem to suggest that, except for very heavy traffic conditions at close-in distances, the effect of particulate deposition due to dry unpaved roadways is usually less than that which would occur under normal conditions. However, an assessment of the specific site conditions is necessary before any final decision can be reached.

\section{Additional Applications}

Heretofore, the methodology has been applied to only the partioulate depusttion from a dry unpaved roadway and the subsequent nuisance which it creates as determined by the human response to dustiness. However, the method can readily be applied to other related situations, such as the possible reduction of photosynthesis. Here an increase in the deposition and actual area coverage would reduce the amount of incident solar energy available for photosynthesis which, in turn; might reduce plant growth and crop yield.

Furthermore, the method could easily be extended to situations incorporating noninert substances, such as the aerial application of insecticides and pesticides. Here a knowledge of the amount of substance deposited outside the target area is especially useful for vegetation very sensitive to certain chemical sprays and powders.

The procedure might even be incorporated into experiments which determine the influence of dry deposition over water 
bodies; a number of such simulations of the transport and deposition of air pollutants to large lakes is given by Hicks (1977) .

These three examples are by no means an exhaustive compilation of possible applications. 
VII. RECOMMENDATORY DEPOSITION MODEL IMPROVEMENTS

Almost every stage of the quantification methodology has, by necessity, incorporated some type of simplifying assumption to allow a workable solution. These include the assumptions of horizontally homogeneous terrain, a nonprofile assessment of atmospheric stability and its characterization, and empirical formulas for calculating the deposition velocity and Moninobukhov length. In the paragraphs immediately following is a discussion of the more important modeling features which should be modified as a better understanding and characterization of the various processes become available.

Atmospheric stability is initially categorized by the discrete Pasquill-Gifford classification method described in Appendix $A$; this is then related to the Monin-obukhov length by an empirical formula. The mathematical form of the empirical relation creates an artificial symmetry. (with respect to neutral stability) of the calculated Monin-Obukhov length. A better apprnarh might be to incurporate a correction term or merely assign a representative mean value for each discrete stability class. The ideal solution is to return directly to the definition of the Monin-obukhov length, but this approach is difficult.

Another major simplification was the assumption of vertical eddy diffusivities that are constant with respect to height. 
This assumption, in turn, was used for the horizontal eddy diffusivities. The vertical eddy diffusivity is known to increase with height near the surface, while the vertical wind shear distorts the eddies into an elongated shape with the lower portion trailing the upper portion. Some diffusion models incorporate these features, but usually at the expense of other simplifying assumptions.

Particles are seldom spherical, although they are often assumed to be. This assumption introduces an error into the true particle full velocity as well as the actual area of coverage by the deposition particles. More accurate particlesizing methods and particle-size distributions may be available, but their increased sophistication further complicates the overall procedure.

The complex dependence of the deposition velocity on the deposition height, roughness height, atmospheric stability and particles size further complicates the total picture, thus necessitating a semi-empirical formula. The deposition velocity is most important in determining the rate of deposition, and much additional research is required before a clear understanding of this term is reached.

It is noteworthy that the entire set of surface-layer modeling assumptions is ill-equipped to handle suurces considerably above ground level. Here a study of the surfacelayer and planetary boundary-layer interactions is necessary. 
before modeling accuracy can be expected to significantly improve.

The necessary numerical integrations of the concentration equation are laborious and require a moderate amount of computer time. The average execution time per downwind distance calculation, using a WATFIV computer, is about 3 seconds, which corresponds to a cost of about $\$ 0.40$. Total cost can be reduced approximately 508 by operating in either level-G or level-H FORTRAN. Clearly, an analytical solution of the integrals is preferable, but the complicated product of the exponential functions and the complementary error function was beyond several books containing tables of integrals (Abramowitz and Stegun, 1965; Gradshteyn and Ryzhik, 1965; Gröbner and Hofreiter, 1957a; and Gröbner and Hofreiter, 1957b).

Finally, although there are no known standards which address particulate deposition, there are the National Ambient Air Quality Standards as established by the National Environmental Protection Agency. The present primary and secondary standards for suspended particulates allow for an annual geometric mean of 75 and $60 \mu \mathrm{g} / \mathrm{m}^{3}$, respectively, and a maximum 24-hour concentration of 260 and $150 \mu \mathrm{g} / \mathrm{m}^{3}$, respectively, not to be exceeded more than once per year. In addition, warning, emergency, and significant-harm alerts are issued when 24-hour ambient concentrations exceed 625,875 , and $1000 \mu \mathrm{g} / \mathrm{m}^{3}$, 
respectively (Seinfeld, 1975). These levels may prove helpful as guidelines for future research. 


\section{SUMMARY}

The proposed methodology sets forth a suggested procedure for quantifying particulate deposition from dry unpaved roadways. This is possible after a coordinate system is defined, the particles fall velocity is determined, a workable expression of the deposition velocity is obtained, and the surface roughness and atmospheric stability have been characterized. The problem is further simplified by considering only a nearground source which incorporates only surface-layer aoncepts. The quantification procedure consists of four stages: (1) a formulation of a mathematical model that satisfies certain initial and boundary conditions, while also conserving mass, (2) extrapolating an experimentally obtained particlesize distribution to obtain an initial source strength, (3) computing the resulting downwind deposition at various distances, and (4) converting the calculated deposition to an effective area coverage. This is then compared to some predetermined standard to nhtain an estinate of the maximum number of vehicle passes permitted for some specified set of conditions and downwind distances.

It is shown that atmospheric stability, followed closely by wind speed and usualiy source height, has the least influence on the total deposition for the range of conditions tested; roughness height and depooitioil helght are observed 
to have a considerable impact on the total deposition. Furthermore, a low total deposition sensitivity to a given set of meteorological and terrain conditions is usually associated with a relative particle-size contribution which is also relatively insensitive to the same conditions.

Finally, the quantification methodology may readily be extended to other applications which also require more than just a subjective appraisal of the impact of source emissions and the accompanying deposition. In short, the overall procedure is offered primarily as a prelimisary guideline for quantifying particulate deposition. However, the incorporation of its numerous simplifying assumptions and empirical relations require that it be updated as state-of-the-art improvements become available. 
IX. BIBLIOGRAPHY

Abramowitz, M., and I. A. Stegun. 1965. Handbook of Mathematical Functions with Formulas, Graphs, and Mathematical Tables. U.S. Department of Commerce, National Bureau of Standards, Applied Mathematics Series No. 55. $1046 \mathrm{pp}$.

Andersen 2000 Inc. 1976. Operating Manual for Andersen 2000 Inc. High Volume Particle Sizing Samplers. Andersen. 2000 Inc. (Atlanta) Publication No. TR-76-900018. 25 pp.

Busch, N. E. 1972. On the mechanics of atmospheric turbulence. Pages 1-65 in Workshop on Micrometeorology. American Meteorological Society, Boston, Massachusetts. $392 \mathrm{pp}$.

Calder, K. L. 1961. Atmospheric diffusion of particulate material, considered as a boundary-layer problem: Journal of Meteorology $18: 413-416$.

Chamberlain, A. C. 1953. Aspects of travel and deposition of aerosol and vapor clouds. Atomic Energy Research Establishment; Report HP/R 1267, Harwell, Berkshire, England. $35 \mathrm{pp}$.

Crawford, M. 1976. Air Pollution Control Theory. McGrawHill, New York. $624 \mathrm{pp}$.

Csanady, G. T. 1955. Dispersal of dust particles from elevated sources. Australian Journal of Physics 8:545550 .

Davies, C. N. 1973. Air Filtration. Academic Press, London. $171 \mathrm{pp}$.

Ermak, D. I. 1977. An analytical model for air pollutant transport and deposition from a point source. Atmospheric Environment $11: 231-237$.

Golder, D. 1972. Relations among stability parameters in the surface layer. Boundary-Layer Meteorology 3:47-58.

Gradshtcyn, I. S., and I. M. Ryzhik. 1965. Table of Integrals, Series, and Products. Academic Press, New York. . $1086 \mathrm{pp}$.

Gröbner, W., and N. Hofreiter. 1957a. Integraltafel, part 1. Springer-Verlag, Vienna, Austria. I66 pp. 
Gröbner, W., and N. Hofreiter. 1957b. Integraltafel, part 2 . Springer-Verlag, Vienna, Austria. 204 pp.

Hale, W. E. 1972. Sample size determination for the lognormal distribution. Atmospheric Environment 6:419-422.

Hancock, R. P., N. A. Esmen, and C. P. Furber. 1976. Visual response to dustiness. Journal of the Air Pollution Control Association $26: 5 \overline{4-57}$.

Hicks, B. B. 1977. Some factors influencing dry deposition to the Great Lakes. Pages 81-80 in Radiological and Environmentai Division Annual Report: Atmospheric Physics, January-December 1976. ANL-76-88, Part IV. Argonne National Laboratory, Argonne, Illinois. National. Technical Information Service, U.S. Department of Commerce, Springfield, Virginia.

Johnson, W. B., and R. E. Ruff. 1975. Nhservational oyotems and techniques in air pollution meteorology. Pages 243274 in Lectures on Air Pollution and Environmental Impact Analyses. American Meteorological Society, Boston, Massachusetts.

Larsen, R. I. 1969. A new mathematical model of air pollutant concentration averaging time and frequency. Journal of the Air Pollution Control Association 19:24-30.

Lettau, H. 1969. Note on aerodynamic roughness-parameter estimation on the basis of roughness-element description. Journal of Applied Meteorology $8: 828-832$.

Lumley, J. H., and H. A. Panofsky. 1964. The structure of Atmospheric Turbulence. John Wiley and Sons, Inc., New York. 239 pp.

Mainwaring, S. J., and S. Harsha. 1976. Size distribution of aerosols in Melbourne city air. Atmospheric Environment $19: 57-60$.

Overcamp, T. J. 1976. A general Gaussian diffusiondeposition model for elevated point sources. Journal of Applied Meteorology 15:1167-1171.

Pasquill, F. 1962. Atmospheric Diffusion. Van Nostrand Company Ltd., London. 297 pp. 
Sehme1, G. A., and W. H. Hodgson. 1976. Predicted dry deposition velocities. Pages 399-419 in Atmospheric-Surface Exchange of Particulate and Gaseous Pollutants (1974). Proceedings of a symposium, Richland, Washington, September 4-6, 1974. CONF-740921. National Technical Information Service, U.S. Department of Commerce, Springfield, Virginia.

Seinfeld, J. H. 1975. Air Pollution. McGraw-Hill, New York. 523 pp.

Shir, C. C., and L. J. Shieh. 1974. A generalized urban air pollution model and its application to the study of $\mathrm{SO}_{2}$ distributions in the St. Louis metropolitan area. Journal of Applied Meteorology 1:3:185-204.

Slade, D. H. 1968. Meteorology and Atomic Energy. U.S. Atomic Energy Commission Division of Technical Information Report No. TID-24190, 445 PP.

Stern, A. C. 1976. Air Pollution, volume 1. Third Edition. Academic Press, New York. TI5 pp.

Sutton, O. G. 1947. The theoretical distribution of airborne pollution from factory chimneys. Quarterly Journal of the Royal Meteorological Society 73:426-436.

Sutton, O. G. 1953. Micrometeorology. McGraw-Hill, New York. $333 \mathrm{pp}$.

Tang, C. 1969. The effects of surface absorption and terminal velocity on the atmospheric diffusion of particulate material. Pure and Applied Geophysics 77:61-67.

Turner, D. B. 1969. Workbook on Atmospheric Dispersion Estimates. U.S. Department of Health, Education, and Welfare, Publication No. 999-AP-26. 84 pp.

U.S. Environmental Protection Agency. June 1974. Development of emission factors for fugitive dust sources. EPA-450/374-037. U.S. Environmental Protection Agency, Office of Air and Waste Management, Office of Air Quality Planning and Standards, Research Triangle Fark, North Carolina. $172 \mathrm{pp}$.

Yordanov, D. 1972. Simple approximation formulae for determining the concentration distribution of high sources. Atmospheric Environment. $6: 389-398$. 


\section{ACKNOWLEDGEMENTS}

I wish to thank my major professor, Dr. Eugene S. Takle, for the suggestion of this topic and for his valuable help and guidance throughout the course of the study, and to Dr. Douglas N. Yarger and Dr. James D.' Iversen for their assistance and teaching in my graduate study program.

I would like to sincerely thank Bill Lee and Dennis 0. Kaldenberg for their comments and suggestions. Furthermore, each made my return to Ames a most memorable and enjoyable experience.

And finally, to my wife, Carol, who has provided support far more important than purely financial and whose love and understanding encouraged me to pursue a goal which at the outset seemed elusive and unattainable. 


\section{APPENDIX A: PASQUILL-GIFFORD STABILITY CLASSIFICATION}

The Pasquill-Gifford stability class definitions represent a simplified method of characterizing atmospheric stability as a function of incoming solar radiation, wind speed, and the degree of cloudiness. Turner (1969) and Seinfeld (1975) present these definitions in a form similar to Table A.1.

During clear conditions, daytime insolation is classified as slight, moderate, and strong for solar altitudes of $15^{\circ}$ to $35^{\circ}, 35^{\circ}$ to $60^{\circ}$, and greater $60^{\circ}$, respectively. Nighttime conditions apply approximately from one hour before sunset until one hour after sunrise (i.e., when the solar altitude is less than $15^{\circ}$ ). The degree of cloudiness is defined as the fraction of the sky above the local apparent horizon which is covered by clouds (Seinfeld, 1975). 
Table A.1. Pasquill-Gifford stability class definitions

\begin{tabular}{|c|c|c|c|c|c|}
\hline \multirow[b]{2}{*}{$\begin{array}{l}\text { Surface } \\
\text { wind speec } \\
\text { at } 10 \mathrm{~m}, \\
(\mathrm{~m} / \mathrm{s})\end{array}$} & \multicolumn{3}{|c|}{ Daytime insolation } & \multicolumn{2}{|c|}{ Nighttime conditions } \\
\hline & Strong & Moderate & slight & $\begin{array}{l}\text { Thin over- } \\
\text { cast or } \\
\geq 4 / 8 \\
\text { cloudiness }\end{array}$ & cloudiness \\
\hline$<2$ & A & $A-B$ & B & & \\
\hline $2-3$ & $A-B$ & B & C & $E$ & $\mathbf{F}$ \\
\hline $3-5$ & B & $B-C$ & C & D & $\mathrm{E}$ \\
\hline $5-6$ & C & C & D & D & D \\
\hline$>6$ & C & c. & D & I & D \\
\hline & extre & nely unst & ole & $D:$ neut & al stability \\
\hline & mode: & tely unst & able & sligh & tly stable \\
\hline & sligh & ly unstak & & $F:$ moder & ately stable \\
\hline
\end{tabular}

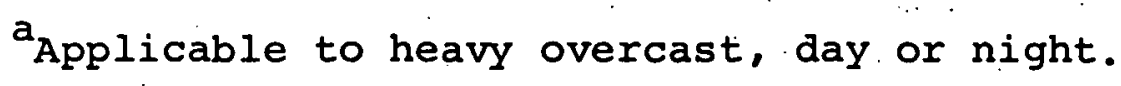




\section{APPENDIX B: PROPERTIES OF THE \\ LOG-NORMAL DISTRIBUTION}

The probability density function of the log-normal distribution is given by

$$
E(D)=\frac{1}{\sqrt{2 \pi} \ln \sigma_{g}} \operatorname{Exp}\left[-\frac{1}{2}\left(\frac{\ln (D)-\ln \left(D_{g}\right)}{\ln \sigma_{g}}\right)^{2}\right]
$$

where $D_{g}$ and $\sigma_{g}$ are the geometric mean diameter and geometric standard deviation, respectively. The cumulative distribution function is given by

$$
F(D)=\int_{0}^{D} f(D) d[\ln (D)]
$$

A distribution is log-normal if a log-probability plot of the cumulative distribution is a straight line. By plotting empirical data on this type of graph, it is possible to determine whether the log-normal distribution is a satisfactory mathematical model of a particular distribution. (Crawford, 1976).

The $50 \%$ point of the log-normal plot of the particlesize distribution corresponds to $\mathrm{D}_{g^{\prime}}$, and $\sigma_{g}$ is given by either of the following ratios of distribution pointes

$$
\sigma_{g l}=\frac{84 \cdot 138 \text { diameter }}{508 \text { diameter }}
$$


or

$$
\sigma_{g^{2}}=\frac{50 \% \text { diameter }}{15.87 \% \text { diameter }}
$$

Whenever these two geometric standard deviations are not equal, then the size distribution is not represented by a straight line and hence is not exactly log-normally distributed. A better method of presenting the geometric standard deviation (Anderson 2000 Inc., 1976) is:

$$
\sigma_{g}=\left(\frac{84.138 \text { diameter }}{15.87 z \text { diametèr }}\right)^{1 / 2}
$$

For a finite interval, $i$, the geometric mean diameter is given by

$$
D_{g i}=\frac{\int_{D_{1}}^{D_{2}} \ln (D) f(D) d[\ln (D)]}{\int_{D_{1}}^{D_{2}} f(D) d[\ln (D)]}
$$

and the corresponding genmetric standard devialiun 15 given by

$$
\sigma_{g i}^{*}=\frac{\int_{D_{1}}^{D_{2}}\left[\ln (D)-\ln \left(D_{g i}\right)\right]^{2} f(D) d[\ln (D)]}{\int_{D_{1}}^{D_{2}} f(D) d[\ln (D)]}
$$

for $D_{1}$ less than $D_{2}$, and where $\sigma_{g}=\operatorname{Exp}\left(\sigma_{g i}^{*}\right)$. 
If a particle number distribution $(n=0)$ is log-normal, then the surface area $(n=2)$, and mass and volume $(n=3)$ distributions will also be log-normally distributed. In general, if any moment of the distribution is log-normal, then the nth moment is also log-normal, with

$$
\ln \left(D_{g n}\right)=\ln \left(D_{g o}\right)+n \ln { }^{2}\left(\sigma_{g}\right)
$$

where $\sigma_{g}$ is the same for any basis (Seinfeld, 1975).

Therefore, for a finite particle-size interval, $i$, the gcometric medn dlameter on an area basis is given by

$$
D_{g 2 i}=\operatorname{ExP}\left[\ln D_{g 3 i}-\left(\sigma_{g i}^{*}\right)^{2}\right],
$$

where $D_{g} 3 i$ is the geometric mean diameter on a mass basis for the ith particle-size interval. 